Portland State University

PDXScholar

\title{
šawaš III?i-šawaš wawa -- 'Indian country--Indian language' : A Participant Observation Case Study of Language Planning by the Confederated Tribes of the Grand Ronde Community of Oregon
}

Gregry Michael Davis

Portland State University

Follow this and additional works at: https://pdxscholar.library.pdx.edu/open_access_etds

Part of the Applied Linguistics Commons, First and Second Language Acquisition Commons, and the Language Description and Documentation Commons

Let us know how access to this document benefits you.

\section{Recommended Citation}

Davis, Gregry Michael, "šawaš III?i-šawaš wawa -- 'Indian country--Indian language' : A Participant Observation Case Study of Language Planning by the Confederated Tribes of the Grand Ronde Community of Oregon" (1998). Dissertations and Theses. Paper 4979.

https://doi.org/10.15760/etd.6855

This Thesis is brought to you for free and open access. It has been accepted for inclusion in Dissertations and Theses by an authorized administrator of PDXScholar. Please contact us if we can make this document more accessible: pdxscholar@pdx.edu. 


\section{THESIS APPROVAL}

The abstract and thesis of Gregry Michael Davis for the Master of Arts in Teaching English to Speakers of Other Languages were presented July 10, 1998, and accepted by the thesis committee and the department.

COMMITTEE APPROVALS:

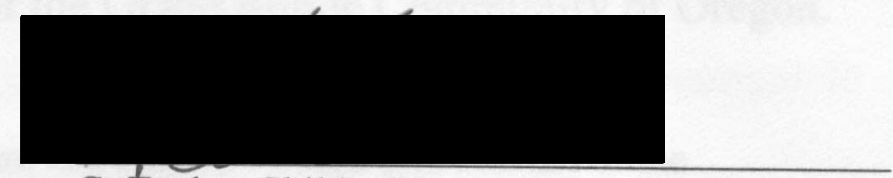

G. Tucker Childs, Chair

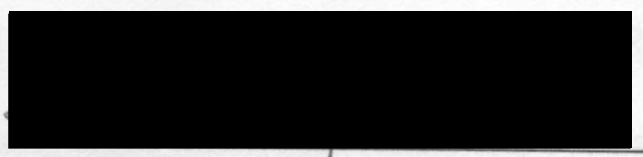

Kimberley Brown

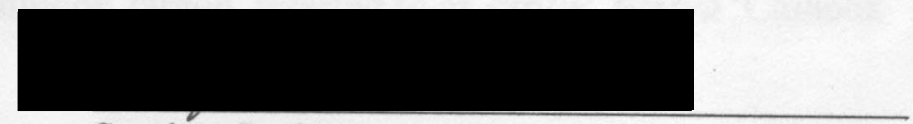

Stephen Reder

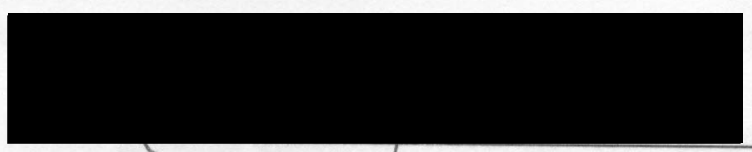

Thomas Biolsi

Representative of the Office of Graduate Studies

DEPARTMENT APPROVAL:

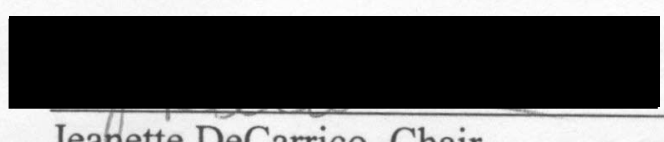

Jeanette DeCarrico, Chair

Department of Applied Linguistics 


\section{ABSTRACT}

An abstract of the thesis by Gregry Michael Davis for the Master of Arts in Teaching English to Speakers of Other Languages presented July 10, 1998.

Title: Šawaš rlı? - Šawaš wawa 'Indian country-Indian language': A participant observation case study of language planning by the Confederated Tribes of the Grand Ronde Community of Oregon.

The Kwelth Tahlkie Culture and Heritage Board (KTC\&HB) of the

Confederated Tribes of the Grand Ronde Community of Oregon (CTGR) have made it a priority to revitalize one of the languages which historically has been associated with being a Grand Ronde Indian - Chinook Jargon, referred to as crmuk wawa 'Chinook talk’ or simply črnok.

The purpose of the present study was to observe the language planning process as executed by the KTC\&HB. Initial guiding questions were: (i) What stages is the KTC\&HB going through in the process of planning for črnuk revitalization? (ii) How do these efforts compare with theory and actual practice in other settings? (iii) How will the KTC\&HB achieve their goals, and how successful will they be? The researcher participated in the language planning process, functioning as a linguistic consultant. From January through May 1998, over 150 hours were spent on location in Grand Ronde, working primarily with the Tribe's language specialist to develop materials on čmuk. 
The language planning efforts have resulted in the production of a variety of language materials which are, at this point, still in draft form. They include an orthography — developed to increase readability and learnability of the language, a grammar-including both syntactic and phonological descriptions, and a dictionarybased on a wide variety of sources on crnuk. Participant observation reveals that there is support for the language planning efforts in GR at a number of levels: the Tribal Council, the KTC\&HB, and the $c_{r n v k} l u l l u$, a group of ten to fifteen tribal members committed to learning the language. This group will assist the language specialist in future language planning decisions. The success of the early stages of language planning in this case can be attributed, at least in part, to the Native locus of control which has been established. Clearly defined and articulated relationships with outside linguists will also contribute to the success of this case. The $c_{m}$ nuk $l u$ ?lu is off to a good start, as well, with highly motivated community members striving to learn the language quickly. 


\title{
Šawaš $\mathbf{I l} ? \mathbf{i}$-šawaš wawa
}

\author{
'INDIAN COUNTRY—INDIAN LANGUAGE':
}

\section{A PARTICIPANT OBSERVATION CASE STUDY OF LANGUAGE \\ PLANNING BY THE CONFEDERATED TRIBES OF THE GRAND RONDE COMMUNITY OF OREGON.}

by

GREGRY MICHAEL DAVIS

A thesis submitted in partial fulfillment of the requirements for the degree of

MASTER OF ARTS

in

TEACHING ENGLISH TO SPEAKERS OF OTHER LANGUAGES

Portland State University

1998 


\section{Table of Contents}

1 Introduction

1.1 Gaining Access

1.2 Statement of the Problem

1.3 Research Questions

1.4 Working Definitions __ 5

1.5 Brief History of čmuk wawa

1.5.1 Origin 7

1.5.2 Linguistic Classification

1.6 Brief History of CTGR 16

1.6.1 Reservation Formation: The First Reservation Generation $\quad 17$

1.6.2 Reservation: The Second Reservation Generation 18

1.6.3 Reservation De-segregation: The Third Reservation Generation $\quad 19$

Chapter One Notes $\quad 22$

2 Literature Review __ 24

2.1 Language Planning Variables __ 24

2.1.1 Language Death __ 25

2.1.2 Language Survival __ 26

2.1.3 Language Change 27

2.1.4 Language Revival 28

2.1.5 Language Shift and Spread ___ 31

2.1.6 Language Contact and Pidgin and Creole Development __ 32

2.1.7 Literacy Development __ 33

2.2 Status and Corpus Planning _ 35

2.2.1 Status Planning 36

2.2.2 Corpus Planning _ _ 41

2.3 Language Planning Process

$\begin{array}{ll}2.3 .1 \text { Research } & 47\end{array}$

2.3.2 Policy Formulation__ 49

2.3.3 Implementation $\quad 50$

2.3.4 Evaluation $\longrightarrow 50$

2.4 Critiques of Language Planning ___ 51

Chapter Two Notes _ـ 53

3 Methodology

3.1 Ethics and Empowerment _ _ 54

3.2 Informants

3.2.1 Grand Ronde

3.2.2 Other tribes 57

3.3 Instruments

3.4 Design and Procedures _ 59

3.4.1 Literature $\quad 59$

3.4.2 Interviews with other tribes

3.4.3 Participant observation $\quad 60$

3.4.4 Evaluation $\quad 66$

3.5 Tools for analysis

Chapter Three Notes _ 69 
4 Results/Discussion $\quad 70$

4.1 Current Sociolinguistic Situation 70

4.1.1 Actors 72

4.1.2 Behaviors 74

4.1.3 People__ 75

4.1.4 Ends 75

4.1.5 Conditions _ 77

4.1.6 Means $\quad 78$

4.1.7 Decision-making process

4.1.8 Effect $\quad 80$

4.2 Status Planning _ 81

4.2.1 Goals 81

4.2.2 Language Selection __ 83

4.2.3 Language Implementation and Evaluation

4.3 Corpus Planning $\quad 93$

4.3.1 Graphization 94

4.3.2 Grammatication _ $\quad 98$

4.3.3 Lexication 110

Chapter Four Notes 116

5 Conclusion

5.1 Summary _ 117

5.2 Evaluation of the Language Planning Process, Myself, and Future Prospects ___ 118

5.3 Recommendations

5.4 Significance of This Case 128

5.5 Beyond Grand Ronde __ 129

Chapter Five Notes 132

References___ 133

Appendixes _ 137

Appendix A-A Typology of Minority-Language-Situation Variables (Edwards, 1992). ___ 137

Appendix B-A Preliminary Typology of crnok in Grand Ronde ___ 138

Appendix C - Proposed Questions for Native Language Practitioners ___ 141

Appendix D-The crmuk Alphabet (Draft 5/12/98) _ 142

Appendix E-CTGR Vision Statement, Preamble to Constitution, \& KTC\&HB Mission State. 143

Appendix F-Towards a syntax of crnuk 


\section{List of Tables}

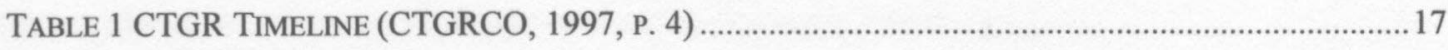

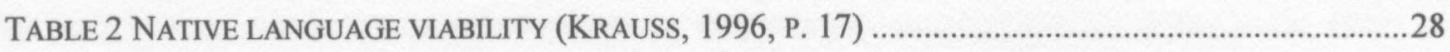

TABLE 3 FISHMAN's (1991) GRADED INTERGENERATIONAL DISLOCATION SCALE (GIDS) .....................29

TABLE 4 HAUGEN'S (1983: 275) REVISED LANGUAGE PLANNING MODEL WITH ADDITIONS (AS

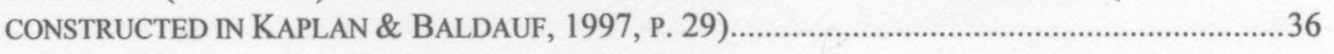

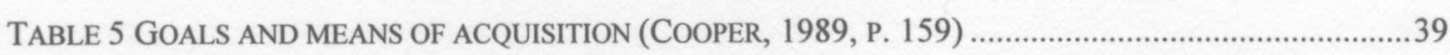

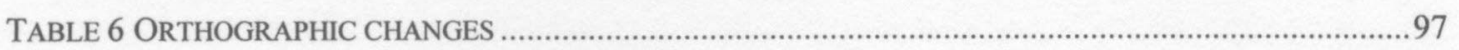

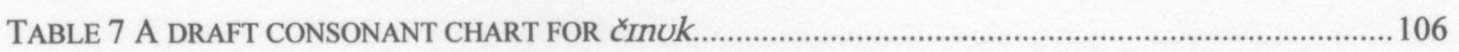

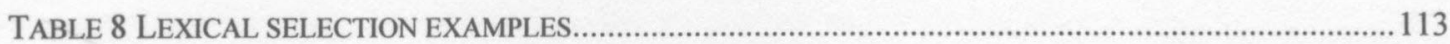




\section{List of Figures}

FigURE 1 NATIVE LANGUAGE VIABILITY IN THE U.S. (KRAUSS, 1996). .28

FIGURE 2 SCHEMA FOR LANGUAGE-IN-EDUCATION POLICY DEVELOPMENT (KAPLAN \& BALDAUF, 1997, P. 124) . .40

FIGURE 3 PRE-SURVEY ACTIVITIES (KAPLAN \& BALDAUF, 1997, P. 107)................................................. 49

FIGURE 4 LAYOUT OF KWELTH TAHLKIE CULTURE AND HERITAGE BOARD OFFICES ...............................62

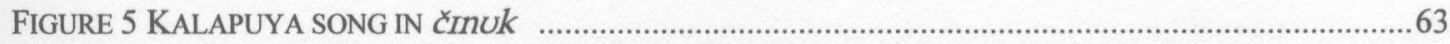

FIGURE 6 AN ACCOUNTING SCHEME FOR THE STUDY OF LANGUAGE PLANNING (COOPER, 1989, P. 98)...68

FIGURE 7 CTGR ENROLLMENT BY COUNTIES ....................................................................................... 71

FIGURE 8 A PARTIAL ORGANIZATIONAL CHART FOR THE CTGR (CTGRCO 1997, P. 22) …....................73

FIGURE 9 GRAND RONDE STATUS PLANNING GOALS (2/17/98 DRAFT) …………………………….....76

FIGURE 10 PRE-PLANNING IMPLEMENTATION SCHEDULE (CTGRCO, 1998) …….................................88

FIGURE 11 ANNOUNCEMENT OF čmUk PROJECT ("LEARN CHINOOK," 1998) …........................................8

FIGURE 12 TECHNOLOGICAL IMPLEMENTATION PLANNING (AS OF 3/5/98) ….......................................93

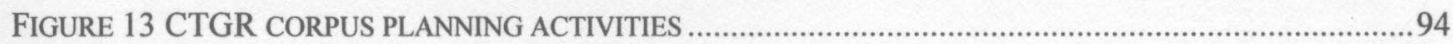

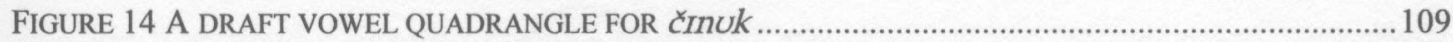

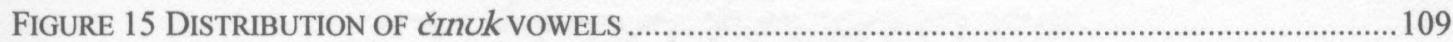

FIGURE 16 SAMPLE DATABASE ENTRIES FOR Črnuk wawa FILES .......................................................111 
Šawaš Ilı? - šawaš wawa ${ }^{1}$ 'Indian country-Indian language': A participant observation case study of language planning by the Confederated Tribes of the Grand Ronde Community of Oregon.

\section{Introduction}

\subsection{Gaining Access}

- "Do you know of anyone around here who speaks Chinook Jargon?"

- "I don't live around here anymore, but I would talk to Elder I'. She gave the prayer in Chinook Jargon for the Pow Wow yesterday, so she would be a good person to talk to."

- "Do you happen to know where she lives?"

- "Let's see, I think she lives in a little white or blue house less than a mile from here. Just take a right when you get on the road back there and it will be the, oh, fourth or fifth house on the left."

As I wandered into the nearly deserted Pow Wow grounds in Grand Ronde,

Oregon, I noticed a gentleman walking about. I pulled up my car and asked him about Chinook Jargon (CJ). After he gave me the information he knew, I thanked him and pulled away. Elder1's house was not as easy to find as I had been told, but after stopping at a few houses and asking directions, I found it, a small, yet sturdy home with no car parked in front. When I knocked on her door, she cracked it open, naturally wanting to know who I was and what I wanted. I told her that I was a graduate student from Portland and wanted to talk to her about CJ. Eventually, she consented to my request to allow me to call her at a future date to talk about Jargon.

Due to a number of unforeseen circumstances, I was unable to call her right away.

Then she became ill and told me she was no longer interested in working with me.

Not willing to give up, I asked if there was anyone else around that I should talk to. 
She recommended I talk with her sister Elder2, who lived just down the road. Elder2 is Elder1's older sister, 91 years old when I first met her. She agreed to meet with me and wawa kopa čmuk'talk in/about CJ'. I was relieved when, with no hesitation, she provided the Jargon words for almost everything I asked her about. Her daughterin-law, who takes care of Elder2 and Elder4 (Elder2's husband), helped me interview Elder2 by asking questions of her.

Later, when Elder2 and Elder4's son came home, he wanted to know what I was doing there. He asked if I knew any of the earlier researchers who had come and recorded their language. "I'm anti-, against that, I'll tell you that right now" he informed $\mathrm{me}^{3}$. Later, when I called to speak with Elder2 again, there was, as I later discovered, a miscommunication about who was to call whom, and I got the strong impression that I should wait for them to call me. Well, no one ever called.

I was a bit discouraged at that point, but I didn't want to sacrifice all the time and energy — over a year-I had put into CJ and the people of Grand Ronde. In a final attempt at doing research there, I tried to contact some people in the tribe who are concerned with cultural issues to find out if they were doing anything with language. I was directed to Tony Johnson, Collections Curator-Language of the Kwelth Tahlkie ${ }^{4}$ Culture and Heritage Board ${ }^{5}$ (KTC\&HB). He talked with me about his interests and asked a lot of questions about my intentions. We met and eventually decided to work together in a mutually beneficial partnership in which I would volunteer my time and 
experience as an educator and linguist, to assist in the planning process. Despite his lack of training as a linguist, Johnson was able to assimilate the information I provided him, mainly different analyses of the language.

The process of gaining access to the community took sixteen months. Before I was offered involvement, my study would have been limited to either a language life history of an elder or a study of language death and/or maintenance. Instead, I am assisting vitally in a language planning project which may have a significant impact on the community. Not gaining access right away led, I believe, to a much more engaged research project with direct involvement in the local community and with the possibility of making a significant contribution to the quality of life within that community.

\subsection{Statement of the Problem}

Increasingly, the fate of many of the world's less widely spoken languages is in jeopardy. Cantoni (1996) underscores the seriousness of the issue:

About $90 \%$ of the world's languages may be extinct in the next century, to be supplanted by those, such as English, Spanish, or Chinese, that have been more widely taught and used. The danger of language extinction and of the loss of linguistic diversity parallels and exceeds the severity of the decline of plant and animal diversity on our earth. (p. viii)

Other researchers have come up with similar figures (e.g., Krauss, 1992).

Despite such grim figures, it is possible to stabilize threatened languages, albeit with considerable effort (Cantoni, 1996). The perspective gained from renewal efforts 
around the world provides an essential knowledge-base from which one can make informed choices:

In attempting to address these questions we have become convinced that the problems are world-wide (like all ecological issues) and that, although action needs to be taken at the local and individual level, it may be more useful to think globally. Thus one might profit from the experience of others, preventing repetition of processes that have proven futile and avoiding wasting time 'reinventing the wheel'. (Cantoni, 1996, p. ix.)

For there to be any success at all, however, others' experiences cannot be adopted wholesale even if wildly successful. The transfer value of a strategy must be evaluated. Nonetheless, with each case our knowledge-base is increased. Kaplan \& Baldauf (1997) note the relative dearth of studies focusing on micro-language planning situations: "Much less is known about the participants or how decisions in such situations are made" (p. 82). Therefore, each setting, if described in sufficient detail, provides another opportunity for everyone involved with language planning to compare and discover trends and relationships between variables.

In this paper I will attempt to characterize the unique features of the language planning process as it has taken shape in the offices of the KTC\&HB, the Confederated Tribes of the Grand Ronde Community of Oregon (CTGR). In part, this study will serve a historical function - documenting the progress of language planning work in Grand Ronde. By providing significant details as to why certain decisions were made, I hope to also provide a context within which other tribal groups can make informed choices for their own unique settings. Thus, the results of this study can be 
generalized and adapted to meet the goals of other groups. For the academic community, this study will add another case to the growing literature on language planning in minority language situations generally, and in American Indian communities, more specifically.

\subsection{Research Questions}

The guiding questions in this study have emerged in the following form:

- What stages is the KTC\&HB going through in the process of planning for čmnuk revitalization?

- How do these efforts compare with: (i) theoretical models for language planning, and (ii) language revitalization efforts in other indigenous settings (based on the literature and on interviews with neighboring tribal practitioners)?

- How successful will efforts of the KTC\&HB be at encouraging language shift to čmuk in certain domains? What types of techniques will work best to achieve the goals of the KTC\&HB?

\subsection{Working Definitions}

There are many terms which have been used for the process of strengthening a dying language: "language revitalization" (Dorian, 1994; Ayoungman, 1991): "language renewal" (Ayoungman, 1991; Otto, 1982; St. Clair \& Leap, 1982), 
"language preservation" and "language restoration" (Hinton, 1997), "language stabilization" (Cantoni, 1996), "language revival” (Dorian, 1994; Fishman, 1991), "language revernacularization" (Fishman, 1991). Dorian (1994) distinguishes between revitalization, where the language only precariously survives, and revival, where the language is no longer spoken. Revitalization has been used in a restricted sense by Spolsky (1996) to refer to "the restoration of vitality ... to a language that had lost or was losing this attribute" (p. 178). Hinton (1997) notes that Native Language activists "despise" the term language preservation as it connotes documentation rather than actual usage. Ayoungman (1991) suggests that the term language revitalization is at times preferable to language renewal but that both terms can be used interchangeably; I have followed this suggestion in the discussion below, but also use language revival to refer to the same processes.

The Native people I have met refer to themselves as "Indians," "American Indians", or "Native Americans." Others have been known to call themselves "First People." They seem to prefer the term Indian, however, because of the ambiguity in the word "native" which can also be used to refer to someone born in a certain location (Spack, 1998). In this way, a "native Oregonian" does not clearly identify one as an Oregon Indian, but could also refer to the child of an "immigrant" born in Oregon. Now, I need to provide some background on the historical development of CJ and CTGR. Since CJ predates the Grand Ronde Reservation, I will begin with a 
description of the language and then continue with a portrayal of the reservation setting. A clearer understanding of the role $\mathrm{CJ}$ played throughout the region, along with a heightened awareness of the multiethnic nature of the CTGR Reservation, should allow the reader to better interpret the language planning activities of the KTC\&HB.

\subsection{Brief History of čnvk wawa ${ }^{6}$}

"Chinook Jargon (or The Jargon, The Oregon Trade Language, or Chinook Wawa) is the best documented contact language in North America" (Silverstein, 1990, p. 127). It has an interesting and controversial history. It is "the lingua franca formerly employed by Indians and whites in the coastal district from southern Oregon to Alaska and west of the Rocky Mountains" (Jacobs, 1932, p. 27). On this point, most are in agreement. The contested issues center on its origin and its linguistic classification. Without going into too much detail, I will address each of these in the context of the Grand Ronde reservation itself (see also §1.6). Although these topics have been written about and discussed in detail in other places (e.g., Kaufman, 1971; Thomason, 1983; Zenk, 1984), a summary is helpful since they play a significant role in framing the current project.

\subsubsection{Origin}

There are two basic theories as to the origin of CJ: (i) because of a purely 
regional or local need before European contact and (ii) because of a need at the time of European contact, i.e., a need to communicate with Europeans. Although we cannot establish with absolute certainty which of the two theories is correct (Kaufman, 1971), we need to address this issue because of the need to answer questions as to the "Nativeness" of CJ. Let me start by highlighting the pre-contact theory.

There are a number of researchers who support the pre-European contact theory. Citing examples from the early 1800 's, Thomas (1970) purports that the Jargon was in use among the natives as a trading language long before the trader and trapper arrived on the scene, and that contact with the whites enlarged and enriched it by the addition of many words of French and English derivation. (pp. 11-12)

Jacobs (1932) points out that in that same period, the early 1800's, "Chinook Jargon was the unique and beautifully satisfactory means of communication between the speakers of a hundred or more mutually unintelligible Pacific Northwest languages" (p. 27). By the 1870's “one estimate places at one hundred thousand the number of people who depended on this picturesque artificiality in everyday commercial and social discourse" (Fee, 1941, p. 178). Thomason \& Kaufman (1988) note that the structure of CJ "does not reflect any participation by whites in its development," with the possible exception of the SVO word order (p. 257). This said, they do not, however, rule out the possibility that Europeans could have been present while the pidgin was being formed. In fact, they argue that the Nootka elements of črnvk were introduced by whites, and cite as evidence that "the marked sounds characteristic of 
the Chinook- and Salish-derived portion of the lexicon do not occur in any of the Nootka-derived words, except for the voiceless lateral fricative / //" (p. 259).

Thomason (1983) concludes that "CJ arose in a context of Indian-Indian communication" (p. 821). Lang (1997) supports Thomason's conclusion but acknowledges that "native-native contact is not necessarily pre-contact contact" (p. 8). In fact, Lang suggests that $\mathrm{CJ}$ developed as a result of interactions between Indian wives, who had married white (mostly French) men, and their children On that note, let's turn to the post-European contact theory.

In the literature on post-European contact, there are a number of both older and more recent articles supporting this hypothesis. Boas (1888) conjectures:

The needs of the trade were such that a means of readily conversing with the natives of all parts of the country was necessary, and out of the clumsy attempts of the Indians and of the French and English traders to make themselves understood sprang a lingua franca, which is known as the Chinook jargon. (p. 220)

Though himself a fluent speaker of $\check{c}_{m} n k^{7}$, Boas made no systematic attempt to support this hypothesis with reference to historical evidence. Howay (1943) brings additional evidence to bear on the claims of Thomas $\left(1970^{8}\right)$ and Fee (1941) that the Nootkans spoke an early form of CJ. "A more ridiculous congeries of incorrect statements is hard to find. There is no line without its error. The source of Thomas's historical facts is his own fertile imagination. ... Fee ... emulates his mentor (pardon the word) in historical inaccuracies" (pp. 38, 40). Forty-five years later, Samarin 
(1986) matter-of-factly states that the "generally accepted" belief is that CJ emanated from the earliest White contacts (p. 24). Drawing on a broader spectrum of ethnohistorical evidence than previous researchers, Hajda \& Zenk (1998) maintain that the social networks manifested especially in links through trade and marriage formed the context of "the emergence of Chinook Jargon" (p. 23) as a variety developed by Chinookans to communicate first with sea traders (from whom came the corrupted Nootka elements, and some English), and then other indigenous peoples (hence, the Salish and Kalapuyan contributions), and non-Native settlers in the area (from whom came French and further English additions). They argue that CJ was not only developed by Indians, it was also spread by Indians to other regions:

That the Chinook Jargon recorded later from Indian speakers up and down the Northwest Coast shows an intact Northwest Coast phonology, argues for primary Indian-to-Indian transmission of Chinook Jargon as it expanded outward from its lower Columbia cradle, as Kaufman and Thomason have pointed out. (p. 46)

An alternative hypothesis is espoused by Samarin (1986). He maintains that the intact indigenous phonology found in $\mathrm{CJ}$ can also be explained by positing "that there was a very divergent jargon at an early stage that was subsequently 'nativized' as it spread and became more widely used by the indigenous population" (p. 27). Samarin believes that CJ was created by early white-Native contacts and only fully "nativized" more recently. In Samarin (1988) he suggests as a "strong possibility" that Nootka Jargon (NJ), a pre-existing jargon, was incorporated into the historical pidgin we know 
as CJ, resulting in the "death" of NJ (pp. 219, 231).

Tony Johnson believes strongly in the Indian origin of črnuk. He comes from čInuk IIr?i ‘Chinook country' (lower Columbia River, Southwest Washington).

Nowhere in the oral history of his people is there mention of Europeans creating a need for a simplified language. At one point he said, "I frankly trust my own people and the stories they told me more than what someone else says."

\subsubsection{Linguistic Classification}

CJ has been given several linguistic labels over the years (Roth, 1994, p. 158): a "jargon" (Silverstein, 1972), a "pidgin" (Thomason, 1983), or a “"creole language' ... in a somewhat restricted or special sense" (Zenk, 1984). Each label will be considered in turn.

\subsubsection{1 $\mathrm{CJ}$ as a Jargon}

A jargon can be defined as a pre-pidgin variety in which there is (a) significant individual variation, (b) a simple phonology, (c) extremely short sentences (1-2 words), (d) a limited lexicon, and (e) severe functional limitations (Fernández Bell \& Gilbert, 1996b). Silverstein (1972) argues that CJ speakers communicated by using CJ lexical items with the grammatical system of their native languages, and thus, CJ can best be termed a "jargon." He was obviously not using the definition given above to determine such a classification of $\mathrm{CJ}$, as the source for his structural analysis was the 
speech of Victoria Howard, as recorded by Melville Jacobs (Jacobs 1932; Jacobs 1936). Henry Zenk (personal communication, June 21, 1998) explains that "Jacobs was quite scrupulous in his marking of phrasal groups and prosodic features in Mrs. Howard's črnuk. Judging by this record, Mrs. Howard spoke an exceptionally fluid and expressively adequate čmok, in which complex sentences ... were not unusual." Thus, it seems that Silverstein's condition for jargon-ness is the lack of an independent grammar. Arguments against this conclusion will be introduced in the next section. In regard to the definition given above, the regional CJ: (a) showed individual variation (Thomason \& Kaufman, 1988, p. 260), but within somewhat constrained bounds ${ }^{9}$ (Zenk, 1996), (b) had a complex phonology, in universal terms (Thomason, 1983), (c) 5-10 word sentences in even the most youngest speakers (Zenk, 1984, e.g., pp. 301303), (d) a reduced "but not puny" (Kaufman, 1971) lexicon ${ }^{10}$, and (e) was used in almost all, if not all, functional domains, at least by the second generation of Grand Ronde Indians (Zenk, 1984, see also §1.5.2). Silverstein's claim that CJ did not have an independent grammar does not seem completely appropriate for regional $\mathrm{CJ}$ or the Grand Ronde variety of čmuk. Grant (1996), in line with Thomason (1983), insists "CJ is a proper language with a determined structure" (p. 1202). This issue will be discussed in the next section.

\subsubsection{2 $\mathrm{CJ}$ as a Pidgin}

Pidgins are considered to be a simplified form of a single language, with 
potential influence from other languages as well (Fernández Bell \& Gilbert, 1996c). A more current view regards "a pidgin as an innovation, a creative variety, that speakers invent to fill a need rather than some simplified or debased form of the language providing only its lexicon" (G. T. Childs, personal communication, May 29, 1998). "A pidgin can therefore be the object or goal of one's attempt at learning to communicate (which is a paraphrase of saying that it is a 'language')" (Samarin, 1988). In the case of čmvk, there are contributions from a number of Northwest indigenous languages, as well as from English and French. In contrast to Silverstein (1972), Thomason (1983) argues that CJ is a "true pidgin" (p. 821). In keeping with the definition above, Grant (1996) describes CJ as a "Chinook-based pidgin," although he admits that such a label can only be applied "with some difficulty" (p. 1188). It is also referred to as a "contact pidgin" (Lang, 1997, p. 8). Hajda \& Zenk (1998) note that it is not a "classic" pidgin in the sense that contributions do not primarily come from one superstrate language (p. 3). On CJ's pidgin-ness, Thomason (1983) argues: "Though CJ was functionally and linguistically restricted, in typical pidgin fashion, it possessed a grammatical norm at which all its speakers aimed—a norm that differed in non-simplificatory ways from their native-language structures" (p. 821). Furthermore, Zenk (1984) made a similar argument for the recent Grand Ronde speakers, most of whom have known only čmuk and English: the čmuk of these speakers exhibits structures differing in non-simplificatory ways from corresponding English structures. 
Thus, many scholars agree that $\mathrm{CJ}$ functioned at least as a pidgin language in the general area of its former use.

\subsubsection{3 črnuk as a Creole}

Silverstein (1972) concedes that, in the context of creolization, the distinction between a jargon and a pidgin would be unnecessary if there were "a communicative niche for a primary language" (p. 622). However, he did not see sufficient evidence to support this idea for CJ. In Grand Ronde, however, "Jargon has been the only Native language [that is, only Indian language] of very many Grand Ronde people" (Zenk, 1984, p. 158). During the later nineteenth century, the community included a large number of community members who were able to speak English," but "seldom did" (p. 167). Since English and črnuk were the only languages shared by most members of the multilingual community, this implies that there definitely was a "communicative niche" for črnuk as a dominant language in the Grand Ronde Indian community. In other words, there was no longer much need for $\check{c}$ Invk as an "indigenous lingua franca," (people could speak English, if they so preferred) yet it persisted because it was preferred, at least in some settings and by some people (Zenk, 1984, p. 174). Zenk (1984) concludes: "By the fact of such adoption [as a language of community and family], CJ was a 'creole language' at Grand Ronde, if in a somewhat restricted or special sense - $a$ language of primary use in community and family, yet hardly anyone's only such language" (pp. iv-v). 
Given the description above, črnuk, as spoken in Grand Ronde seems deserving of the label "creole." But let's look at how čmuk compares with the traditional definition of a creole. Classically, a creole is:

A language that developed from a pidgin by expanding its vocabulary and acquiring a more complex grammatical structure....the native language of most of its speakers. Therefore its vocabulary and syntactic devices are, like those of any native language, large enough to meet all the communication needs of its speakers. (Fernández Bell \& Gilbert, 1996a)

In §1.4.2.2 it was claimed that črnuk was a Northwest indigenous pidgin.

Consequently, the predecessor to the language spoken during Grand Ronde's reservation period was indeed a pidgin. This satisfies the first condition of creolization. On the issue of lexical expansion and increased grammatical complexity, Zenk (1984) notes that indications of both were found in his data, though he acknowledges that "it is unclear whether these would meet the strict criteria of the foregoing definition (Zenk, personal communication, May 25, 1998). Silverstein (1972) argues that the nativization of a pidgin language to form a creole involves the pidgin attaining the status of the first and only language (p. 621). Given the multilingual setting of Grand Ronde, like so many other places around the world, it is no surprise that "Jargon seems to have been almost no one's only language" (Zenk, 1984, p. 157). Based on Zenk's description, however, črnuk was one of the languages in the linguistic repertoires of children growing up in the late nineteenth, early twentieth century reservation community. Furthermore, many of those children 
learned it at least as a co-first language (i.e., bilingually). On the subjective level, finally, črnuk was “a 'language' in all Grand Ronde speakers' perceptions” (Zenk, 1984, p. 173). Returning again to the definition above, does črnuk have the syntactic and lexical complexity of a full language? To satisfactorily answer this question would require a fairly elaborate discussion not necessary here.

Thus, it seems that $\check{c}_{m}$ nuk was in the process of being creolized in Grand Ronde, whatever the classification of Grand Ronde čmuk. My purpose here is not to end discussion on the classification of crmuk as spoken in the Grand Ronde community, but rather to highlight the unique and rather complex sociolinguistic nature of this speech community. To gain a better understanding of this speech community, however, we must understand the historical context in which the community was formed and how črnuk was used at different stages in the CTGR.

\subsection{Brief History of CTGR}

There have been several key events which have shaped the history of this diverse group as is highlighted in Table 1. The development of the Confederated Tribes of the Grand Ronde Community of Oregon can best be conceived as encompassing four historical periods: (i) Reservation Formation, (ii) Reservation, (iii) Reservation De-segregation, and (iv) Revitalization. The first three phases correspond to three successive generations of community members as described in detail in Zenk (1984). I will briefly summarize the salient issues from each of these periods as they 
relate to language use and

traditionalism. The fourth

phase is the focus of this study

and will be discussed in $\S 4$ and

in Appendix B.

\subsubsection{Reservation Formation: The First Reservation Generation}

The Grand Ronde

Reservation was officially

established in 1857. As

indicated in the June 1997

Resource Directory, there were

Table 1 CTGR Timeline (CTGRCO, 1997, p. 4) 1850's Establishment of Grand Ronde

Reservation on over 60,000 acres by:

- Treaty arrangements (1854-1855)

- Executive Order (June 30, 1857)

1887 General Allotment Act

- 33,000 acres of original res. allotted to individuals

\section{Sale of res. land to non-Indians}

-25,791 acres declared "surplus" and sold

1936 Indian Reorganization Act

- Tribe allowed to purchase land for homes of tribal members

1954 Termination Act

- "severed the trust relationship between the federal government and the Tribe"

1983 Restoration Act (November 22)

- Public Law 98-165 re-established the CTGR

1988 Grand Ronde Reservation Act

- Tribe "regained 9,811 acres of the original reservation"

"over 20 tribes and bands from western Oregon and northern California that were relocated to the Grand Ronde Reservation in the 1850's," including “the Rogue River, Umpqua, Chasta, Kalapuya, Molalla, Salmon River, Tillamook and Nestucca Indians" (CTGRCO, 1997). For our purposes, it is significant to note not only the tribal, but also the ethnic and linguistic diversity of the early reservation. "Taken together, the major tribal and ethnic segments of this community represented fully nine mutually unintelligible languages, to which may be added a number of 'minority' languages spoken by smaller scatterings of individual community members" (Zenk, 1984, p. 
257). Because crmuk "was the only Native (that is, Indian) language that belonged to the entire Grand Ronde community" (Zenk, 1984, p. 80), and because of "the lack of marked social, linguistic, or cultural dominance on the part of any particular tribe vis$\grave{a}$-vis the rest of the community" (Zenk, 1984, p. 98), it seems quite natural that čmuk functioned, at least in this formative stage, as a lingua franca (Zenk, 1984, p. 158). This first generation came to the reservation with their traditional Indian ways intact. Based on historical accounts and family reconstructions, Zenk (1984) comments that "many Native ways [were] maintained with undiminished vigor by the first reservation generation [from the 1850's to the turn of the century]" (p. 125). Unfortunately, much of this traditional culture was not passed on to subsequent generations.

\subsubsection{Reservation: The Second Reservation Generation}

This group was "the first and only generation to grow from birth to adulthood under conditions of reservation segregation (this was the generation of Jacobs' Grand Ronde consultants Victoria Howard and John Hudson)" (Zenk, 1984, pp. 81-82). Despite the extreme heterogeneity of this group, there developed "a sense of solidarity within this community - a development reflected terminologically in the usual designation 'Grand Ronde Indians' (or less frequently, 'Grand Ronde Tribe') in reference to the entire community" (p. 119). Zenk notes that, although people maintained a consciousness of their original tribal heritage, the conditions on the reservation created a distinct separation between them and the "dominant society" (p. 
115). "Membership in the reservation community very much affected individuals as Indians; it affected them much less as Tualatins, Klickitats, Shastas, and so on" (p. 115).

Culturally, this period was marked by decreased attention to traditional ways (Zenk, 1984). In fact, "with a few exceptions, notably Native basketry and the continuing use of Chinook Jargon, there simply seemed to be no Native traits at all left at Grand Ronde by 1934" (p. 124). This generation was definitely familiar with the ways of their parents' generation, and had participated in traditional ceremonies, notably, tamanwas ${ }^{11}$ "winter spirit-helper" or wam haws ${ }^{12}$ "warm house" dances, but they apparently did not deem it essential to pass these traditions along to their children (pp. 130-131).

\subsubsection{Reservation De-segregation: The Third Reservation Generation}

From the third generation on, the Indian community in Grand Ronde experienced a substantial amount of change. Citing Indian agents' records, Zenk (1984) notes the cession, in 1901 , of all of the approximately 26,000 acres of previously unallotted lands to the United States government (p. 138). Arable portions of this acreage were soon occupied by "an influx of White families" who moved into the region (p. 138). In 1907, "Grand Ronde Agency itself ceased independent existence" with the merger of Grand Ronde and Siletz agencies at Siletz (pp. 138-139). With the increased contact with Whites, there naturally came less segregation from the 
dominant society ${ }^{13}$ (p. 139). In 1934, according to Joel Berreman's report on the cultural adjustment of the Grand Ronde Indian tribe, the prospects for the Native community were quite bleak: "Community members had virtually abandoned traditional Native ways by then, but they had yet to gain equality of opportunity for economic and social advancement on the terms of the dominant society" (Zenk, 1984, p. 139).

Let's look more closely at the Native culture during this period. "With the third and fourth, more educated and missionized generations, a deep 'generation gap' emerges with respect to Native ways" (Zenk, 1984, p. 125). The tamanwas dances in later years, as Wilson Bobb recalled in his interviews with Zenk, were not very elaborate proceedings (p. 133). Occurring in later reservation years only infrequently (3-4 times per winter), the tamanwas dances persisted until around 1910 (p. 134). Yet despite the bleak outlook for traditional ways, CJ, remarkably, has persisted, even to the present (see $\S 4.1$ for a description of the current status of $\check{c}$ mnvk at Grand Ronde). Zenk (1984) attributes the long persistence of črnuk at Grand Ronde to acquired symbolic associations with Indian identity (p. 141). That is, črnvk became a symbol for being Indian. In fact, some of Zenk's informants consistently referred to “Jargon” as šawaš wawa 'Indian talk', (p. 175) 'Indian', or 'the Indian language' (personal communication, May 25, 1998). Without recourse to any other common Native language, Grand Ronde Indians used čmok instrumentally as a means of 
transmitting Native culture, as well as phatically as an expression of Indian identity (p. 176). Thus, črnuk not only served as an icon for Indian ness, it also served as the medium through which oral traditions were transferred to others (see Zenk, 1984, §3.2.3 passim). 


\section{Chapter One Notes}

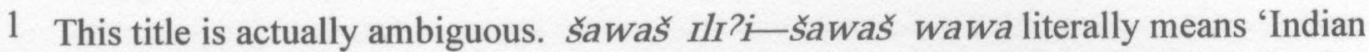
land-Indian talk' but it has special meaning in the Grand Ronde community. H. Zenk (p.c., April 22, 1998) explains that older Grand Ronde Indians regularly used šawaš Ilı?i to refer to the Grand Ronde Reservation. Clara Riggs, Delmore Croy, and other elders interviewed by Zenk (1984) regularly referred to čmvk as "the Indian language," while Wilson Bobb, among others referred to šawaš wawa while speaking črnuk (p. 175). This ambiguity is intentional; the connection between being Indian and speaking čmuk in the Grand Ronde Indian community was well established in Zenk (1984) and will be built upon here.

2 Throughout this paper, elders who speak the language will be referred to by numbers. If there is an interest in contacting someone in the Grand Ronde community regarding language, Tony Johnson should be contacted first in the Kwelth Tahlkie Culture and Heritage Board offices: (800) 422-0232, extension 2084.

3 The informant's son explained that he did not approve of researchers coming into the community and taking the language and culture away from there without giving anything. In this sense, he was trying to defend his mother and his people from those he perceived to be a threat. He asked me if I was doing the same thing other researchers had done, and I responded by saying "Oh no, I just want to learn Jargon," which I could ethically say because I really didn't have any clear focus in mind as to the research direction I would be able to take. In response to his question, his wife, who had been there the whole time added, "I already listened. If it wasn't [legitimate] he would have been out the door."

4 The crnvk terms $q^{w} \varepsilon t t^{\prime}$ ?an $\nmid k i$ literally mean 'pride/proud yesterday.' In discussions with Johnson, we wondered which word "Kwelth" was meant to represent: $q^{w} \varepsilon l t^{\prime}$ 'tight' or $q^{w} \varepsilon \mathcal{F}^{\prime}$ 'pride.' It would make sense to talk about the "tight" connection one might have with the ways of "yesterday." Tony is currently trying to find a better name for the Culture Board. A name which has been suggested is $k a k^{w} a$ anqati' like before/ancestors'. At least one reason why this name might be better is that, as Tony explains, it is much easier to pronounce for non-speakers and it is more descriptive.

5 There are currently three individuals who are employed by the KTC\&HB to carry out the board's directives. The three positions are: (i) Executive Director, (ii) Language Specialist (formerly Collections Curator-Language), and (iii) Administrative Assistant, none of whom ere members of the board. See Figure 8. 
6 Chinook Jargon has been referred to using a number of terms. Zenk (1988) comments that most of the recent elderly speakers in Grand Ronde referred to the language as simply "Jargon" (p. 107). Tony Johnson prefers the label "črnvk wawa" or simply "črnvk" despite the fact that this causes some confusion with what linguists term Chinookan (Upper and Lower Chinook) or Chinook proper (Lower Chinook). Johnson usually refers to Chinookan as "anqati čnvk"—“old/ancient Chinook." Henry Zenk (personal communication, May 12, 1998) suggested referring to Chinookan as "ćinuk," "the assumed original form of the name given by Boas (1911, p. 563)."

7 Boas communicated with his Chinookan informant in čmuk (that is, the Jargon) since that was their only common language. He must have had adequate proficiency to procure the understanding he gained of ćinuk.

8 This source was originally published in 1935.

9 Zenk (1996) uses the metaphor of focusing and diffusion to describe the phonological variation found in four fluent speakers of Chinook Jargon at Grand Ronde. "The approach's advantage is that it can accommodate linguistic order-focusing - without finding it imperative to explain away chaotic diversity-diffusion" (p. 173).

10 As of the beginning of May, 1998, there were 599 crnvk words in the database.

11 The $\operatorname{taman}(\partial)$ was dance was "a rather free-form ceremon[y] in which individuals, shamans first and foremost but everyone else as well, sought to heighten and dramatize the powers of their respective spirits" (Zenk, 1984, p. 130).

12 The wam haws dance was "a highly organized and public form of ceremonialism. ... This was certainly identically the 'earth-lodge cult' indigenous to central and northern California, itself a variant of the 'ghost dance' movement of late-nineteenth century western North America" (Zenk, 1984, p. 131).

13 For Grand Ronde Indians, there was a "long tradition of [relatively] free access to the outside world" (Zenk, 1984, p. 139). Thus, the notion that the influx of Whites to the area in the early 20th century ended reservation segregation must be tempered with the historical pattern of contact with Whites, as Zenk duly notes (p. 97). 


\section{Literature Review}

This chapter discusses the issues involved with language planning in the American Indian setting. The first question is definitional, simply, what is language planning? Kaplan \& Baldauf (1997) define it as "a body of ideas, laws, and regulations (language policy), change rules, beliefs, and practices intended to achieve a planned change (or to stop change from happening) in the language use in one or more communities" (p. 3). More simply put, "language planning is an attempt by someone to modify the linguistic behaviour of some community for some reason" (p. 3).

Tollefson (1991) differentiates between two approaches to language planning. The neoclassical approach focuses on the individual learner without the complication of matters such as class struggle and systemic injustice; the historical-structural approach focuses on "the social, political, and economic factors which constrain or impel changes in structure and language use" (p. 31). The real difference is that the neoclassical approach tends to deemphasize the political nature of language planning. In Grand Ronde, the latter approach is being employed. Their language planning goals envision significant social change for the betterment of the Tribe and its members.

\subsection{Language Planning Variables}

According to St. Clair (1982), there are five variables involved with language 
planning: institutionalized purism, reform, standardization, modernization, and revitalization (p. 5). A slightly expanded view is presented by Kaplan \& Baldauf (1997), which presents eight primary elements involved in language planning, in general: "language death; language survival; language change; language revival; language shift and language spread; language amalgamation; language contact and pidgin and creole development; literacy development" (pp. 271-272). These factors may be in operation at the same time in any given social environment. In the space below, I will briefly describe each ${ }^{1}$ variable and its relevance to this study.

\subsubsection{Language Death}

Language death can be defined as "the ultimate state of language loss"- a total community shift to a new language, resulting in the cessation of use of the old language (Fernández Bell \& Gilbert, 1996b). Krauss (1992) enumerates a broad spectrum of causes for language death:

The circumstances that have led to the present language mortality known to us range from outright genocide, social or economic or habitat destruction, displacement, demographic submersion, language suppression in forced assimilation or assimilatory education, to electronic media bombardment, especially television, an incalculably lethal new weapon (which I have called "cultural nerve gas"). (p. 6)

Cantoni (1996) notes, however, that currently

languages are more likely to disappear as the result of the destruction of the cultural habitat of their speakers than because of direct attack upon their use. ... But it is important to remember that there are political forces pushing national and state constitutional amendments to make English the official language of this country that could harm efforts to save indigenous languages. (pp. viii-ix) 
In summary, Kaplan \& Baldauf (1997) note the three necessary conditions for language death to occur:

(1) Parents are reluctant or unable to pass on a language to their children.

(2) The language ceases to serve key communicative functions (registers) in the community.

(3) The community of speakers is not stable and/or expanding, but rather is unstable and/or contracting. (p. 273)

Language loss and language death have taken their toll on the Grand Ronde community. Where črnuk was once a preferred language for many people, now English is the only language for the vast majority of people.

\subsubsection{Language Survival}

Language survival is closely related to language death. As the name implies, it involves the persistence of the language within a given community. "The conditions for language survival are exactly the opposite of the conditions for language death" (Kaplan \& Baldauf, 1997, p. 274). These conditions are:

(1) Parents must be willing and able to transmit the language to their offspring and must actually do so.

(2) No condition may exist which will cause a more powerful language $(\mathrm{H}$ variety) to be imposed on a less powerful one ( $\mathrm{L}$ variety), and functional registers must be retained.

(3) The community of speakers must be vibrant, stable, or increasing. (pp. 274275)

Henry Zenk's (1984) dissertation documents the persistence of črnuk in Grand Ronde into the time of universal English ability. Many people apparently preferred črnuk to English in the home and community. Later on, however, English $(\mathrm{H})$ 
replaced črnuk $(\mathrm{L})$ in almost all registers.

\subsubsection{Language Change}

Languages change in different ways. One way is through normal processes, exemplified in such classical phonological processes as Grimm's and Verner's in Indo-European. The second way languages change is through language contact (Kaplan \& Baldauf, 1997, p. 276). Kaplan \& Baldauf explain that "as each technology spread[s], by contact, from one community to another, the adopting community accept[s] not only the technological implement, but also the value system and the modified social structure accompanying the technological innovation" (p. 276).

With regard to the first process, it appears that in Grand Ronde the regional CJ at least began to become creolized in the early twentieth century, undergoing several of the more regular processes of language, e.g., the use of clitic pronouns and the contracting of longer lexical items (Zenk, 1984). Additionally, it is likely that local indigenous languages influenced the lexicon of črnvk. Tony Johnson informs me that as needs arise for new words to be added to crmuk, it is likely that the Native languages formerly spoken at Grand Ronde will be consulted for possible new forms. Thus, črnuk will continue to change and be influenced by both planned for, and, as yet, unforeseen factors. 
As discussed in $\S 1.3$, there are a variety of terms used to describe the process of breathing new life into a dead or dying language. There are also several different ways to classify candidates for revitalization. The languages which need to be revived or revitalized are generally referred to as endangered languages. Krauss (1996) posits four categories of viability in regard to Native languages (see Table 2). He has also calculated the approximate numbers of languages in each category for the Table 2 Native language viability (Krauss, 1996, p. 17)

A Languages still being learned by children in the traditional way

B Language still spoken by the parental generation, but not taught to children

C Language spoken by the middleaged and grandparental generations only

D Language spoken by only a few of the very oldest people

175 American Indian languages of

the United States (see Figure 1). One of the most vocal and prolific writers on the

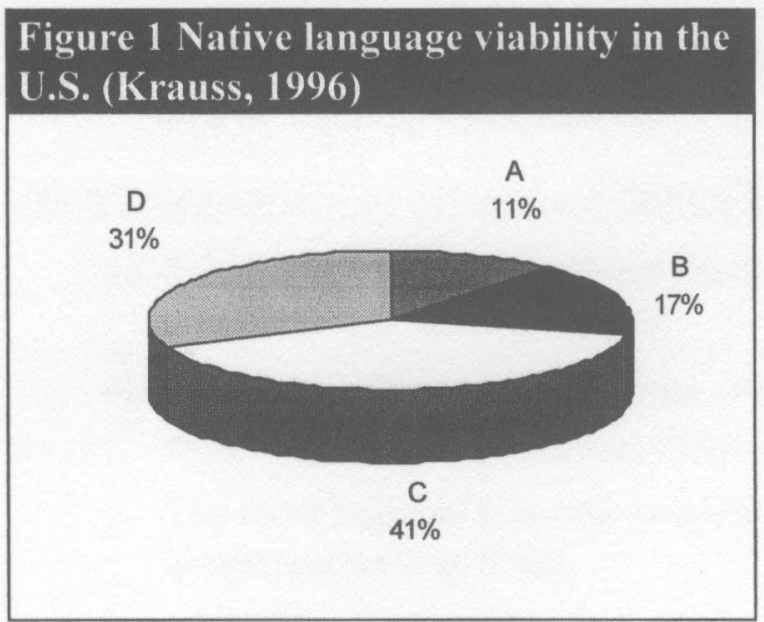

topic of language revival is Joshua

Fishman. In his Graded

Intergenerational

Displacement Scale (GIDS),

Fishman (1991) provides a detailed description of the stages involved in reversing language 
shift (RLS) (pp. 87-121). He uses "Xish" to represent the endangered language and "Yish" to represent the majority language-the language to which people switched. Marshall (1994) points out that this scalar can be "utilized for measuring language maintenance and revival" (p. 22). Table 3 illustrates the eight levels of endangerment. Fishman emphasizes that the activities intended to improve the viability of a language must be correspond with the stage of displacement.

In order for language revival to be successful, all the factors contributing to

\section{Table 3 Fishman's (1991) Graded Intergenerational Dislocation Scale (GIDS)}

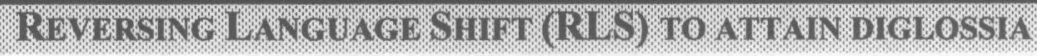

8. Reconstructing Xish and adult acquisition of XSL.

7. Cultural interaction in Xish primarily involving the community-based older generation.

6. The intergenerational and demographically concentrated home-familyneighborhood: the basis of mother tongue transmission.

5. Schools for literacy acquisition, for the old and for the young, and not in lieu of compulsory education.

\section{RIS TO TRANSEEND DICLOSSIA, SUBSEQUENT TO TTS ATT AINMENT}

4a. Schools in lieu of compulsory education and substantially under Xish curricular and staffing control.

4b. Public schools for Xish children, offering some instruction via Xish, but substantially under Yish curricular and staffing control.

3. The local/regional (i.e. non-neighborhood) work sphere, both among Xmen and among Ymen.

2. Local/regional mass media and governmental services.

1. Education, work sphere, mass media and governmental operations at higher and nationwide levels. 
language death must be reversed (Kaplan \& Baldauf, 1997, p. 278). In fact,

successful language revival depends not only on the availability of a large pool of speakers of the language being revived, not only on the willingness of those speakers to pass the language on intergenerationally, but on the availability of opportunities to use the language in a large number of registers and on the availability of economic opportunity in the language being revived. (p. 281)

Kaplan \& Baldauf divide language revival into four sub-categories: educational

revival, economic revival, ethnic revival, and language transformation (pp. 281-282).

The first three are fairly straightforward, but the fourth, language transformation, warrants special attention. Because language changes over time, the language that is to be revived must not be the language "as it was," but rather a transformed, modernized variety capable of meeting "communicative demands in a variety of new domains" (p. 282). Burnaby (1996) explains that, based on national surveys of language maintenance in Canada, the best places for indigenous languages to be maintained are large, isolated communities (p. 25). Schiffman (1997), summarizing Kloss's article on German-American language maintenance, outlines six primary factors which strengthen language maintenance: (i) "regio-societal insulation/isolation"; (ii) "time of immigration: priority/simultaneity with AngloAmericans"; (iii) "Sprach-Inseln², large or small"; (iv) "denominational fostering of parochial schools"; (v) "pre-immigration experience with language maintenance efforts"; and (vi) "prestige resulting from official use as only tongue during preAnglo-American period." 
Based on the conditions for success listed above and in $\$ 2.1 .2$, Grand Ronde's prospects do not look too good. Grand Ronde is a somewhat isolated community, but it is small, and thus not the best candidate for language maintenance. The Indians who were relocated to Grand Ronde were clearly in the area long before whites came. Since they were not immigrants, some of the other conditions for success do not directly apply to this sociolinguistic situation. However, before one can make any predictions about $\check{c}$ mnvk in Grand Ronde, the language needs to be learned by a greater number of people. Kaplan \& Baldauf (1997) affirm that before revitalizing a language, it must first be stabilized (p. 78). Just how many speakers would constitute a critical mass is difficult to predict, but there certainly must be more than the present three or four speakers. Thus, until the number of speakers is expanded, and the socioeconomic viability of crmuk in Grand Ronde is explored, it would be impossible to determine how effective language revival efforts might be.

\subsubsection{Language Shift and Spread}

Kaplan \& Baldauf (1997) note that "all languages shift at various times in their histories" but that this does not necessarily imply a threat "to the continued existence of a language" (pp. 282-283) ${ }^{3}$. This shift may include any linguistic (e.g., lexical, morphological, syntactic, or phonological) movement in the direction of another language. Cooper (1982, p. 6, cited in Kaplan \& Baldauf, 1997) describes language spread as "an increase over time, in the proportions of a communicative network that 
adopts a given language or language variety for a given communicative function" ( $\mathrm{p}$.

285). In other words, language spread is simply "a more active notion of language shift" (p. 285) in which "potential adopters see a personal advantage in using [another language]" (Cooper, 1989, p. 106).

Historically, in Grand Ronde, there was a community shift from more than nine tribal languages on the early reservation to črnvk, the indigenous lingua franca shared by all. With time, however, knowledge of English increased in the community. Finally, almost the entire speech community shifted to English (Zenk 1984). With the spread of English came a drastic reduction in the number of domains in which čmuk was used. Presently, the KTC\&HB hopes that community members will shift back to crmvk at least in some domains. Thus, it is their hope that crnvk will spread throughout the community and come to a stable diglossic state with English.

\subsubsection{Language Contact and Pidgin and Creole Development}

"When two communities speaking mutually unintelligible languages come into sustained contact with each other, a reduced form deriving from both of the contact languages may come into existence" (Kaplan \& Baldauf, 1997, p. 286). The results of such a creative endeavor to forge meaning is a pidgin and may eventually be learned as a first language by children, thus expanding into a creole.

As discussed in $\S 1.5 .2$, the regional CJ functioned as a pidgin, with speakers of mutually unintelligible languages using $\mathrm{CJ}$ as a lingua franca. In Grand Ronde, the 
regional pidgin seems to have at least begun the creolization process. If future language planning is successful, and community members shift to speaking črnvk in at least some domains, it will be interesting to see how language use in the community would change. Such "success" with črnuk would necessarily entail a reduction in the number of domains dominated by English. How would črnuk change to meet the increased demands placed upon it by modern speakers? Would it creolize? And if it did, in what ways would it expand? Would it become more English-like (compare claims that modern Hebrew is a relexified Slavic language)? For answers to these and similar questions, we will simply have to wait.

\subsubsection{Literacy Development}

All of the other variables deal primarily with oral language behavior, but the next deals with written language since the issue of literacy has now become central to modern society (Kaplan \& Baldauf, 1997, p. 288). Although it is important to bear in mind that "possession of literacy is not a panacea to all the problems of society" (p. 146), literacy has played a critical role in language revitalization. It must be understood that "literacy (if by literacy one means the ability to deal with written text - both to encode it and to decode it) is not part of the human genetic baggage; on the contrary, it must be learned in each generation and by each individual" (p. 143). In language revitalization efforts, especially when dealing with a virtually moribund language, literacy takes on an increasingly important role. It facilitates access to 
cultural and linguistic resources that would otherwise be inaccessible. With the advent of literacy, the formerly prestigious memory owners for a group saw the need for their services diminish greatly (p. 144). Traditionally, American Indians have transmitted cultural knowledge, including their languages, "by observation and participation in the traditional context of the home community" (Zaharlick, 1982, p. 44). Thus, literacy development is not simply a technological advance; it can involve a fundamental change in the group's culture. It is hoped that literacy will indeed foster such a change within the CTGR community.

Historically, there has been no one accepted writing standard for CJ. Traders, explorers, anthropologists, linguists, and common folks each had their own way of writing the language. For example, the word for 'good' has been written in a number of ways: kloshe, closhe, hloosh, tlush, and tuš. Linguists employed either phonetic or phonemic transcription depending on the orientation of the researcher ${ }^{4}$. Among nonlinguists, spellings varied greatly and were based on either French or English orthographies, depending on the writer's native language. Non-English sounds, such as the voiceless lateral fricative [ł], have been written "cl" "kl," "tl," "hl," and "thl." Such inconsistencies make it difficult to determine the pronunciation of words no longer in general use and even more difficult to establish writing conventions.

The issue of the traditional method of transmission of "language-in-culture" (Fishman, 1991) has been discussed from time to time during language planning 
sessions. Tony Johnson has indicated that he would like language learners to use the orthography we have developed to enhance their learning opportunities. The new orthography provides both a more isomorphic representation of the phonology of čmvk and opportunity for students to practice and reinforce their learning outside of the language classroom. The objective at this stage is to get this small group of people understanding and speaking črnvk in the shortest time possible, so that they can then serve as resources for the rest of the community. The literacy these group members obtain in the process will not only assist them in the learning process, but it will also equip them to fulfill their roles as future teachers and Native language supporters.

\subsection{Status and Corpus Planning}

Hamel (1997) credits Haugen with coining the term "language planning" in 1959. Language planning activities are often divided into corpus planning - "those [activities] that are concerned specifically with attempts to modify language itself"and status planning — "those [activities] that are concerned with attempts to modify the environment in which a language is used" (Kaplan \& Baldauf, 1997, p. 28). Kaplan \& Baldauf point out, however, that it is almost impossible to separate these two activities in practice. In Table 4 one framework for language planning is presented. This model will be used to describe the language planning I observed in Grand Ronde (see $§ \S 4.3$ \& 4.4). The neo-Haugenian model was selected because it places the traditional terms "status planning" and "corpus planning" into a larger framework which moves from 
form to function based on the goals of the language plan.

\begin{tabular}{|c|c|c|}
\hline & $\begin{array}{l}\text { Form } \\
\text { (policy planning) }\end{array}$ & $\begin{array}{l}\text { Function } \\
\text { (language cultivation) }\end{array}$ \\
\hline $\begin{array}{l}\text { SOCIETY } \\
\text { (STATUS } \\
\text { PLANNING) }\end{array}$ & $\begin{array}{l}\text { 1. Selection (decision } \\
\text { procedures) } \\
\text { a. problem identification } \\
\text { b. allocation of norms }\end{array}$ & $\begin{array}{l}\text { 3. Implementation } \\
\text { (educational spread) } \\
\text { a. correction procedures } \\
\text { b. evaluation }\end{array}$ \\
\hline $\begin{array}{l}\text { LANGUAGE } \\
\text { (CORPUS } \\
\text { PLANNING) }\end{array}$ & $\begin{array}{l}\text { 2. Codification } \\
\text { (standardization } \\
\text { procedures) } \\
\text { a. graphization } \\
\text { b. grammatication } \\
\text { c. lexication }\end{array}$ & $\begin{array}{l}\text { 4. Elaboration (functional } \\
\text { development) } \\
\text { a. terminological } \\
\text { modernization } \\
\text { b. stylistic development } \\
\text { c. internationalization }\end{array}$ \\
\hline
\end{tabular}

\subsubsection{Status Planning}

Status planning is concerned with the social functions of language. Fishman (1991) explains that "status planning seeks to allocate societal resources ['such as intelligence, funds, time, effort, and implementational power' (p. 81)] in such ways as to foster the use of a language in more (and in more important) societal functions among larger and larger numbers (and proportions) of individuals" (p. 338). Fishman also notes that when reviving endangered languages, status planning is where the language planners' primary focus must be because "it is status planning, not corpus planning, that is the engine of all language planning success" (p. 349). The two main 
elements of status planning are language selection and language implementation. I will describe each of these processes below, whereas discussion of these elements in relationship to črnuk in Grand Ronde will be developed in $§ 4.2$.

\subsubsection{Language Selection}

As the title suggests, language selection comprises "the choice of a language(s) by/for a society through its political leaders," with the focus on developing language policy (Kaplan \& Baldauf, 1997, p. 30). When dealing with low prestige languages, "an environment must be created through 'revalorizing' them where there is an appreciation of the contribution they make to social and cultural life" (pp. 30-31). Several criteria for selecting a language have been proposed. Kale (1990) lists the following criteria: (i) "political neutrality," (ii) "dominance," (iii) "prestige," (iv) “a great tradition," and (v) "areal affinity" (pp. 185-186) Since "political neutrality" is not possible in reality, I will use "mutually acceptable" as the first criterion in the discussion in $\S 4.2 .2$. Kaplan \& Baldauf point out that in language selection, efforts should be made to minimize disruption to the polity (p. 32). The discussion on "allocation of norms" is not relevant to the Grand Ronde situation and will thus not be discussed here.

\subsubsection{Language Implementation}

Once a language has been selected and normative policies have been 
established, then it is time to execute the planned spread of that language (Kaplan \& Baldauf, 1997, p. 36). The promotion of a language can be achieved by a number of different means-most commonly, either "through the educational system" and/or "through other laws or regulations which encourage and/or require the use of the standard and perhaps discourage the use of other languages or dialects" (p. 36). Kaplan \& Baldauf cite a couple of examples of language implementation laws: (i) offering tax incentives to promote use of a particular language, and (ii) requiring bilingualism as a pre-, or co-requisite for employment (p. 37). In the following section I will explore the role of education as a means to language acquisition in the implementation stage.

\subsection{Language Acquisition}

In the context of language planning generally, and language implementation specifically, it might be better to use what Cooper (1989) refers to as "acquisition planning"- "organized efforts to promote the learning of a language" (p. 157). This is because this broader term subsumes "language-in-education planning" (Kaplan \& Baldauf, 1997, p. 122) and highlights important distinctions for this study. Cooper lists three main goals of acquisition (acquisition as a second or foreign language, reacquisition of a language formerly used as a vernacular, and language maintenance) and three means of achieving those goals (through the creation or improvement of learning opportunities, learning incentives, or both simultaneously) as illustrated in 
Table 5 .

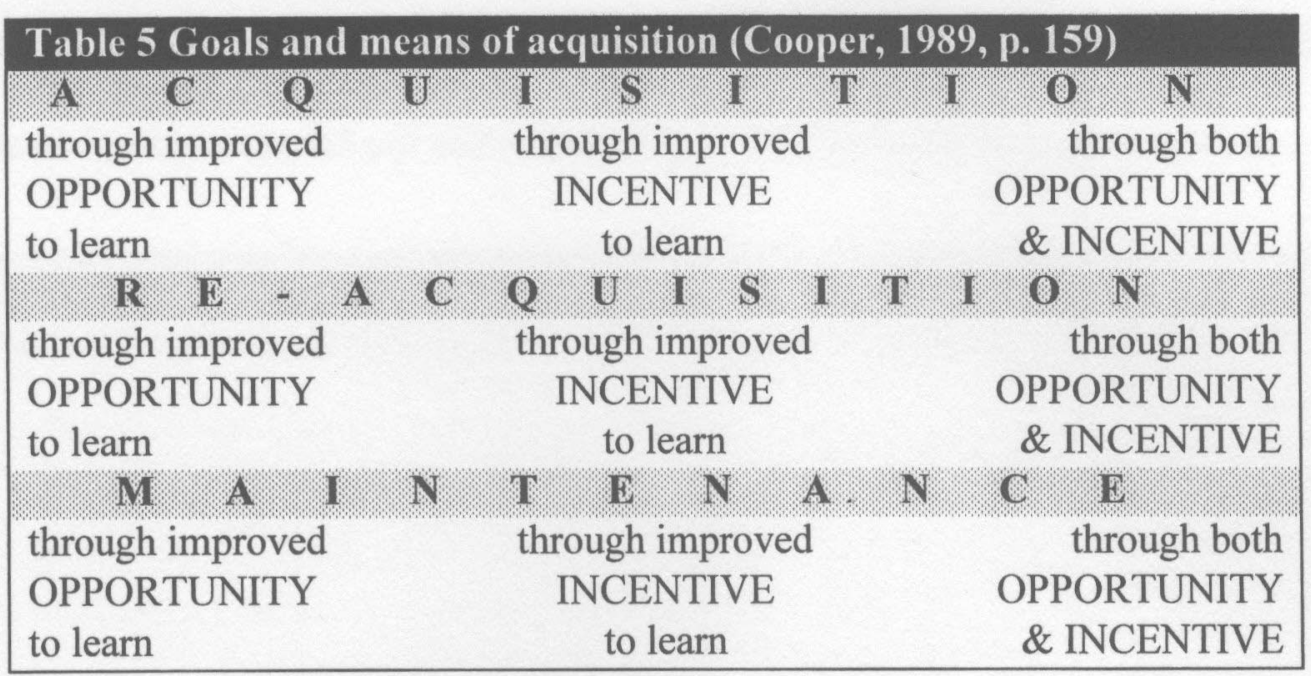

A closer look at the role of education in acquisition planning reveals the

limitedness of its effect outside of the school. Kaplan \& Baldauf (1997) warn that

formal education should be only one component of the language implementation plan

(p. 37). Fishman (1991) explains:

The assumption that 'proper schooling' can really help a threatened ethnolinguistic entity to break out of this vicious cycle (the cycle of running harder and harder in order to finally end up, at best, in the same, or nearly in the same, place, generation after generation) is quite widespread, particularly among educators and other language-conscious segments of the lay public, and even among many sociolinguists too, although the latter should really know better. (p. 369)

"The education sector lacks the authority to impact on other segments of society"

(Kaplan \& Baldauf, p. 36) such as the crucial "family-neighborhood-community arena in which the school plays only a circumscribed role" (Fishman, p. 373). Despite the 
valid criticisms of formal education as a means for promoting language learning, schools are, nonetheless, useful, at least as part of the overall language implementation plan. As Figure 2 illustrates, educational planning should be done only after the initial research has been carried out and reported on. Numbers seven through twelve in

\section{Figure 2 Schema for language-in-education policy development (Kaplan \&} Baldauf, 1997, p. 124)

\section{Language Polley and Plamming}

1 - PRT PI A MNUNG Stage historical research, cost estimation

2 = S13rVtr. Stage, design, test, disseminate collectledi data

3 - REPOR Stage write report, test reconmendations

4 - Pourcy Stage design and test pollcy strategies.

5 - MrLGMEVIATION Stage, devise, implement strategies

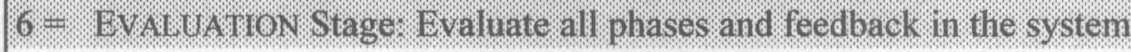

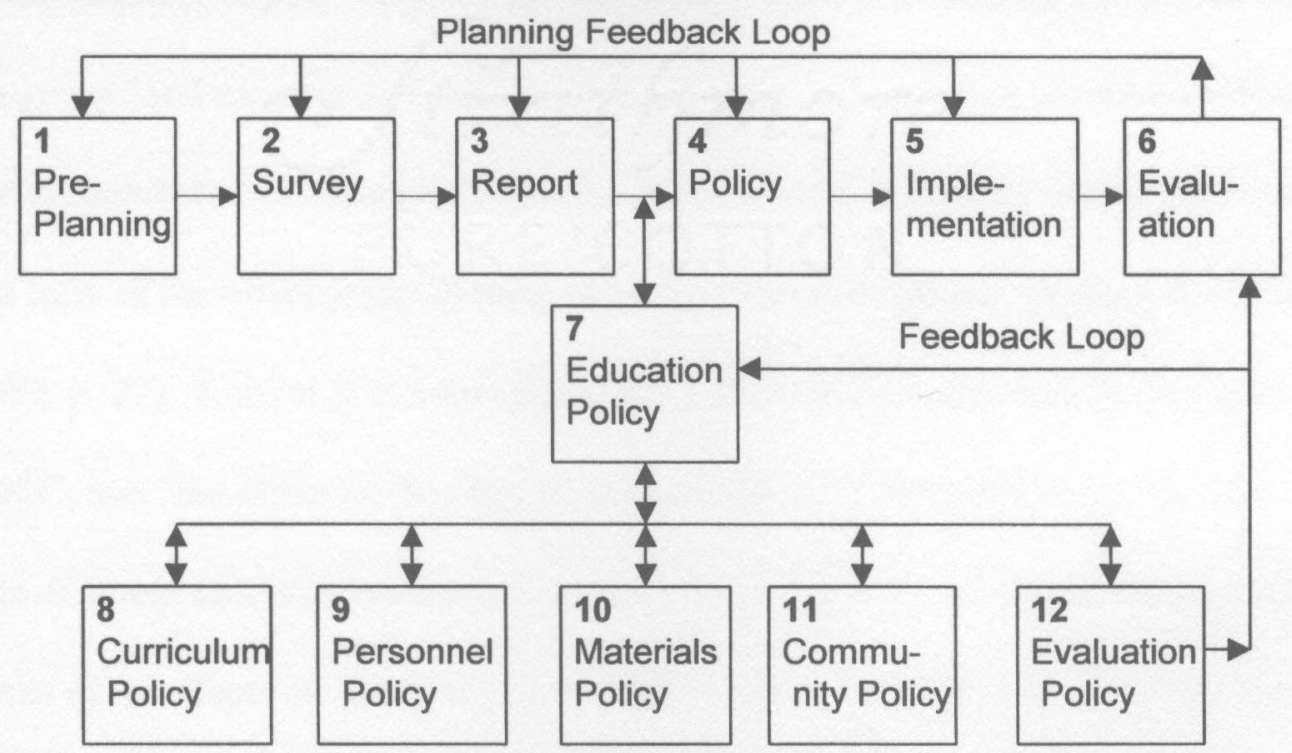

\section{Language-in-Bducation Policy}

7 - EDUCATION Policy separate from general policy

8 - Cirricul UM Pollcy, what languages, when

9 - PERSONNEL Polley: in service pre-service training

10 - MATERIA.s Policy, what, how nuch, how soon

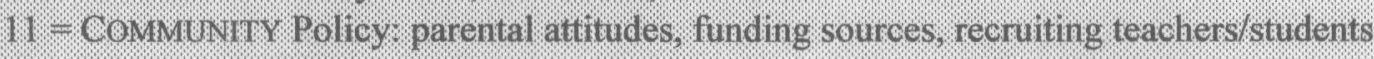

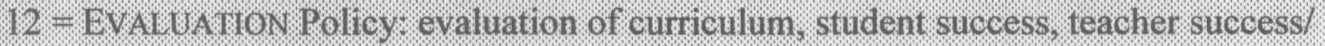
interest, cost effectiveness, societal change, basic policy. 
Figure 2 refer to language-in-education policies, but for more information on the actual process of language-in-education planning, see Kaplan \& Baldauf, pp. 113117). The teaching of $\check{r}$ rnuk in Grand Ronde will be discussed in $\S 4.2 .3$. The discussion here - on the importance of approaching language acquisition in broader terms than formal education - was intended to set the stage for my examination of the practices and plans in Grand Ronde.

\subsubsection{Evaluation}

Determining the effectiveness of a language implementation plan is rather complicated (Cooper, 1989, pp. 162-163). As Figure 2 illustrates, evaluation must be on-going "and must be designed in such a manner as to provide constant feedback for the implementation strategy, so that the implementation strategy can be corrected in the light of the information flowing from the evaluation phase" (Kaplan \& Baldauf, 1997, p. 37). Kaplan \& Baldauf argue for simultaneous evaluation of: "the plan itself", and "the effect of the plan on various sectors of the population" (p. 37). The different facets of evaluation of each element of the KTC\&HB language plan in terms of its effects on the community will be discussed in the context of the language planning process $(\$ 2.3 .4)$.

\subsubsection{Corpus Planning}

In contrast to status planning, where the focus is on society, Kaplan \& Baldauf 
(1997) define corpus planning as "those aspects of language planning which are primarily linguistic and hence internal to language" (p. 38). Status planning was discussed before corpus planning because of the all important relationship between the two. Cooper (1989) explains the nature of this relationship: "Form follows function not only in the sense that a desired communicative function precedes a designed linguistic form but also in the sense that non-communicative goals (functions) influence the desired form of the corpus" (p. 125). When dealing with "threatened" languages, Fishman (1991) stresses the increased importance of "successful" corpus planning, which, he stresses, "is much harder than mere corpus planning, the latter activity being one in which most mortals dabble from time to time and to no apparent societal effect" (p. 347). Again, we see the relationship between linguistic features and societal outcomes.

As illustrated in Table 4, corpus planning can be divided into two broad categories: (i) "Codification" or standardization; and (ii) "Elaboration" or "the functional development of language" (Kaplan \& Baldauf, 1997, p. 38). In the space below I will outline each category, highlighting the sub-categories contained in each. In $\S 4.3$, the current language planning efforts in Grand Ronde will be described using the categories and sub-categories described below.

\subsubsection{Codification}

The codification process involves the establishment of language norms through 
standardization (Kaplan \& Baldauf, 1997, p. 39). This activity usually concentrates on written rather than spoken language. There are three results which codification typically produces: “a prescriptive orthography, grammar, and dictionary" (p. 40). The three processes involved in codification are graphization, grammatication, and lexication.

\subsection{Graphization}

Kaplan \& Baldauf (1997) observe that graphization is usually the first step in the standardization process. Graphization is concerned with the writing of language. For languages which already have a written tradition, the language planner must choose between making do with the existing system or inventing an entirely new one (Cooper, 1989, p. 126).

There are two main categories of criteria for the selection of an adequate writing system: (i) psycholinguistic and (ii) sociolinguistic (Cooper, 1989, pp. 126131).

Psycholinguistic, technical principles and criteria are concerned with the extent to which the writing system is easy to learn, easy to read, easy to write, easy to carry over to another language (transfer of skills), and easy to reproduce by modern printing techniques. (Cooper, 1989, p. 126)

Each of these five issues: learnability, readability, writability, transferability, and printability will be discussed in relationship to čmok in $\S 4.3 .1$. 


\subsection{Grammatication}

Grammatication entails "the extraction and formulation of rules that describe how a language is structured" (Kaplan \& Baldauf, 1997, p. 41). All aspects of the grammar - syntax, phonology, morphology, etc.- would be included in the full grammar of a language. Kaplan \& Baldauf point out that because of the inherent complexity of such a full grammar, a partial grammar is often constructed to focus on certain pedagogical elements. One aspect of the grammar which is almost never described is pragmatics (p. 41). Because of the mutable and somewhat capricious nature of speech acts, the pragmatics of a language are not only difficult to describe synchronically, but difficult to remain up-to-date on diachronically.

\subsection{Lexication}

As the name indicates, lexication involves selecting and expanding the lexicon of a language (Kaplan \& Baldauf, 1997, p. 42). Whereas the grammar of a language may stabilize and thus require less maintenance, the lexicon is constantly changing. Lexication involves not only the creation of new words, but also establishing norms of domain-specific word use (p. 42). Kaplan \& Baldauf outline four principles for devising new lexical items: (i) borrow foreign words, (ii) invent new words from foreign roots, (iii) revive words which are no longer in use, and (iv) combine existing words to create new meanings (p. 43). Lexication is very similar to terminological modernization which is discussed in $\S 2.2 .2 .2 .1$. 


\subsubsection{Elaboration}

Elaboration involves modernizing the language (Cooper 1989), so that it can meet all the demands placed on it in all social domains (Kaplan \& Baldauf, 1997, p. 43). It is not the same as lexication in that, under the rubric of elaboration, language planners seek primarily to "encourage the use of the language in every possible sector" (p. 44). By its very nature, this is an on-going and complex undertaking (p. 44). The three processes involved in elaboration are terminological modernization, stylistic development, and internationalization.

\subsection{Terminological Modernization}

In order to be adequately expressive in all domains, a language must develop thousands of new terms every year (Kaplan \& Baldauf, 1997, p. 44). As technologies change, so must the terminology used to describe them. Paralleling the lexication principles, Kaplan \& Baldauf list four main strategies for modernizing the lexicon: (i) borrow the term from a contact or international language, with or without transliteration; (ii) translate a term into the language; and (iii) innovatively build words by (a) drawing from indigenous root words, or (b) reusing archaic or obsolete terms (pp. 44-45).

\subsection{Stylistic Development}

Not only must the lexicon be augmented, but the style also requires fine-tuning and maintenance. Kaplan \& Baldauf (1997) maintain that "without appropriate 
development of linguistic style in those domains important to a language, it is not fully able to meet all the demands placed upon it" (p. 45). They go on to say that each domain in which the language is used must develop and refine a discourse which works in that area. Furthermore, as new domains are encountered and the necessary vocabulary developed for those domains, Kaplan \& Baldauf affirm the need for new genres and their corresponding rhetorical styles. Of prime importance in the area of style are good models. Kaplan \& Baldauf accent the importance of stylistic models in high prestige domains such as politics, technology, and culture, to which I would add higher education.

\subsection{Internationalization}

Internationalization can be conceived of "as a particular type of language spread which affects the corpus of a language" (Kaplan \& Baldauf, 1997, p. 46). As the language spreads to different cultural groups, standardization issues resurface. Lexically, Cooper (1989) suggests coordinating terms for shared items across cultural and national boundaries (p. 151). This would seem to still allow for different forms of the language to develop in different polities but would encourage more unity in common areas.

\subsection{Language Planning Process}

In the process of language planning there are two basic things one needs to 
know: the language situation and the language planning goals. There are several stages to language planning as illustrated in numbers 1-7 in Figure 2. In slight contrast to this model, Pousada (1996) proposes four stages: "research, policy formulation, implementation, and evaluation" (p. 505). Her research stage would correspond to pre-planning, survey, and report; policy formulation coincides with policy; implementation is the same in both schemes; and evaluation would cover both evaluation and the feedback loop in Kaplan \& Baldauf's model. I prefer the emphasis on evaluation throughout the language planning process as illustrated in Figure 2; however, Pousada's four stages provide a good guide for the following discussion of the elements of the language planning process.

\subsubsection{Research}

This stage of the language planning process plays a critical role, "for only through careful investigation into the linguistic resources, attitudes, and goals of the people can a responsible and sensitive policy be derived" (Pousada, 1996, p. 505). It seems, however, that this stage is often rushed through or skipped altogether. Kaplan \& Baldauf (1997) recommend that the following specialists be included on a survey team: "a historian, an anthropologist, an economist, a professional planner, a data processor, a political scientist, and a linguist, all well acquainted with the target state" (p. 105). When gathering data in a smaller setting, individual researchers must be "multi-skilled" (Kaplan \& Baldauf, p. 88) - somehow covering the breadth of skills 
entailed in the team above in significantly fewer individuals. This is a challenge, but with talented people like Tony Johnson, Grand Ronde is in good hands.

Before a group can conduct a survey, there are a number of activities which must be completed in order to determine the best procedures to follow for the specific setting. Because the KTC\&HB in Grand Ronde is at this first stage of the process, I have included Kaplan \& Baldauf's (1997) flow chart of pre-survey activities in Figure 3. Some of the tasks are to be undertaken simultaneously, so that situation description, government policy review, and non-government practice review would all be investigated at the same time, preferably by different team members to expedite the process. 


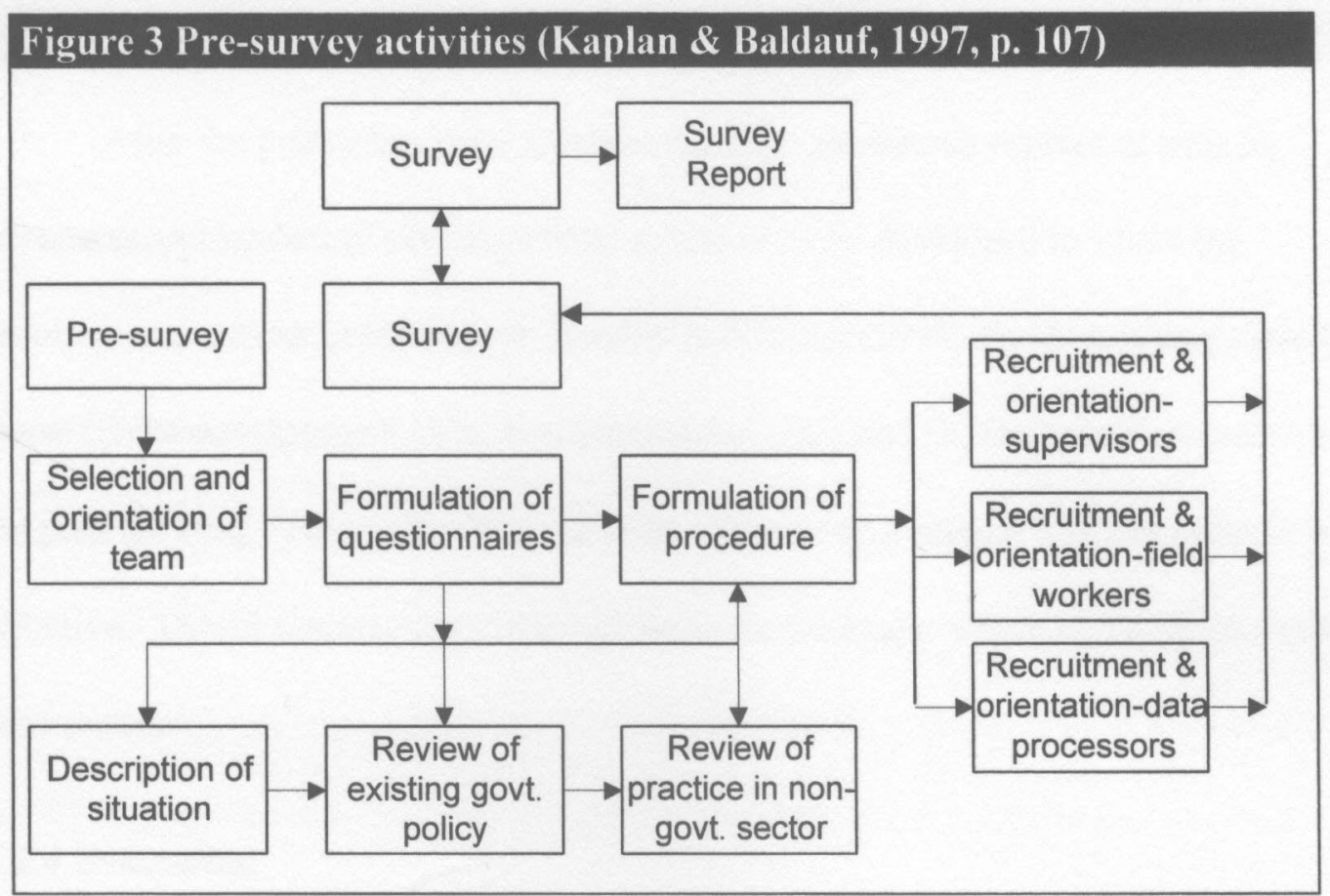

\subsubsection{Policy Formulation}

The next stage in the process involves the forming and shaping of language policy. Policy decisions are informed by the results reported from the research stage. Fishman (1991) stresses the importance of ownership by all stakeholders in the policy to be implemented: "Without such prior consensus [among those who advocate, formulate, implement and evaluate it], RLS [Reversing Language Shift] policy itself may become a bone of contention even among its own advocates" (p. 82). As Figure 2 connotes, sub-policies must be developed for certain areas, such as education. The policy should not, however, discriminate against ethnolinguistic minorities within a given polity (e.g., Fishman, 1991; Hamel, 1997; Kaplan \& Baldauf, 1997). 


\subsubsection{Implementation}

After the policy has been established, with unanimous support at least by advocates and leaders (Fishman, 1991), a plan must be developed to fulfill the requirements set out in the policy. Kaplan \& Baldauf (1997) divide this stage into two steps: (i) the development of an implementation plan, and (ii) the actual execution of the plan (p. 106). This plan will need to be adjusted on a regular basis in order to be effective. This is accomplished through periodic feedback, which is the subject of the next section.

\subsubsection{Evaluation}

Evaluation is not merely the sixth and final stage of the language planning process. Kaplan \& Baldauf (1997) explain that "evaluation should occur at every stage of the language planning process" (p. 91). The feedback loops in Figure 2 depict the on-going nature of evaluation. Kaplan \& Baldauf point out that a formal evaluation is necessary in order to determine how well the goals of the implementation plan have or have not been met. There are a number of ways one can carry out student assessments and program evaluations: surveys, case studies, observations of language use, and language testing (p. 93). Less formally, one could investigate language use patterns such as: "sales of books, library use, television, radio, video shop use, cultural activities, advertising, language of graffiti, bumper stickers, or just watching/listening to people on public transport" (p. 93). Naturally, evaluation procedures must be 
tailored for each unique sociolinguistic situation.

\subsection{Critiques of Language Planning}

In setting the stage for my description of the language planning process in Grand Ronde, it is important to note any opposition to such efforts. The complaints of local people will naturally depend on the setting, but the root underlying that criticism has likely been voiced before. It has been argued that language planning (LP) is "the ready tool of language rulers" (Luke, McHoul, \& Mey, 1990, p. 42). Fishman (1994, p. 91) summarizes the five most common criticisms raised: (i) those in power engage in LP for their own benefit; (ii) LP does not rectify inequalities but exacerbates them; (iii) LP works against cultural diversity; (iv) LP is a tool of Western thought to colonize non-allied groups; and (v) the cure-all for LP research is ethnography. Kaplan \& Baldauf concede that "where there is such a gap [between theory and practice] and to the extent that language planners ignore language rights of minorities, they are open to justifiable criticism" (pp. 80-81). Fishman's (1994) eloquent riposte to the criticisms raised serves as a fitting conclusion to this section:

Both of them [language planning theory and theoretically informed language planning research] must be relevant to hegemonic and proto-hegemonic as well as anti-hegemonic efforts. Both of them must strive toward multimethodological skills and train neophytes to be able to choose and implement the research methods that are best suited to particular problems and research circumstances. Language planning specialists must know how to choose between methods rather than being locked into any one all purpose method. Lastly, language planning specialists must realise that although much of the post-structuralist and neo-Marxist criticism directed at them has been and 
continues to be fully rectified, that most of the issues raised by this criticism cannot be fully rectified, even were society to be entirely overturned and rebuilt. Authorities will continue to be motivated by self-interest. New structural inequalities will inevitably arise to replace the old ones. More powerful segments of society will be less inclined to want to change themselves than to change others. Westernisation and modernisation will continue to foster both problems and satisfactions for the bulk of humanity. Ultimately language planning will be utilised by both those who favor and those who oppose whatever the socio-political climate may be. This is a truth that neo-Marxist and post-structuralist critics of language planning never seem to grasp and, therefore, they never seem to go beyond their critique as decisively or as productively as they state their critique. (p. 98) 


\section{Chapter Two Notes}

1 The variable "language amalgamation" which means "the folding together of two independent language systems" (Kaplan \& Baldauf, 1997, p. 285), will not be discussed because it does not apply to the situation in Grand Ronde.

2 Sprach-Inseln comes from German and means 'speech islands' or pockets of speakers of language $X$ within the larger context of speakers of $Y$.

3 Fishman's (1991) definition of "language shift" is more limited with its focus on the threat of shift on "intergenerational continuity" (p. 1).

4 Henry Zenk (personal communication, June 21, 1998) claims that Franz Boas transcribed more phonetically, while Melville Jacobs used a more normalized (intuitively phonemic) representation.

5 The term "language-in-culture" refers to the notion that language and culture are inseparable. Fishman (1991) argues that "languages are linked to particular ethnocultures in three major ways: indexically, symbolically, and in a part/whole fashion" (p. 20). Indexically, the language traditionally associated with a given culture is best able to express "the interests, values, and world-views of that culture." Symbolically, language use can be linked to membership in a certain cultural group. Finally, in terms of the partwhole relationship between a language and its culture, there is often something "lost" when some aspect of the culture is described in a language other than the one traditionally associated with it. A cultural groups' songs, prayers, proverbs, tales, curses, blessings, etc. "do not have the same 'flavor', the same 'charm', the same 'magic', not to mention the same 'associations and memories', when translated into any other language" (p. 24). 


\section{Methodology}

\subsection{Ethics and Empowerment}

The issue of ethics and politics in language research must be addressed before discussing the specifics of this case. One issue to take into consideration is the role of the researcher. "We inevitably bring our biographies and our subjectivities to every stage of the research process, and this influences the questions we ask and the ways in which we try to find answers" (Cameron, Frazer, Harvey, Rampton, \& Richardson, 1992, p. 5). Thus, truly "empowering research" in the sociolinguistic context entails observing ("research on"), advocating ("research on and for"), and participating in the process ("research on, for and with") (p. 22). Three maxims emerge: (i) "Persons are not objects and should not be treated as objects" (ii) "Subjects have their own agendas and research should try to address them" and (iii) "If knowledge is worth having, it is worth sharing" (pp. 23-24). Kaplan \& Baldauf (1997) stress that "language planners need to contribute to the empowerment of the disadvantaged and the education of the advantaged" (p. 81). In various subsequent sections of this paper, it will become clear that I support in theory and uphold in practice the principles presented above.

With great respect to previous researchers, there have apparently been some 
problems in the past in Grand Ronde with regard to these principles. Actually, the problems, I believe, are largely perceptual rather than entirely factual. Dr. Henry Zenk collected anthropological and linguistic information in the Grand Ronde Indian community between 1981 and 1984 . His work was with the best speakers of črnuk, who by that time were but a few elders. Before beginning my own research in Grand Ronde, he advised me that things were extremely political there. He informed me that he had tried to stay out of the politics and focus his time and energy on his elderinformants. As a result, some community members don't want any more anthropologists or linguists to come in and "steal" their language and culture. Because the people did not see any tangible benefit for themselves or their community, they may have perceived the documentation of their language and community as a one-way street. Although I believe the results of this important research should have been shared as soon as they were finished (i.e., necessitating political involvement with the tribal power structure), I am consoled by the fact that these materials are finding their way back into the community. The archive of historical sources on the language and culture has already grown significantly in the past eight months, with new material being added almost daily. Thus, the results of the information taken from the community for academic purposes are slowly being taken back by the Tribe's newly created Language Specialist, Tony Johnson.

From the very beginning, I have feared offending people in the local 
community because of my status as an outsider meddling in their cultural affairs. One time, after I expressed this fear to Tony, he reassured me: "The difference is that you have me. Right now I'm in good favors with the Tribe. People are pleased with the program, so as long as you work with me, you aren't going to have any problems." When people meet me, I am introduced as "our linguistic intern from Portland State."

\subsection{Informants}

There are two basic settings in which I interacted with informants: Grand Ronde, and other reservations. I will describe the informants for each setting in turn.

\subsubsection{Grand Ronde}

In Grand Ronde, I observed the language planning process by volunteering as a linguistic intern with Tony Johnson of the Kwelth Tahlkie Culture and Heritage Board (KTC\&HB) from January through May, 1998. He is a part of the Chinook tribe ${ }^{1}$ and grew up around Willapa Bay, Washington, but he has relatives who are enrolled members of the CTGR. Along with his father, he has been a member of the Chinook Tribal Council and Culture Board. Since September of 1997, he has worked in Grand Ronde. His official title was originally "Collections Curator-Language", but was then changed to "Language Specialist" (Mitchell, 1998). He is extremely committed to being traditional. "He is trained in carving, print making and jewelry making" (Mitchell, 1998). I highly respect him; he has devoted his whole life to finding out 
about his people - their history, their beliefs, their language, their arts, etc. He did not read about these things in a book; he has invested hours upon hours in talking with elders and listening to their stories and the stories of his people.

\subsubsection{Other tribes}

As part of my role in the language planning process, I interviewed language planners, teachers, and administrators, who are currently involved in language renewal efforts with Northwest Indian tribes. Their expertise and recent experience has helped to provide a current picture of what is being done in the region and which approaches have been successful in different settings. In choosing informants, I took the following factors into consideration: geographic proximity and level of language activity. My first choice was the Confederated Tribes of Warm Springs. Their language program has been actively working with their three languages (Sahaptin, Paiute, and Wasco) for several years. They provided valuable insight into the process of language program development. Because of its geographic proximity and its similar characteristics, the Confederated Tribes of Siletz, Grand Ronde's closest neighbor, was also chosen as a focus group. Their unique approach has served to stimulate our creativity.

\subsection{Instruments}

This section discusses: (i) the questionnaire I used in my interviews with tribal 
language practitioners - those actively involved in language revitalization and (ii) the sociopolitical typology used to characterize Grand Ronde. The questions in Appendix C, organized according to the hierarchy suggested by Spradley (1979), served as a guide for the interviews with tribal language practitioners. These questions were formulated to get as complete a picture as possible of how each group's language program was started, how it has developed, how it functions now, and what plans each group has for the future of the language. The hierarchy is designed to start with more general questions which can then be fleshed out in greater detail later. Another feature which this format includes is the experiential element. Anecdotal information about the process of language planning or teaching might bring to light some less tangible results that might not readily be listed in a more formal evaluation of program effectiveness.

The sociopolitical typology outlined in Appendix A was developed in order to provide a broad yet detailed framework for describing and comparing different language settings. Edwards (1992) formulated the typology in reaction to unsatisfactory geography-based typologies. Although the labels for the questions are stereotypical and oversimplified, the questions are helpful. These questions developed from that typology will be used to characterize the Grand Ronde community in the broad context of language maintenance and loss. It can also be used as a way to evaluate candidate strategies. For example, a setting which has more variables in 
common with Grand Ronde would be more similar and its strategies more relevant than one with fewer. It should be noted, however, that the variables are not equally weighted, and so the metric cannot be used blindly. Demography, for instance, is much more relevant than history.

\subsection{Design and Procedures}

There are three main sources of information for this project. One source is the review of literature pertaining to language revitalization efforts by Native American groups. A second source are the interviews with language practitioners from tribes currently involved in such efforts. These first two sources are characterized in §2. A third source of information comes from observations gathered from my own active participation in the language planning efforts with the tribe (see $\S 4)$. Below, I will describe each element in greater detail.

\subsubsection{Literature}

First of all, the extant literature was reviewed to explore the issues involved with setting up a language renewal project in the American Indian setting. Other settings were also explored, though neither systematically nor extensively. Overall, the focus was on discovering the features of successful programs, as well as the things to be avoided. 


\subsubsection{Interviews with other tribes}

Along with the review of pertinent literature, informal interviews were carried out with local Native language practitioners to determine to what degree local tribes are actively promoting their languages. One thing that I have learned from these interviews is that there are different ways to measure the success of one's program. Although there may not be sizable increases in numbers of speakers or readily measurable improvement, there might be an improvement in community morale or attitudes with community members actively using the language at whatever level they can. These dimensions are, of course, much more difficult to evaluate.

\subsubsection{Participant observation}

Throughout this time, I was also working (as a volunteer) approximately two days a week with the KTC\&HB in Grand Ronde. I helped them to choose an orthography and systematize their lexical database. Tony Johnson set up a dictionary to be used in the teaching and learning of črnvk. I offered linguistic advice based on my studies in Applied Linguistics at Portland State University. As a linguistic consultant, I assisted them with language planning and policy decisions as well. In the process, I established a solid connection with the community and got to know its characteristics. More importantly, working with the KTC\&HB and learning what they envision for the language program have provided me with essential information as I make recommendations for the community. 


\subsubsection{Typical Interactions}

Since I live in Portland (70 miles from Grand Ronde), I don't arrive at Grand Ronde until around 10:00 a.m. ${ }^{2}$. Tony works from 8 a.m. to 5 p.m., with an hour for lunch. When I come in, he's usually working on the computer at his desk (See Figure 4,\#1). We greet each other in crnvk: "qata mayka?' 'How are you?' "wik qata" 'not bad" ${ }^{3}$ or "(dret) tuš" '(very) good' is the usual response. After getting some tea from the break room, Tony and I move to the large unused desk (\#3) nearest the break room where we discuss what we have been working on since we last saw each other. Tony has other responsibilities besides language planning, but when I come, he is able to concentrate completely on language issues. We usually spend most of our time working on corpus planning activities, but we also regularly discuss cultural differences between Indians and non-Indians. We also practice speaking črnuk as much as possible. In the two paragraphs that follow, I will provide examples of the types of activities we engage in.

The second full day I was in Grand Ronde, our conversation was particularly interesting. Tony had gotten a call from the Tribal Chair asking how things were going with the language program. They had discussed the role of outside researchers in the project. As I was listening, I became uncomfortable as I heard the terms paston tIlxam 'white person' and wik saywaš 'non-Indian' a number of times. After he finished talking on the phone, Tony described the conversation and some of the 


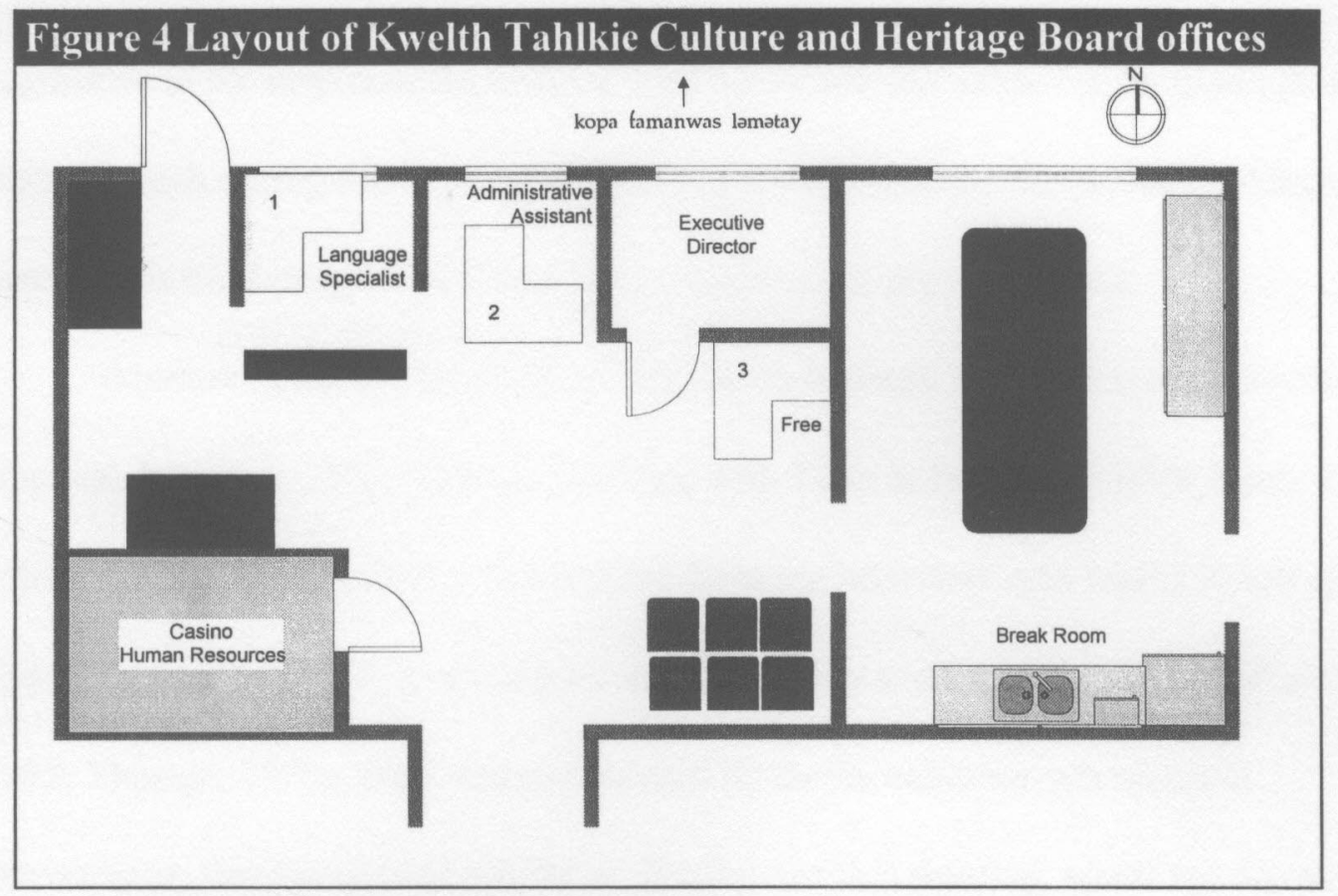

perceptions that exist in the community regarding some outside researchers (see §3.1). At this point I asked him, "Are there any taboos I should know about?"

I am glad I asked him. I only wish I had asked him the very first day. He gave me three bits of very good advice. (i) Don't shake hands too firmly. "All you need to do is barely touch the other person's hand." This surprised me since my culture growing up taught me to shake hands firmly (read, violently) to communicate self-confidence and respect. (ii) Don't talk about yourself too much. "If you go around saying, 'I am going to ...' or 'I think you should...' people will call you an 'I-I'.” After hearing this I reflected back on what I had said in talking with him and others that day. I also have been making a conscious effort to talk about our project and what we are doing together. (iii) Don't look into someone's eyes too much. "You shouldn't get too 
aggressive in the conversation or cut people off or talk too much." I am glad I didn't talk too much during our first meeting when I wanted to share my opinions. Since hearing this third suggestion I have been careful about my eye contact.

Another important part of the interactions between Tony and myself involved language learning. When I started working with Tony in January of 1998, I only knew a few words of $\check{r}$ muk which I had learned from my interview with Grand Ronde elder Elder2 in April of 1997. I had looked at some readily available dictionaries (Pasco, 1993; Thomas, 1970), but I was so confused by the inconsistent orthographic conventions, that I could not use them. During our first meeting, where we discussed how we might be able to work together, Tony informed me that he wanted me to learn to wawa 'speak (črnuk)' so that he could have someone with whom he could practice. Much of the time I spent down there involved such activities. He gave me copies of the lexical database he was compiling, so that I could learn the words at home. He often had me translate texts from crmuk into English. See Figure 5 for an example of one such text. In 1-5, I have provided line-by-line translations of myself, Tony Johnson, and Henry Zenk respectively. This order corresponds to the order in which this song was translated. Methodologically, Tony did not want to influence my interpretation, so he had me

Figure 5 Kalapuya song in čmvk ${ }^{\dagger}$ taxayam bastən orəgən nayka łatuwa saxəli Iləhi ukuk saywaš orəgən tuš musmus Iləhi alta tipsu mitit nayka təmtəm

- Recorded as sung by Yamhill band of Kalapuyas by Lieutenant William A. Slocum, c. 1835-1837 
translate the text without telling me how he had translated it. The same approach was employed subsequently when Henry rendered his translation.

$$
\begin{array}{ll}
\text { taxayam } & \text { baston } \\
\text { pitiful/salutation } & \text { white/American }
\end{array}
$$

GD (4/14/98): 'Good-bye pitiful white Oregon'

TJ (4/14/98): 'Good-bye white Oregon'

HZ (4/21/98): 'Good-bye white Oregon'

(2)

$\begin{array}{llll}\text { nayka } \begin{array}{l}\text { łatuwa } \\ \text { lsg go }\end{array} & \text { saxəli } & \text { Ilohi } \\ \text { top/up/high } & \text { land/place/earth }\end{array}$

GD: 'I go to higher ground'

TJ: 'I go to heaven'

HZ: 'I'm going to heaven'

$$
\begin{array}{lll}
\text { ukuk } & \text { saywaš } & \text { orəgən } \\
\text { this/that } & \text { Indian } & \text { Oregon }
\end{array}
$$

GD: 'This Indian Oregon'

TJ: 'This Oregon Indian country'

HZ: '-Indian country'

(4) tuš musmus Ilahi good cow land/place/earth

GD: 'A good place for cattle'

TJ: 'Good place for ungulates'

HZ: 'Buffalo country'

$$
\begin{array}{llll}
\text { alta, } & \text { trpsu } & \text { mitrt } & \text { nayka təmtəm } \\
\text { now grass/fur/fringe } & \text { be/live/sit } & 1 \text { sg heart/feel/think }
\end{array}
$$

GD: 'Now pastures are on my mind'.

TJ: 'Now flowers live in my heart'.

HZ: 'Now I'm pushing up daisies'.

I had been studying and practicing cmmuk with Tony for a little over three months when we looked at this song. You can see that I got a very different message from the poem than did either of the more proficient speakers. I tended to interpret literal 
meanings, while the other two used the context to better translate items more idiomatically. They saw compounds where I saw individual words. For example, in 2, saxəli Iləhi, when used as a compound, means 'heaven'.

These examples are indicative of the types of activities Tony and I engaged in. They by no means cover the entire range of things we worked on, however. This will be discussed further in $\S 4$.

It might also be helpful to hear how Tony and I interacted. As an example, one day $(4 / 23 / 98)$ we were doing some status planning: I was asking guiding questions of Tony on what Kaplan \& Baldauf (1997) would call internationalization. In this context, we were talking about the spread of $c r n v k$ to other Northwest tribes as an indigenous lingua franca.

TJ: 1 I believe, talking to folks, that the people who used črnuk actually had a 'Chinook'

2 pretty high regard for it as a real usable language, an important language. I think we've just kind of formulated [negative opinions] because all paston tIlyam taska wawa "it's a poor language" so we just start 'white people $3 \mathrm{pl}$ say'

3 believing that. Right? Maybe this is our proving ground. I would very much like to see, especially the tribes that don't have a language [learn čmok]. 'Chinook'

4 I wouldn't tell Wascos to drop their language for čmvk but maybe 'Chinook'

5 enhance it kopa črnuk. And then we can all [a::1] ... you know 'in/with Chinook'

GD: 6 wawa kanamaqst ... 'talk together'

TJ: 7 wawa kak wa ... 'talk like'

GD: $8 \mathrm{kak}^{w} a$ anqati trlyam ... 
'like ancestors'

TJ: 9 well, yeah, right

GD: $10 \mathrm{kak}^{w a}$ Šwaš trlxam ...

'like Indian people'

TJ: 11 kak $^{w} a$ kanawi tIlxam łosko wawa the same [TJ laughs] ... similar. 'like all people $3 \mathrm{pl}$ speak'

'If we speak a common language other than English, we will all be able to communicate with different tribal groups in a language all our ancestors used.' Given the context, this is the meaning that was intended. As Tony was explaining, I understood what he wanted to say, and thus made several attempts to use the crmvk that I knew to convey that meaning. In so doing, I became more actively involved in the conversation, resulting in a negotiation of meaning. This was a significant step for me to have taken. When talking with both Henry and Tony I often felt intimidated because of my lack of comparable proficiency. In this setting, however, I began to take risks, and participate more fully in the conversation.

\subsubsection{Evaluation}

After this information was collected, in the form of field notes, tape recordings, and artifacts, I was able to evaluate the Grand Ronde situation. The language policies of the Tribal Council and the KTC\&HB (both explicit and implicit) are one factor I considered. The work I did with the KTC\&HB volunteering twice a week has given me more specific information on the community. My observations while in Grand Ronde have provided me with sufficient ethnographic information to make relevant, 
broad suggestions.

Because of the large scope of my suggestions, a curriculum designer will need to do a more detailed needs analysis to determine which specific approaches to use. This would likely need to happen before implementing the recommendations I make.

\subsection{Tools for analysis}

In order to provide a more reader-friendly text, I will not list all the things I did and observed in chronological order. In order to systematize my findings, I will use two frameworks for the description and explanation of language planning. Each of these will be fleshed out in $\S 4$. The first was designed as a process framework (Kaplan \& Baldauf, 1997, p. 52), which seeks to account for the following eight elements: "What actors ... attempt to influence what behaviors ... of which people ... for what ends ... under what conditions ... by what means ... through what decisionmaking process ... with what effect" (Cooper, 1989, p. 98). See Figure 6 for more details on each element and $\S 4.1$ for my findings within this scheme. This framework will provide a means for organizing what often tends to be disparate and isolated information on the elements involved in language planning into a concise, if cursory, template.

The second framework is somewhat more traditional. It involves the division of planning into status and corpus planning (Kaplan \& Baldauf, 1997, p. 28). As can be seen in Table 4, language planning tends to focus on society (status planning) or on 
a language (corpus planning). For purposes of systematization and comparability with other language planning approaches, this neo-Haugenian framework serves us well.

Figure 6 An accounting scheme for the study of language planning (Cooper,

\section{9, p. 98)}

What actors (e.g. formal elites, influentials, counter-elites, non-elite policy implementers)

II attempt to influence what behaviors
A. structural (linguistic) properties of planned behavior (e.g. homogeneity, similarity)
B. purposes/functions for which planned behavior is to be used
C. desired level of adoption (awareness, evaluation, proficiency, usage)

III. of which people
A. type of target (e.g. individuals v. organizations, primary v. intermediary)
B. opportunity of target to learn planned behaviors
C. incentives to target to learn/use planned behavior
D. incentives of target to reject planned behavior

IV. for what ends
A. overt (language-related behaviors)
B. latent (non-language-related behaviors, the satisfaction of interests)

V. under what conditions
A. situational (events, transient conditions)
B. structural
1. political
2. economic
3. social/demographic/ecological
C. cultural
1. regime norms
2. cultural norms
3. socialization of authorities
D. environmental (influences from outside the system)
E. informational (data required for a good decision)

VI. by what means (e.g. authority, force, promotion, persuasion)

VII. through what decision-making process (decision rules)
A. formulation of problem/goal
B. formulation of means

VIII. with what effect 


\section{Chapter Three Notes}

1 The Chinook tribe is not officially recognized by the United States government and thus does not have the rights that were promised them in earlier unratified treaties.

2 I work at a part-time job from 6:30 - 8:00 am every weekday, so I cannot leave Portland any earlier.

3 wik qata is a contraction of wik-rkta qata 'nothing's wrong' and is given in answer to the question Ikta qata? 'anything wrong?' (H. Zenk, personal communication, June 21, 1998).

4 Tony Johnson and Henry Zenk note that this text, as we have it today, may not be authentic. It is possible that some liberties were taken by the recorder of this song. 


\section{Results/Discussion}

This section contains the results of the participant-observation case study I carried out from January through May, 1998, with Tony Johnson and the KTC\&HB of the CTGR. In this chapter I will characterize language planning efforts by first describing the current sociolinguistic situation in Grand Ronde (4.1). Next I will outline the status (4.2) and corpus (4.3) planning decisions and results.

\subsection{Current Sociolinguistic Situation}

There are, naturally, many ways to describe sociolinguistic settings. In this section, I will highlight the key elements of the present situation with the CTGR and in Grand Ronde, in particular. Two frameworks have been used to organize this information. The first, as described in $\S 3.3$ and completed in Appendix B, provides a fairly comprehensive investigation of the sociopolitical setting. The second framework, as portrayed in Table 4, accounts for all the players and elements involved in language planning.

The typology outlined in Appendix A (based on Edwards (1992) has been fleshed out in Appendix B. Based on this information, I would like to highlight some of the key aspects of the sociopolitical setting in Grand Ronde. First of all, this rural community has suffered from significant out-migration after the termination of their 
reservation status in 1954. Even before that, much of the reservation was sold off by the United States government. Now, there are only a few speakers left-all female elders. They have been characterized as being semi-fluent. Of the 3982 enrolled members of the CTGR, $42 \%$ live in the six-county service district (see Figure 7). Only $10 \%$ of the enrolled members live in the area immediately surrounding Grand Ronde (Polk County). In general, education is viewed positively by the community. Currently a minimal amount of language is taught in the tribal preschool$t^{\text {wax }}$ san cago 'bright day coming' - and in before-, and after-school programs. There is support, however, from the Education Division of the CTGR for expanding language programs in grades $\mathrm{K}-12$ locally. A core language group-črnuk $l u ? l u^{1}$

'Chinook gathering

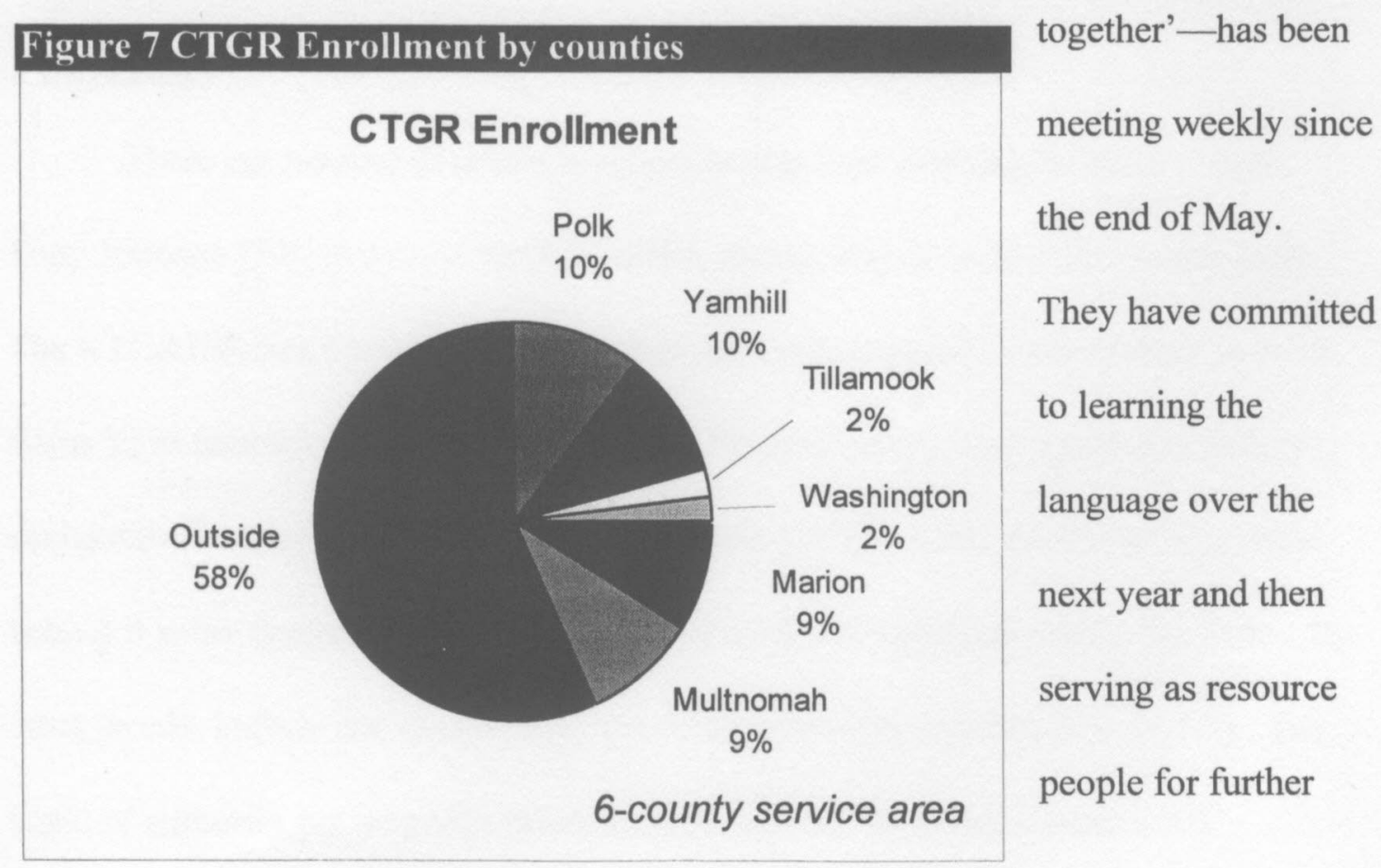


language promotion efforts. Another factor which may contribute to increased success in language planning in Grand Ronde is the potential of increasing numbers of tribal members returning to the Grand Ronde community. With the success of triballyowned Spirit Mountain Casino has come increased economic viability for the region. Some of those who left after the Tribe was terminated in 1954 may decide to return now that is more economically feasible to do so.

In the second framework, a conceptualization of language planning through asking the traditional questions of who, what, where, when, how, and why is proposed. Cooper (1989) has put these basic questions together into a framework intended to give "a descriptively-adequate account of any given case of language planning" ( $p$. 97).

\subsubsection{Actors}

There are number of actors involved in language planning with the CTGR. Tony Johnson (TJ), as part of the KTC\&HB, makes decisions on a day-to-day basis. The KTC\&HB members must make policy decisions (explicit or otherwise), so as to allow TJ to coordinate the actual work. The Tribal Council must approve of policy decisions affecting the entire Tribe. The impetus for this work and the driving force behind it is the desire to improve living conditions and standards within the Tribe. In other words, Indians are in control of the decision-making process (see §4.1.7). The chain of authority for language planning is as follows: (i) Tribal Council; (ii) 
KTC\&HB Members; (iii) KTC\&HB staff- (a) Executive Director, KTC\&HB; (b) Language Specialist, and (c) Language Staff (see Figure 8).

They have sought assistance from non-Indians experts, as well. My background as an educator and linguist has prepared me to give advice based on my training and experience. I have also been able to volunteer my time to assist Tony both by collecting literature on language revitalization and by conducting interviews with language practitioners from other tribes. Henry Zenk is also working with the KTC\&HB as a language consultant. Because of his research, he, better than anyone else, knows and speaks the variety of crmuk spoken in Grand Ronde by the most recent fluent elders.

Figure 8 A partial organizational chart for the CTGR (CTGRCO 1997, p. 22)

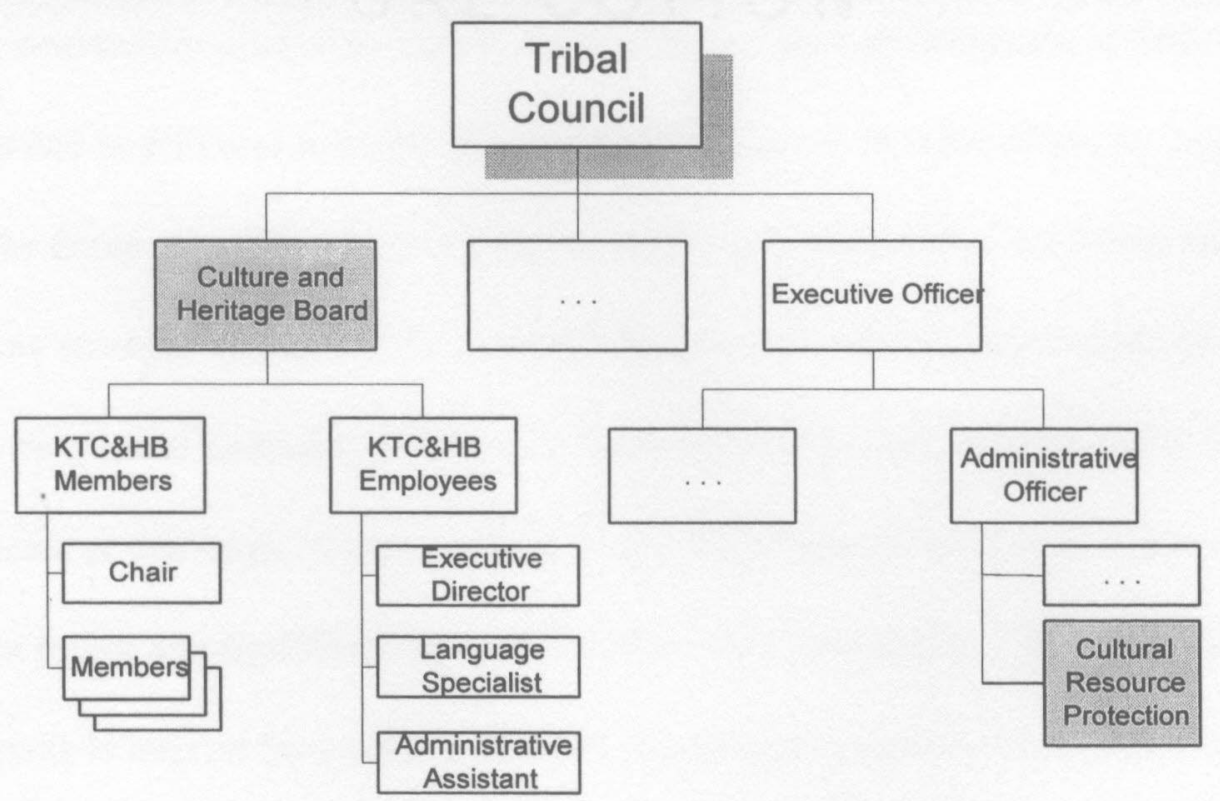


These actors-both Tribal employees and outside consultants - do not work in isolation from the community, however. In the crmuk $l u ? l u$ 'Chinook language group', committed community members, who are learning the language, assist in making decisions based on group consensus wherever possible. Thus, there is a good deal of cooperation within the community itself and with outside specialists who agree to work within the parameters established by the Tribe.

\subsubsection{Behaviors}

What behaviors are the actors introduced above attempting to alter? First and foremost, the goal was to establish a group of Tribal members, the crmuk lu?lu introduced above in 4.1.1, who would learn crmuk over the next year and a half. After that, we hope the language will spread. In particular, the črnuk $l u ? l u$ could help other community members - adults and children — learn the language at different levels and in different settings. We would like crmuk to be used within the community and the home. English will retain a place within the community, but črnvk will become stronger and move into a stable diglossic state with English — each being used in its own social domains. To what extent $\check{c}$ Invk will extend, can not readily be predicted at this stage. Later, it is hoped that $\check{c}_{m} n v k$ may be used as an indigenous lingua franca amongst Northwest Indian tribes, as it was earlier. Tony Johnson reports that there is interest for such an undertaking amongst numerous tribal groups he has spoken with. 


\subsubsection{People}

Who is supposed to engage in the behaviors as outlined above? Since the language planning is being done by the KTC\&HB of the CTGR, enrolled members of the Tribe would be the intended audience. The KTC\&HB plans to have language classes outside of the immediate community for those not living in Grand Ronde. Over ten people in Portland, Oregon alone have contacted Tony with an interest in taking črnuk classes. Because over half of enrolled members are not located in even the six-county service area (Figure 7), strategies to deal with this issue will have to be developed in greater detail. At some time, it is possible that other Northwest Indian tribes might become involved in learning and using čmvk to foster better interrelationships amongst tribes. As mentioned in the previous section, there is apparently some interest in doing this.

\subsubsection{Ends}

What is the desired result of the language planning efforts? I talked about the behaviors the actors are attempting to influence. The goals of the language plan must be made explicit in order to both guide current activity towards a target result and to provide a means of evaluating the successfulness of the language plan. Refer to Figure 9 to see the overall goals of the language plan. In this plan, there are both overt and latent goals.

Overtly, it is hoped that, within GR, črnuk will be spoken and understood and 


\section{Figure 9 Grand Ronde Status Planning Goals (2/17/98 draft)}

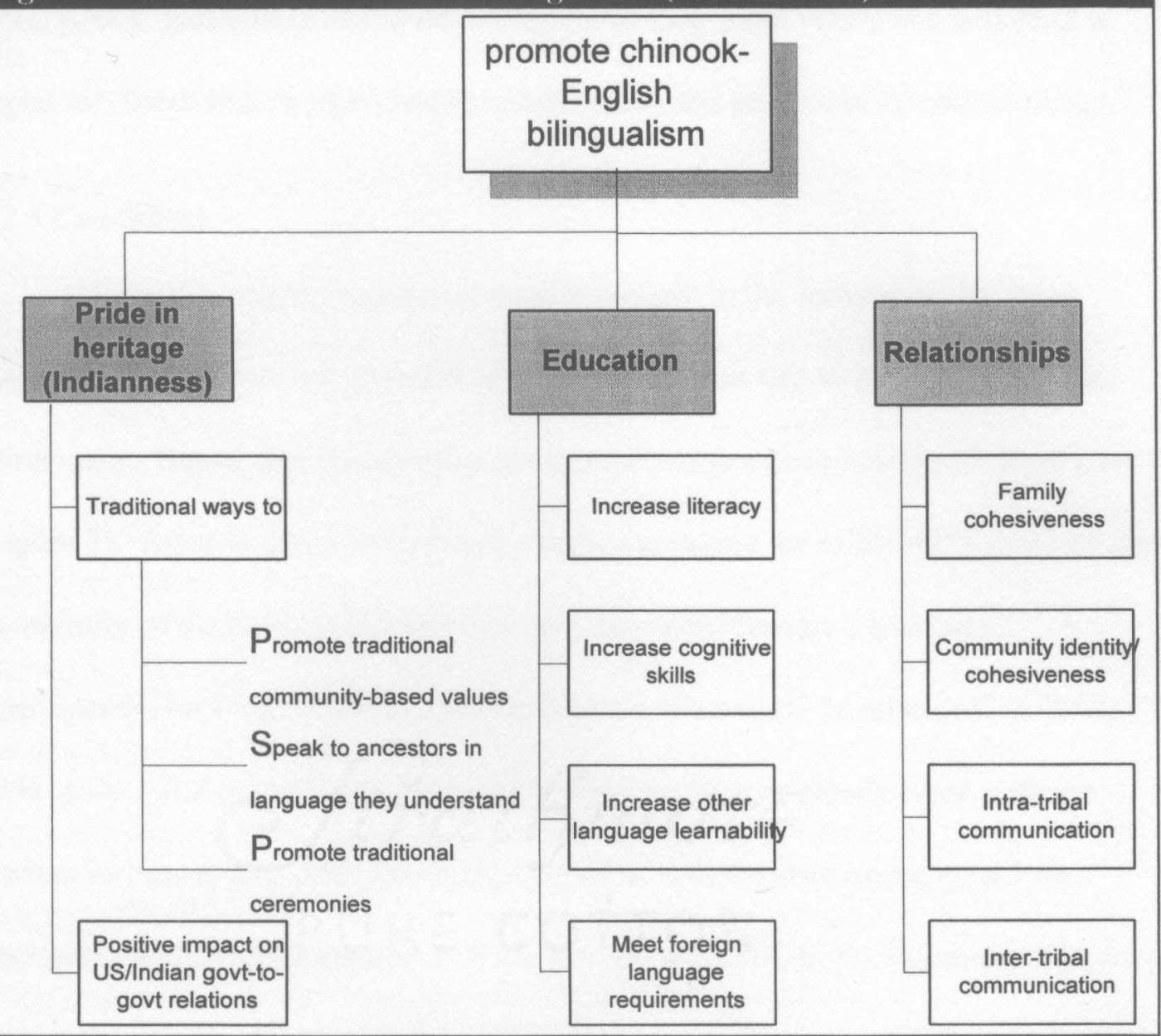

eventually, passed on to successive generations as the Native language of GR. It could be used in tribal ceremonies and government proceedings. Beyond GR, it is hoped that $\check{c}$ Invk will serve as an indigenous lingua franca amongst Northwest Indian tribes, as it once was.

Latently, the desired results would increase community and individual pride in being different, in being "Indian." It would provide a means for reviving other traditional beliefs and practices within the "language-in-culture" model (Fishman, 
1991, p. 66). Because of the re-establishment of traditional values and beliefs, it is hoped that there will be more family cohesiveness and greater social responsibility.

\subsubsection{Conditions}

Given the renewed economic vitality brought to the community by Spirit Mountain Casino, it is hoped that more CTGR enrollees will be moving back to the community. Recall that the majority of enrolled members live outside the local area (Figure 7). A needs assessment survey conducted during the mid-1980's revealed that "a majority of the [non-local] members said they would return if adequate employment, housing, health care and general services could be provided" (CTGRCO, 1998, p. 4). The economic situation for Indians in GR is relatively bleak with the median income at $\$ 21,300$, almost $\$ 6,000$ lower than the state average, and the unemployment rate estimated at $20-25 \%$ (CTGRCO, 1998, p. 3). However, there is great potential for growth with the casino and recent Tribal investments. In fact, over 1,400 new jobs have been created by the Tribe over the past three years. "However, the great majority of these positions are filled by non-members because of education, experience, and background requirements of the positions." Politically, the Tribe has a good relationship with the State of Oregon as is evidenced by the voluntary Gaming Compact signed in early 1997 (CTGRCO, 1996, p. 4). If political, economic, and social conditions are maintained at present levels, they should not significantly hinder language plans, but they would also likely not enhance language planning efforts. 


\subsubsection{Means}

The language plan will be implemented not by force, but by persuasion. Tribal members will be asked to revive the ways of their ancestors in language and in behaviors. This will be accomplished

by establishing outlines for curriculum development and implementation with Tribal and Public Education, continuing research focusing on the location of other speakers of črnuk, reviewing of current language materials and completing a comprehensive survey regarding the status of crmuk in the Community of the CTGR. (CTGRCO, 1998, p. 6)

Kaplan \& Baldauf (1997) argue that "proposed solutions must be 'sold' to the population" (p. 120). People are not likely to make such a drastic change in their lives as acquiring a new language, then using it in the family and community, and eventually passing it on to their children if there is no clear benefit for doing so. The language planning actors must demonstrate the advantages of acquiring the language in question to the people whose linguistic behaviors they hope to influence. Even if there is some sense of loyalty or affinity to čmuk within the GR community, learning a language is very labor-, and time-intensive. Investing themselves in such a venture would displace current activities and responsibilities community members are engaged in.

There are some other alternatives to simply encouraging Tribal members to become involved with $\check{c}_{\text {rnuk. At }}$ At the appropriate time, employment policies at the tribal government level could be enacted which would require either (i) a certain 
proficiency in črnuk or (ii) enrollment in črnuk classes to attain the desired proficiency. Fishman (1991) claims that at as low as Stage 6 (see Figure 3), the work sphere, within the local community, can be used to promote opportunities for language use (p. 103). Thus, given the current status of $c r n v k$ at Stage 8, it would currently be inappropriate to draft such work-related policies. For now, providing increased opportunities for language learning and use outside of the classroom would probably go a long way towards increasing people's motivation.

\subsubsection{Decision-making process}

Which actors make the language planning decisions in GR? Tony Johnson and I brainstormed and drafted overall goals for the language program (see Figure 9). As Tony works with the crnok $l u ? l u$, they will make some corpus planning decisions as a group, rather than having that work done by the language specialist or the consulting linguists. More broadly, Tony explains that "direction for the language program comes from collaboration between the KTC\&HB, the [Language Specialist] and The Cultural Resources Team" (CTGRCO, 1998, p. 4). Under the current Tribal organization, the Cultural Resource Protection department and the KTC\&HB are in separate departments and are located in different buildings (see Figure 8). The Cultural Resources Team consists of five members: (i) the executive director of the KTC\&HB office, (ii) the Language Specialist, (iii) the Chair of the KTC\&HB, (iv) the Administrative Officer of the Tribe, and (v) the Cultural Resource Protection Director. 
The KTC\&HB members (not the employees-see $\S 1$, note 5) have expressed their preference for functioning only as a board-to check up on what individuals or groups are doing rather than doing the work themselves ${ }^{2}$. The Tribal Council is the ultimate authority on the cultural activities undertaken by the KTC\&HB.

\subsubsection{Effect}

In the preceding sections, I have introduced both the behaviors and the ends for the language plan, but what effect might these sociolinguistic changes have on the community? Enrollees of the CTGR will hopefully gain proficiency in crmuk and use it in the home and in certain community settings. A situation resembling stable diglossia will arise in which črnuk and English coexist, each in their own domains. Additionally, črnuk could be used in ceremonies and in tribal meetings. Socially, there would likely be an increased pride in being Indian as enrolled members of the Tribe come to realize and honor the rich heritage of their culture and the inherent responsibilities each person has to uphold the ways and beliefs of their ancestors. As long as it is economically feasible (though this is hardly the only factor) to learn and use črnuk, more and more enrolled members may move back to GR and reconnect with the ways of their ancestors. This would possibly result in the development of a moderately sizable, fairly stable local community of čmvk speakers. If the language attains sufficient prestige or status within the community, there is a possibility that it might be transmitted to childrẹn growing up there. 
Once črnvk got established and stabilized in Grand Ronde, the CTGR would then be in a position to aid in the spread of cmuk to other Northwest tribes. Consequently, čmuk might be used in meetings of the Affiliated Tribes of Northwest Indians (ATNI) and in other Indian-to-Indian communications.

\subsection{Status Planning}

The process of status planning is, by nature, more political than corpus planning, especially when dealing with a language which is almost extinct. Besides being more political, it is also more important. Without careful planning in the early stages, any advances in corpus planning will be less likely to succeed because there will be insufficient social realms within which the language can be used. Before discussing the elements of status planning discussed in $\S 2.2 .1$, it is important to enumerate the goals of the language plan in GR. This will provide a better context for interpreting the sections which follow.

\subsubsection{Goals}

There are number of different levels of planning which occur within the CTGR. At the highest, and most general level, it has been a "long term goal of the Tribe ... to restore its tribal community-to bring people back home" (CTGRCO, 1998, p. 3). In both the preamble to its constitution and its vision statement, the CTGR affirm their commitment to preserving their unique culture and identity (see Appendix E). Thus, it is the policy of the Tribal Council to safeguard and uphold the 
Tribe's culture and heritage. All of these activities are included in the Tribe's

Comprehensive Plan, developed in 1988 and updated several times in the intervening years.

The Tribal Council has recognized a need within "the Community to revitalize culture and language" and have thus created the KTC\&HB "to be a cultural resource for the community" (CTGRCO, 1998, p. 5). The Mission Statement for the KTC\&HB emphasizes the connections with the past along with a commitment to the present: "The mission ... is to recognize, affirm, and celebrate the historical and contemporary cultural achievements of the Grand Ronde people." Figure 9 illustrates the status planning goals as of mid-February, 1998. In an application for an Administration for Native Americans (ANA) planning grant (program announcement 93.612-982, CTGRCO, 1998, p. 6), the language planning goals were explicitly stated:

The goal of this project is to reunite our community and to once again maintain a community proficient in crnuk. We will accomplish this goal, with the help of ANA funding, by establishing outlines for curriculum development and implementation with Tribal and Public Education, continue research focusing on the location of other speakers of crnvk, the review of current language materials and the completion of a comprehensive survey regarding the status of crnvk in the Community of the CTGR.

There is no mention made of English in these goals. Nevertheless, the plan is to establish črnuk in at least some domains while maintaining English proficiency. As has been suggested before, the desire is for a stable diglossic condition to obtain with English and črnuk. 


\subsubsection{Language Selection}

The selection of which language(s) to promote in GR has been interesting, but not too difficult. It was interesting because črnuk is linguistically classified in drastically different ways, with significant implications associated with each classification (§1.5.2). However, the decision was not difficult because crmok is the only Native language still spoken by any speakers in GR, not to mention that, historically, črnuk was associated with Indian-ness in GR. In the space below I will describe the choice of $c r n v k$ based on the five criteria for language selection introduced in $\$ 2.2 .1 .1$.

The first criterion is mutual acceptablity. As has been mentioned earlier, there were over 20 different tribal groups represented on the CTGR Reservation. To have chosen one of the languages of one tribe would have been divisive, to say nothing of the fact that no one speaks any of those languages anymore, nor did few if any beyond the second reservation generation (§1.6.1). In the late 19th, early 20 th century, as črnuk became more prevalent in the community, it came to symbolize being a Grand Ronde Indian. Since there are so few speakers left, hardly anyone is starting out with a significant advantage over anyone else. Everyone will have to learn črnuk together.

The second criterion is dominance. Dominance can be viewed in a number of ways. The first aspect is numerical superiority. The only language of most CTGR Indians is English, though a few know a very limited amount of crmuk. Since the 
focus of the language planning efforts of the KTC\&HB center on reestablishing a connection with Indian ways, they want to select something other than paston wawa 'White man's talk' (i.e., English), “which,” asserts Tony, "we all agree is not the preferred language to talk." Since the only Native language still spoken today is čmuk, it seems to be the most logical candidate for revitalization. One day, Tony commented: "It's not like we had this great big decision to make over the ten Molalla speakers and the fifteen Kalapuya. ... Jargon seemed obvious." Kale (1990) advances two other aspects of dominance: (i) how "functionally diverse" it is, and (ii) how "readily [it can] be learned as a second language by speakers of other languages" ( $\mathrm{p}$. 185). At one time, črnvk was functionally adequate for the family-neighborhoodcommunity setting. Because of its reduced grammar and lexicon, čmok is also fairly easy to learn. I can attest to this fact; although I am far from fluent, I understand everything except some idioms used by Tony or Henry [Zenk].

The third criterion - prestige - does not quite as clearly support the selection of črnuk. Tony explains his early perceptions of črnuk.

I had a poor opinion of crmuk basically the same as everybody else, although it was sort of changing. It was real poor when I was younger. I mean it was all right, but I had a real real poor opinion of the dictionaries in črnuk which I still sort of do. But I definitely knew there was a real difference between what I heard as čmuk and what was in those dictionaries, so I had respect for it as being at least Indian.

This is not an isolated view. In fact, the Confederated Tribes of Siletz Indians considered choosing $\mathrm{CJ}$ as a language to revitalize but eventually elected not to do so 
for many reasons, one of which was the low prestige of the language in comparison with Tututni, which was ultimately selected. Tony posits some reasons why people might have such a low opinion of $c r n v k$ and why such beliefs are not valid:

I think mostly it's younger people who've got a low regard for it. I believe, talking to folks, that the people who used $c_{I n}$ uk actually had a pretty high regard for it as a real usable language, an important language. I think we've just formulated [such a low opinion of crmuk] because paston trlyam łaska $w w^{3}{ }^{3}$ 'White people say' it's a poor language, so we just start believing that.

The fourth criterion is having a great tradition. The best choice of languages is one which provides "continuity with the past" (Kale, 1990, p. 186). Clearly, in GR, the best choice would be črnuk. In its heyday, črnuk was often preferred to English as the language of the home and community. Tony, who is not an enlisted member of the CTGR, has polled some people about Native language use in GR: "Every time I talked to a Culture Board member, they made a list of who they had known who spoke Indian, and it was almost invariably čmuk and it was almost invariably people passed away."

The final criterion is an areal affinity. The chosen language should ideally be lexically and semantically related to other languages in the region. Since črnvk is comprised of lexical items from a number of different Native languages of the region, along with the non-Native English-, and French-derived elements, it seems to be a good choice. The role CJ once played in the northwestern United States and in southwestern Canada provides another good argument in favor of čmuk in GR. 
Dell Hymes (personal communication to Tony Johnson, March 18, 1998)

wrote the following in support of čmvk language planning in GR

Your plan to concentrate on Chinook Jargon makes good sense. It is clear that it has been a major medium of communication and cultural transmission in western Oregon and beyond. Melville Jacobs recognized this in his work with Victoria Howard, herself from Grand Ronde, in 1929 and 1930, noting myths she had learned in Chinook Jargon. More recently, Henry Zenk's study of the recent history of the language has shown this as well. Although languages with such a name are sometimes thought of as makeshift, it was made clear to us by people at Warm Springs that there is such a thing as speaking Chinook Jargon poorly, such [a] thing as speaking it well. (Judge Coquille Thompson was one source for this).

Since it has been widely shared, and a part of the history of so many of the Native Americans of the Grand Ronde area, a program in Chinook Jargon can be unifying. It has the means to serve a variety of cultural and practical interests. The texts which I have studied show literary patterns of the same sort found in the other native languages of the region.

This strong letter of support from an academician is echoed also by other local tribes.

Pat Duncan, the Tribal Chair of the Confederated Tribes of Siletz Indians, (letter in support of ANA grant, March 24, 1998) wrote

Chinook-wawa is an important part of our history and the continuance of it is important for all the Native peoples of the Pacific Northwest. We would like to express our willingness to provide Jargon-related assistance to this project if possible. Good luck with your endeavors.

After a language or languages have been selected, then an implementation plan must be devised. That is the topic for the next section.

\subsubsection{Language Implementation and Evaluation}

Because the language planning in GR is at such an early stage, the 
implementation and evaluation phases have not been completely fleshed out yet. The implementation stage encompasses the means of achieving the goals of the overall language plan. Referring to Figure 9, it should become clear that promoting črnuk through education alone will not achieve the broad, socio-cultural goals set out in the language plan (see §2.2.1.2.1 for a more complete discussion on the role of education). Education alone can not possibly "reunite our community and ... maintain a community proficient in črnvk' (CTGRCO, 1998, p. 6). Thus, education must be viewed simply as one of the means of attaining the re-acquisition of črnuk within the GR community (see Table 5). The implementation discussed below, however, does not correspond to the true implementation stage as depicted in Figure 2, but refers, rather, to the means of accomplishing pre-planning goals (Stages 1-3 in Figure 2). Likewise, the evaluation touched on below more precisely agrees with the planning feedback loop portrayed in Figure 2.

In the ANA planning grant application, four activities are suggested which would help the KTC\&HB begin to meet its long-range goals: (i) performing a "comprehensive črnuk language survey," (ii) "establish[ing] a plan to introduce the črnvk language into education settings," (iii) "retriev[ing] and review[ing] all available language materials for use in training and education activities," and (iv) creating a "core group of community members" engaged in an "informal language learning program" (CTGRCO, 1998, pp. 7-8; see also Figure 10). These activities are 
all steps in the pre-planning or research process which may eventually lead to attaining the broader, more abstract goals (see Figure 9). For each of the four activities explicated below, feedback will occur throughout the implementation process based on the timeliness and effectiveness of the subprocesses involved with each activity.

The first stage of the implementation plan (see Figure 10) involves the core language group, the čmuk lu?lu. Those interested in becoming members of this

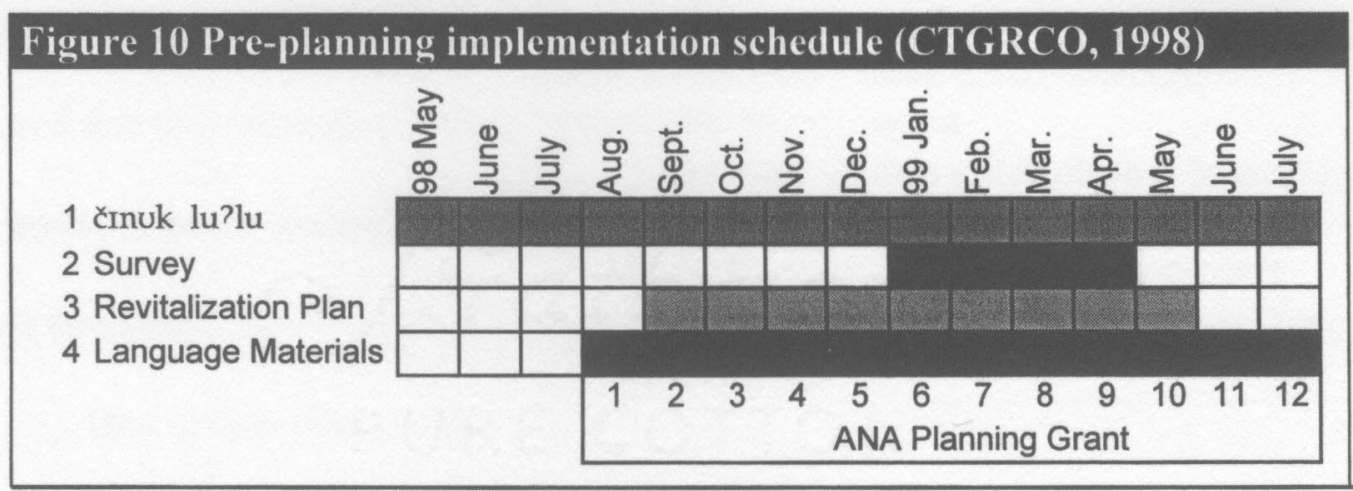

group were asked to write a letter of intent to the KTC\&HB office. In Figure 11 the announcement from the bi-monthly tribal newspaper Smoke Signals is reproduced. Tony informed me that the most important criterion for inclusion in the group was a willingness to commit time and energy to learning črnuk. The first meeting was on May 20, 1998. Depending on how many of their children they bring with them, fifteen to twenty people come regularly to the meetings. Currently, Tony is developing a pledge for them to memorize and recite at the beginning of each class. This pledge will affirm their efforts and focus their attention on the overall goals of the project. In 
reference to learning črnuk, one

of the crnvk lu?lu members

told Tony that he was ready to

be a full-fledged Tribal member

rather than simply a number on

the Tribe's enrollment records.

This story was related to the rest

of the crmuk lu?lu and they all

agreed that they were committed

to investing in the heritage of

their ancestors.

One critical phase of the
Figure 11 Announcement of črnuk project ("Learn Chinook,"1998)

Learn Chinook Jargon

The Culture Board is seeking tribal members who are willing to commit to a "pilot" Chinook (Jargon) project. Project participants will be required to meet weekly, on evenings, throughout the upcoming year.

This group will provide support for the teaching of Chinook. A tentative start date for this group has been set for

WEDNESDAY, MAY 20. Meeting dates and locations will be discussed there.

An interest in "Chinook" is all that is required to apply. Individuals associated with Tribal and Public Education are especially encouraged.

A letter stating your interest to apply, and your commitment to attend classes, is required for consideration for the project. Letters of application must be received by Friday, May 15.

project (number 2 in Figure 10) involves systematically determining the state of crnvk within the GR community and within the six-county service area of the CTGR. If for nothing else, this survey will serve as a baseline against which future results can be compared. The survey will measure several factors including: (i) čmok proficiency;

(ii) knowledge of čmuk, and (iii) extent of črnuk use. The survey team should develop the questions and measures to most accurately obtain the desired information. The questions will, of course, need to be pilot tested before surveys are sent out. At least one thousand survey forms will be mailed to Tribal members within 
the service area. From that group, no less than fifteen speakers will be interviewed. At least five čmnk speakers will be recorded for future planning purposes. Funding for the project will come from the ANA grant, if it is awarded. Otherwise, the KTC\&HB will have to adjust its budget to account for the costs of such research. These survey activities will be carried out over a four-month period, resulting in an assessment report which will then be used to develop an implementation plan. Another phase will be the development of a revitalization plan for čmvk (number 3 in Figure 10). As outlined in the ANA planning grant application (CTGRCO, 1998), this stage would involve the establishment of the language plan along with the development of implementation recommendations. At this stage, the language program will work closely with the Tribal Education Division of the CTGR to develop implementation agreements with both Tribal Education and public schools. An outside curriculum consulting team will meet with the local planning groups to develop curriculum guidelines. An outside software development consultant will also meet with the planning group to make recommendations. When the team completes its draft of a language plan for $c_{m} m u k$, the community will be given an opportunity to voice concerns and/or support for the plan.

The results of the development of this language plan will be a formal "Language Preservation Plan" which will need to be accepted and adopted by both the KTC\&HB and the Tribal Council. The explicit instantiation of a pro- $\check{r}$ muk language 
policy by the Tribal Council would be a significant stride in the right direction. It would signify a serious commitment-on the part of both the Tribal government who adopted the policy and the community members who contributed to the planning - to the ultimate goal of čmvk-English bilingualism (see Figure 9).

The fourth activity of the pre-planning implementation plan (number 4 in Figure 10) encompasses efforts to add to, or to organize the existing archive of črnuk materials. There are two primary areas of focus for this activity. (i) Current language materials in the archive and the linguistic database will be reviewed. Tony will carry out this analysis with help from language consultant, Henry Zenk. As mentioned above, Henry knows crmuk as spoken in GR better than any other linguist or anthropologist. The objective for this first activity is to create suitable language materials for subsequent teaching and dissemination. (ii) The second area of emphasis is the identification of $c r n v k$ speakers in other local Indian communities. At least ten Oregon and Washington tribes will be contacted to locate črnuk speakers and to ascertain their availability for assistance with the project. The information gathered will be incorporated in the revitalization plan developed in number 3 (see Figure 10). This stage has important implications for future corpus planning. Tony and I have been making preliminary corpus planning decisions on our own, relying on his intuition and my training and experience. See $\S 4.3$ for a discussion of the corpus planning work we engaged in. As the črnok language consultant, Henry can look at 
the linguistic database Tony has created and offer his professional opinion. Because of his research with the best čmuk speakers of the early 1980 's, he will provide the much needed historical perspective of GR črnuk.

Besides these four activities enumerated in the ANA grant application, Tony has invested some time and thought into the use of technology to enhance črnuk learning opportunities. Besides the development of a font with a custom keyboard layout for čmuk (see §4.3.1), there are several other programs which Tony would like to see created. Figure 12 outlines the software components of the $c r m u k$ acquisition plan, as described by Tony in March, 1998. Since that time, however, the only program to have a working model is the talking word teacher (number four in Figure $12)^{4}$. All or some of these technological innovations could be bundled together into a software package which could be distributed to CTGR Tribal members. This would be especially useful for Tribal members not living in the immediate area. Such efforts will hopefully facilitate the attainment of the overall goals of the language plan.

Figure 12 Technological implementation planning (as of 3/5/98)
PHASE ONE TECHNOLOGY
1. Electronic orthography chart of individual phonemes in alphabetical order
2. Electronic alphabet with example words for each phoneme
3. Typing tutor, showing key placement, speaking as you type ( $\approx 3$ lessons)
PHASE TwO TECHNOLOGY
4. Talking word teacher (teaches lexicon in 10 -word units, within 1250 -word
modules)
5. Stories in multimedia (with animation or video)
6. Reader/Writer program (computer plays recorded sound files from typed text)


This section, entitled "Implementation and Evaluation," has dealt primarily with the implementation of pre-planning goals. Nevertheless, feedback is inherent at each stage. If certain activities do not result in the desired products, adjustments will be made. The KTC\&HB, the Cultural Resources team, and the crmuk $l u$ ?lu will "provide recommendations for the project" on an on-going basis (CTGRCO, 1998). Thus, the implementation and evaluation of this early stage of the overall language plan are "underwritten" by a cadre of concerned and dedicated individuals.

\subsection{Corpus Planning}

The majority of the time I did my participant observation in GR was spent on corpus planning. Since we are only in the research phase of the language planning process, the corpus planning issues of elaboration have not come into play yet (see Table 4, number 4). Thus, this discussion will focus on codification; namely, graphization, grammatication, and lexication. These corpus planning activities will result in an orthography, a grammar, and a dictionary, respectively. At this point they are not completed, however. Figure 13 illustrates a rough estimate of the relative amount of time spent on each activity during Tony's and my planning sessions. 


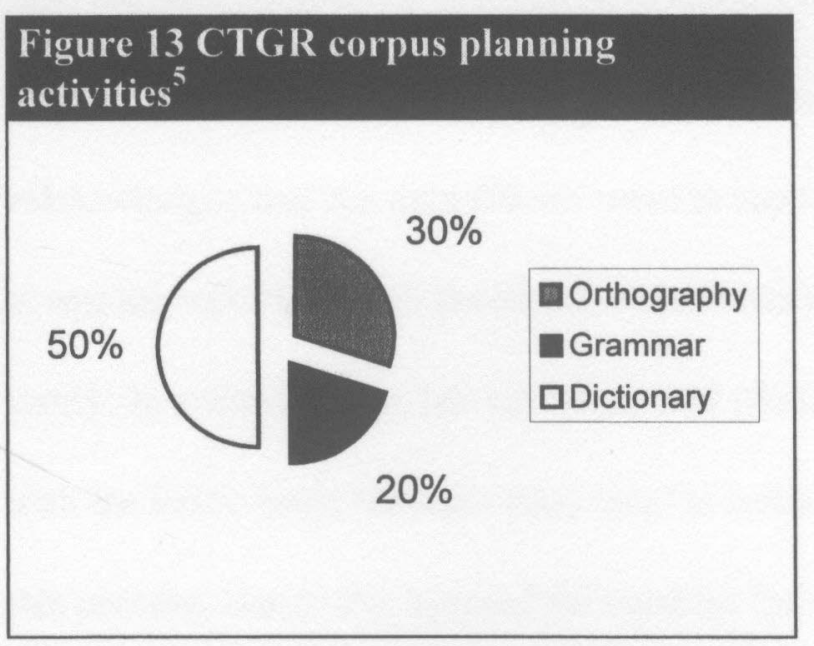

\subsubsection{Graphization}

A significant amount of

time has been invested in

developing a new orthography.

From the very beginning this topic

has been one of the most frequently

discussed and worked on. In this

section I will characterize the stages of development of the current orthographic

system in light of the five technical principles introduced in $\$ 2.2 .2 .1 .1$. Once again,

these standards are: (i) learnability, (ii) readability, (iii) writability, (iv) transferability, and (v) printability.

First of all, let me set the stage for the ensuing discussion by highlighting the dilemmas Tony faced as he drafted a writing system for črnuk. The linguistic transcriptions he was investigating (e.g., Boas ,1888, Jacobs, 1932, and Zenk, 1984) were not consistent in the way they represented the sounds of either crmuk or Chinookan. The latter two researchers opted for a "phonemic" ${ }^{\text {" }}$ representation which collapsed what they considered phonetic variants into one "phonemic" form. In so doing, however, it seems that they may have conflated meaningful distinctions. For example, in crmuk both [i] and [r] occur word-initially. By the conventions of Northwest Coast phonology, the /i/ is used to represent both sounds with the following 
rule: the high front vowel is heightened when it is stressed word-initially (i.e., [r] $\rightarrow$ [i] /\#__ [+ stress $])$. After looking through the lexicon that Henry had assembled, he acknowledged that the data did not seem to support the rule. One example we looked at was the word for 'get', [Is-kəm], which Henry has never heard pronounced [iskəm]. In a similar way, [rk-ta] 'what' and [Ik-tas] 'things, clothes' are pronounced with the lower form, whereas [ixt] 'one' is realized with the higher form. Throughout this process, Henry has stressed the need for the representation to be phonemic rather than phonetic. Because Tony wanted the orthography to be rather transparent (i.e., a one-to-one symbol-to-sound correspondence), he wanted to maintain the phonetic distinctions that would increase both readability and learnability for non-črnvk speaking learners.

Given that setting, let's look at the process of development of the orthography. When I began working with Tony in January of 1998, one of the first things he did was show me the database he was compiling (see $\S 4.3 .3$ for a full description of the database-dictionary). As I began leafing through the pages of a printed copy of the database, I tried to predict how to pronounce the words based on the orthography and my experience with other foreign languages. For example, when I tried to read the črnvk word meaning 'far', which was originally written saia, I had a difficult time knowing whether to pronounce each vowel separately or to pronounce some combination of the vowels as a diphthong. I also did not know where to place the 
stress. In order to improve readability for English-speaking čmuk learners, I later suggested marking the two crmuk diphthongs as $a^{i}$ and $a^{u}$. This improvement in readability resulted in a significant decrease in writability. After consultation with Henry Zenk, Tony and I decided to follow the Americanist convention of marking diphthongs with offglides: ay and $a w$. Tony decided to make the change because he agreed with Henry that the diphthongs were better represented with glides than with separate raised symbols. Table 6 illustrates the major changes that were made from the initial orthography to the present one. This example highlights the process we went through in getting to the current orthography. It should be noted, however, that the present orthography is not final and still may need some revising. In fact, during the writing of this paper, the orthography has undergone some changes which are not described here.

The complete orthography is still in draft form and has not been included with this paper. The orthography was chosen by Tony after consultation with Henry Zenk and myself. There were several factors which influenced his decision. First of all, he wanted symbols which could adequately represent the sounds of $c_{I n v k}$, an end not satisfactorily achieved in either the extant čmnvk dictionaries or linguistic analyses. 


\begin{tabular}{|c|c|}
\hline \multicolumn{2}{|c|}{ Table 6 Orthographic chang } \\
\hline \multicolumn{2}{|c|}{ SYMBOLS } \\
\hline Yritial. & Qurrent \\
\hline aa & e \\
\hline 3 & $\varepsilon$ \\
\hline $\mathrm{i}$ & I \\
\hline ii & $\mathrm{i}$ \\
\hline $\mathrm{u}$ & $U$ \\
\hline & $\partial$ \\
\hline uu & $\mathbf{u}$ \\
\hline$x$ & $x$ \\
\hline$\check{\mathbf{x}}$ & $x$ \\
\hline $\mathrm{ts} / \mathrm{c}$ & c \\
\hline ai & $a^{i m a y}$ \\
\hline $\mathrm{au}$ & $a^{u} \rightarrow a w$ \\
\hline
\end{tabular}

Some might argue that the best writing system would be one which introduces the least number of new symbols (increased initial learnability). However, a precedent has been set by other Northwest tribes for using an orthography based on linguistic symbols. Hilbert \& Hess (1982) note that within the Lushootseed region (Washington state), within one to two weeks, even "elders who have had only a few years of formal schooling in the elementary years" are able to read language written with linguistic symbols. Lushootseed elders say, "Our language sounds different [from English]. It ought to look different, too" (p. 83). Tony has commented to me several times on how nice the orthography looks. Thus, if GR Indians learn the new črnuk orthography, they would be able to transfer their knowledge of those symbols to other Northwest Coast languages, which share a number of marked phonological characteristics, including some of the tribal languages historically spoken on the GR Reservation.

In order to facilitate the writability and printability of the new writing system, Tony had a new True Type font developed by Marvin Plunkett (see note 4), a Northwest software designer. This font, called "Chinook Wawa," maps the needed symbols onto the keyboard in the layout Tony specified and is available to all 
Microsoft Windows-based programs ${ }^{7}$. This font, though developed by a software consultant, belongs to the CTGR who have full legal rights to it. All of the čmuk words in this paper are written in the "Chinook Wawa" font. We are currently working on establishing transliteration standards for use in programs which do not have access to the font (e.g., e-mail). When writing by hand, however, we always use the standard orthography.

Throughout the development of an orthography for čmuk, efforts have been made to improve its learnability, readability, writability, transferability, and printability. The goal of this entire process is, of course, to provide a systematic means of representing the sounds of čmuk.

\subsubsection{Grammatication}

Planning for grammatication at Grand Ronde occupied almost one third of the time Tony and I worked together. More specifically, we focused on phonology and syntax. Phonology was discussed throughout the process, especially in the context of the orthography, while syntax only came up after a couple of months of observation and consultation. In this section, I will describe first the syntax of črnuk and the process of standardizing it and then the phonology of čmvk along with its development. 


\subsubsection{Syntax}

When the issue of syntax arose, Tony and I both had a difficult time understanding the extant descriptions of the grammar of either CJ or čmuk. In the end of February, Tony put together a draft of črnvk syntax based on all the different grammatical notes he had in the KTC\&HB language archive. Some of the terminology was unfamiliar to him, so I tried to clarify such terms as particle, clitic, attributive, aspect, etc. As I explained terms to him, he, in turn, gave me examples supporting or refuting the descriptions based on his linguistic intuition. In the middle of March, Tony produced a second draft of the syntax which included notes on the meanings of some of the linguistic terms. The purpose for the document is to create materials which will help in teaching and learning the language. Highlighting the difference between academia and the Reservation, Tony commented: "My motivation is entirely different than theirs [linguists'], and I would never expect them to understand the levels that I'm motivated at, just like I don't understand theirs." His vision is to once again see črnuk become a significant part of community life in Grand Ronde, not to conform to the standards of linguistic theory. However, he is not opposed to the input I give him on my interpretation of how linguistic theory would expect things to be organized and explicated. On the contrary, several times he has said that he appreciates the added perspective it gives him. Finally, in the end of March, Tony updated the description of the čmuk syntax to incorporate our latest 
discoveries and decisions. This description of the syntax, with some modifications by me, is given in Appendix F, and is discussed next.

Before looking at the syntax of črnuk, let me set the stage a bit. Since only a few elders speak črnuknow, many of the politically charged standardization issues typically faced by corpus planners simply do not exist for the CTGR. To a certain extent, Tony is in a position to promote whatever form or dialect of the language seems most appropriate for achieving the desired goals. Tony, Henry, and I have discussed this position of power and have taken and will continue to take measures so as not to abuse that power. Such responsibility is not something we take lightly. Tony has plans for Henry to examine all the linguistic work Tony and I have done and compare it with the data he collected in the 1980 's. Tony is very committed to maintaining the historical element of $c_{r n v k}$ as spoken by the best speakers from GR. Where "corruption" from English crept into the crnnuk spoken by some of the speakers of the recent past, Tony has decided to return to the variety of Victoria Howard, a Clackamas-speaking GR Indian—recorded by Melville Jacobs in the 1930's — who regularly contrasted clitic and full form pronouns. Tony will use her variety as a model for future language learners. Thus, the syntactic descriptions that follow are based on either descriptions, or varieties of črnuk as spoken by at least some GR Indians.

črnuk does not have a very complicated syntax. Naturally, the extreme 
morphological complexity of Chinookan did not carry over to regional CJ or the GR variety of čmvk, which served as lingua francas (CJ throughout the entire northwestern region of the United States and čmuk within the GR Indian community). Appendix F contains the fullest and most up-to-date description of crnok syntax as it is intended to be taught to community members in GR.

Let me highlight a few of the most prominent features of the syntax. First of all, črnok is a Subject-Verb-Object (SVO) language, but there are several situations in which a Verb-Subject order is possible. When sentences contain intransitive verbs, (i.e., there is no object), a V-S word order is preferable. Furthermore, in attributive and equational sentences, the V-S ${ }^{8}$ word order is preferred. Number 11a (Appendix F) provides an illustration of the word order of an attributive sentence:

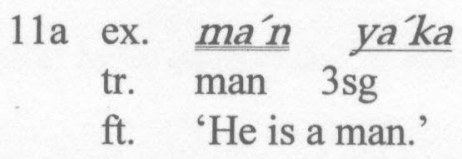

As can be seen from this example, there is also no copula in črnuk.

Another interesting feature of the syntax is the pronominal system, including both clitic and full form elements (see the first section in Appendix F). The clitic pronouns attach to the nearest word and are the prefered form in the following contexts: (i) when used as a possession marker; and (ii) when used as the subject with all verbs. For example, na=a' $w$ 'my brother' (as seen in 1a) is composed of the first person singular clitic pronoun na, used here as a possessive marker, attached to the 
noun $a w$ with the $=$ symbol. Although recently, GR speakers do not generally use clitics, they were an important part of Victoria Howard's speech ${ }^{9}$, and add an extra measure of complexity to the syntax which allows for grammaticalized differences in meaning.

It is important to bear in mind that the description of the syntax above and in Appendix F is not in a polished, final form. Nothing has been cemented as of yet. In fact, the pronominal system is still under investigation. The descriptions included here represent the current, early stages of the development of a prescriptive grammar for teaching čmvk.

\subsubsection{Phonology}

Throughout the language planning process to this point, phonology has been a regular topic of discussion amongst Tony, Henry, and myself. These discussions have often dealt with the means of systematically representing the sounds of crmuk with symbols of one kind or another. In this section, I will first characterize the development process of the phonology and then provide the current prescriptive phonological description of črnvk. The discussion will cover segmentals, both consonants and vowels, but not suprasegmentals such as stress, which, unless marked, is placed on the first syllable and is marked by an accent mark following the stressed vowel.

The process of developing the current phonology of $\check{c}$ mnvk has progressed 
through several stages. First of all, Tony brought a lot of knowledge to the task based on his own informal research with the elders from his own tribe who spoke crmuk. Furthermore, he practiced speaking črnuk with me as we worked together. As he taught me čmuk, I asked many questions, trying to differentiate between sounds which are not differentiated in English, such as the [k] - [q] distinction. In the process of answering my questions, Tony was forced to analyze the phonology based on descriptive grammars and on his own production of different sounds. One day, in reference to the above distinction between the voiceless velar and uvular stops, I said, "I have a hard time hearing the difference between the [k] and the [q]. When I say qata mayka?('How are you'), both sound the same." Tony replied, "I hear a difference, but I sometimes have a hard time making my [q] far enough back in my mouth so that it actually does sound different." With time, however, he began consistently and clearly differentiating the sounds. My own budding knowledge of čnnvk certainly helped me to perceive the differences better, but I believe that Tony also became more cognizant of the way he was speaking because of his student. Another activity Tony engaged in which enhanced our understanding of phonology was conducting field interviews with local Tribal elder, Elderl. After visiting with her and speaking crmuk most of the time, he transcribes the recorded conversations from tape. His analysis of the language from the dialogue includes a look at the phonology. He enters lexical variants introduced in the conversation into 
the database which will later be compared in the lexication process (see §4.3.3).

Besides studying published phonological descriptions of CJ and čmuk, teaching me čmvk, and conducting his own field research, Tony met regularly with Henry and myself to simply wawa kopa črnuk 'speak Chinook'. It has been interesting to note the changes in Tony's and my speech as a result of these meetings. One example involves the third person plural pronoun, which, in our database, is recorded as łaska. In the midst of normal conversation between Tony, Henry and myself, Henry said taska several times. When there was a lull in the conversation, I asked Henry about the pronunciation of this pronoun. He said, based on his research in GR, that vowels tend to become more centralized when unstressed. From then on, both when I talked with him alone and when talking with Henry, Tony used the taskə form, which encouraged me to do the same. He incorporated it into his speech and made a note about that rule in the database.

Thus, the process of developing a full phonological description of crnvk has involved four main activities. First, Tony contributed his own knowledge of crmuk as spoken by Indians. He has also conducted interviews with a tribal elder and analyzed the phonology. A third activity has been teaching me the language through modeling and answering my questions about the sounds of $\check{c}_{m}$ nuk. Fourth, Tony has met with other čmok speakers, primarily with Henry, to develop greater fluency, with the fringe benefit of discovering the pronunciation used by the informants in Henry's research. 
Now that I have sketched the process of development of the phonology of čmuk, I will briefly describe it. The phonology of črnvk is quite intact (i.e., uncorrupted by non-Amerindian languages) in terms of the sound inventories of other Northwest Coast languages. I will highlight those features which are different from English. Again, bear in mind that a full phonemic analysis of črnuk has not been performed yet, so Table 7 and the description that follows is in draft form as formulated by Tony, Henry, and myself.

There are some sounds in črnuk which are very different from English. When non- $\check{c} m$ nuk speakers listen to čmuk, one of the first things they notice is the very common voiceless lateral fricative (nicknamed, "slurpy $l$ "). It is found in such commonplace words as 'go' ta'tuwa, 'hello/good-bye' taxa'yam, 'good' tu'š, 'later' a'łqi, 'they/them/their' ta'ska, and 'who' ta'ksta. The voiceless ejective lateral affricate also occurs regularly (e.g., tła' $x$ 'tear/rip', $t$ ' $ə m i^{\prime} n x^{w} \partial t$ 'lie/untruth', and $t^{\prime}$ 'u'nas 'maybe/doubtful').

There are other sounds in $\check{r n}$ nuk which are unlike English as well. The voiceless velar and uvular fricatives provide good examples of such dissimilar sounds. Let's look at some examples. The $[x]$ sound can be found in the following sample words: ila' ytix 'slave', $i^{\prime} x t^{\prime}$ 'one', sa'xəli 'top/up/high', and na'x'dear/honey'. The labialized velar fricative $\left[x^{w}\right]$ is also possible: $m I^{\prime} t x^{w} t t^{\prime}$ 'stand up' and $\operatorname{sia}^{\prime} x^{w} \partial S$ 'eye/face'. The segment $[x]$ is found in a number of words and is said to be 


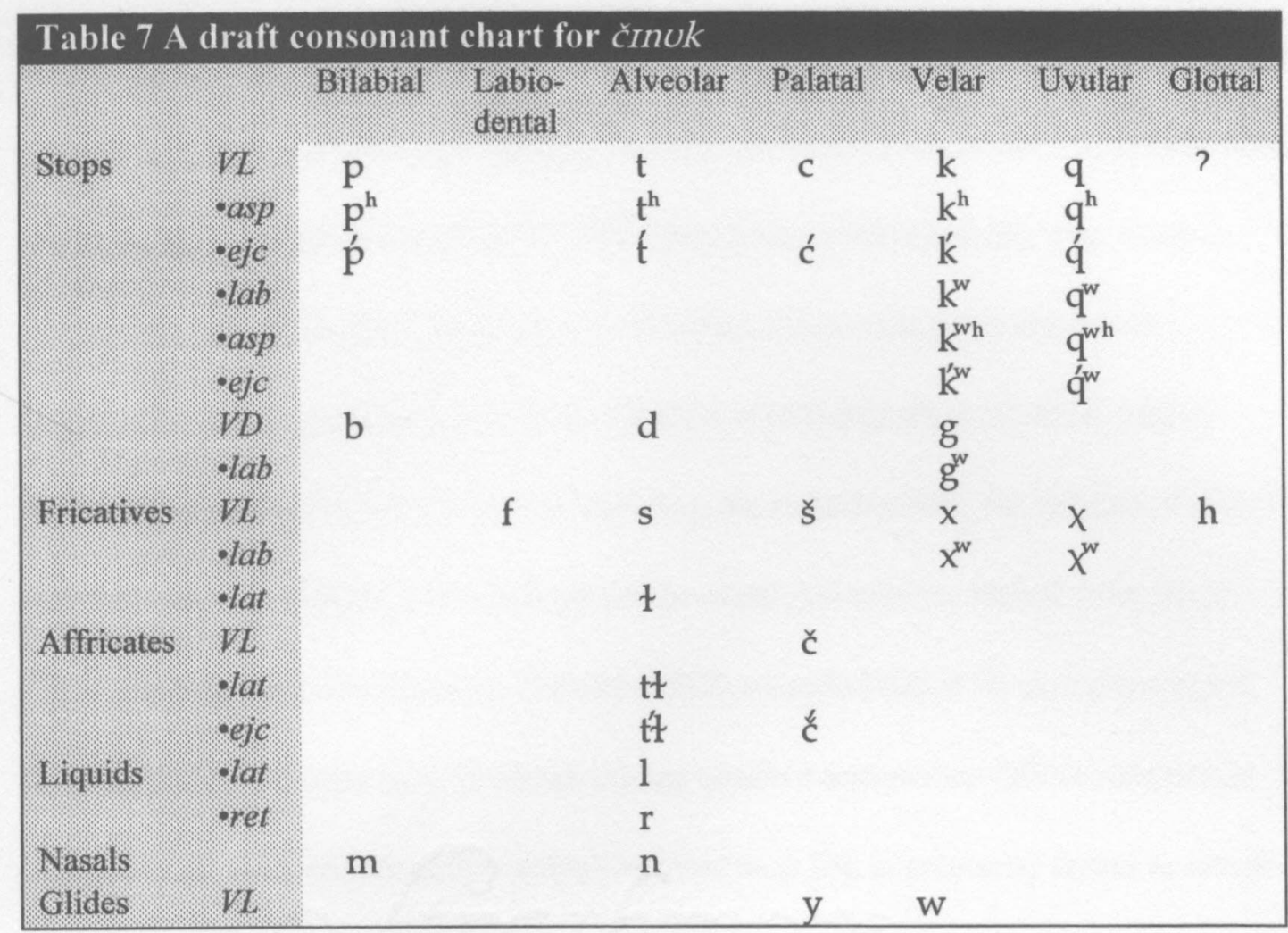

pronounced as if choking on a fish-bone in the back of the throat. The word for

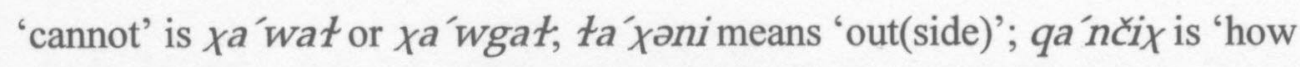
many/anyhow'. The labialized form $\left[\chi^{w}\right]$ is also realized in $\check{c r n n}^{\prime} k . I^{\prime} c x^{w} v t^{\mathrm{t}}$ black

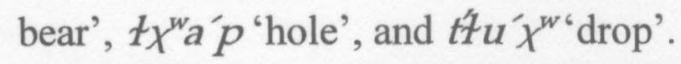

Certain sounds can occur in čmuk, which have a limited distribution. For example, when the English words 'fire' was introduced into CJ, it was realized as pa'ya because [f] and [r] were not part of the phonological constraints of CJ. In GR,

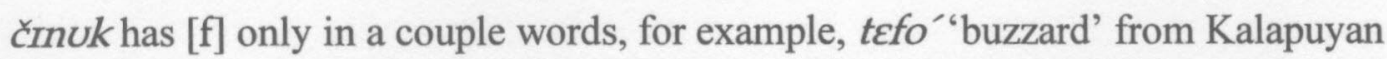
and $g^{w}$ כofi' 'coffee' from English. In places other than GR, 'coffee' has been recorded 
as $k a^{\prime} w p i$, following the pattern of early additions from English. In a similar way, [r] is not typically a part of CJ phonology. In GR, however, French-derived lexical items containing [r], sometimes retain $[\mathrm{r}]$ rather than being realized as [1]. The most common example is $d r \varepsilon^{\prime} t^{\prime}$ right/yes' ${ }^{10}$. In other places, this general term of affirmation has been recorded as dili't (Jacobs, 1932) and dale't (Gibbs, 1863), demonstrating the typical pattern of replacing the retroflex with the unmarked (for CJ) lateral liquid. A similar phenomenon can be observed with the čmuk term ku'ri 'run', also derived from French. Jacobs (1932) recorded this item as ku'li or gu'l, thus providing another case in which $[\mathrm{r}]$ has attained acceptance GR in contrast to regional CJ. A third sound, the voiced bilabial stop [b], is primarily found in words adopted from English or French. For example, there are English-derived words such as ba'ston 'American/white (person)' and br't 'dime' and French-derived words such as bi 'bi 'kiss', laba'rb 'beard', and labu'š'mouth' which all contain the somewhat marked [b]. The last example is a variant of lapu'šs. The unaspirated voiceless bilabial stop in lapu's is not pronounced with the aspiration an English speaker would naturally add. Analogously, ba'ston is more commonly written as pa'ston. These are just a few examples of rare but permissible sounds in GR črnvk.

There does not seem to be a voiced-voiceless distinction for most stops in čnvk, except for in the alveolar and velar positions. Even in these positions it is not entirely clear that the differnces are phonemic. In čmuk stops can be aspirated. We 
have yet to determine whether this feature is, in fact, phonemic or not. Possibly it is a form of interference from English, as almost all čmvk speakers, both historically and presently, spoke English in addition to črnuk. A more detailed analysis is needed.

Another distinguishing characteristic of $c_{m}$ muk phonology is that there are both velar and uvular stops. The velar stops include not only the voiced and voiceless pairs like English, $[\mathrm{g}]$ and $[\mathrm{k}]$, but also the labialized forms $\left[\mathrm{g}^{\mathrm{w}}\right]$ and $\left[\mathrm{k}^{\mathrm{w}}\right]$, and the voiceless aspirated and ejective forms $\left[\mathrm{k}^{\mathrm{h}}\right],\left[\mathrm{k}^{\mathrm{wh}}\right],\left[\mathrm{k}^{\prime}\right]$, and $\left[\mathrm{k}^{\mathrm{k} w}\right]$ (see Table 7). There is also a series of ejectives occurring at five different points of articulation, as illustrated in Table 7: (i) bilabial stop [ṕ], (ii) alveolar stop [t́], (iii) palatal stop and affricate [ć] and

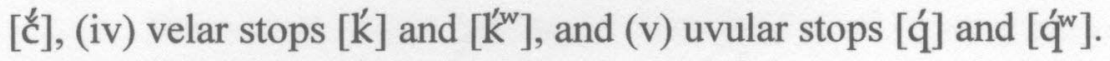

The vowel system of $\check{r}$ Inuk is not as clear as the consonants. As depicted in Figure 14, there are nine vowels in the inventory. The vowels [e] and [o] are permissible, but there is a preference for $[\mathrm{i}]$ and $[\mathrm{u}]$ respectively when a variant with the preferred vowels exists. For example, there are two variants for the word for 'paper': pe'pa and pi'pa. Although it would not be incorrect to use the first form, the second form is preferred. In a similar way, o' lali and $u^{\prime}$ lali 'berries' are both workable, but the second form is preferable. We decided to use this heuristic because we needed some way to systematize what, for at least some speakers of črnuk, was phonetically realized as a tense vowel somewhere between $[u]$ and $[0]$. Henry explained to me that many indigenous Northwest Coast languages, including 


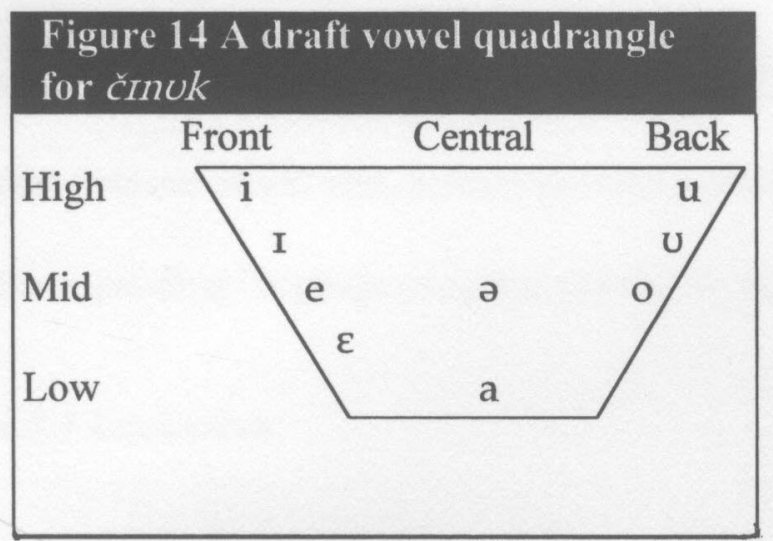

Chinookan, do not distinguish between the high and mid back rounded vowels; linguists usually mark the vowel as $/ \mathrm{u} /$. The phonetic realization of the vowel may reflect

environmental influences (e.g., /q́u?/ $\rightarrow$ [q́o?]). In črnuk, however, where a formal phonemic analysis has yet to be done, Tony wants to be able to represent both sounds. Since the $[u]$ occurs more often than the $[0], 10 \%$ compared with $6 \%$ of the times a vowel occurs in črnvk words, it seemed the best choice for a standard (see Figure 15).

The notion of standardization is central to all three of the codification activities discussed in this chapter. The goal of creating a pedagogical grammar to assist learners in acquiring $c r n v k$ has been kept in mind throughout the development of adequate descriptions of both the syntax and the phonology. There is a significant amount of work yet to be done in the grammatication process. As the crnok lu?lu meets Figure 15 Distribution of čmok vowels and learns čmvk over this

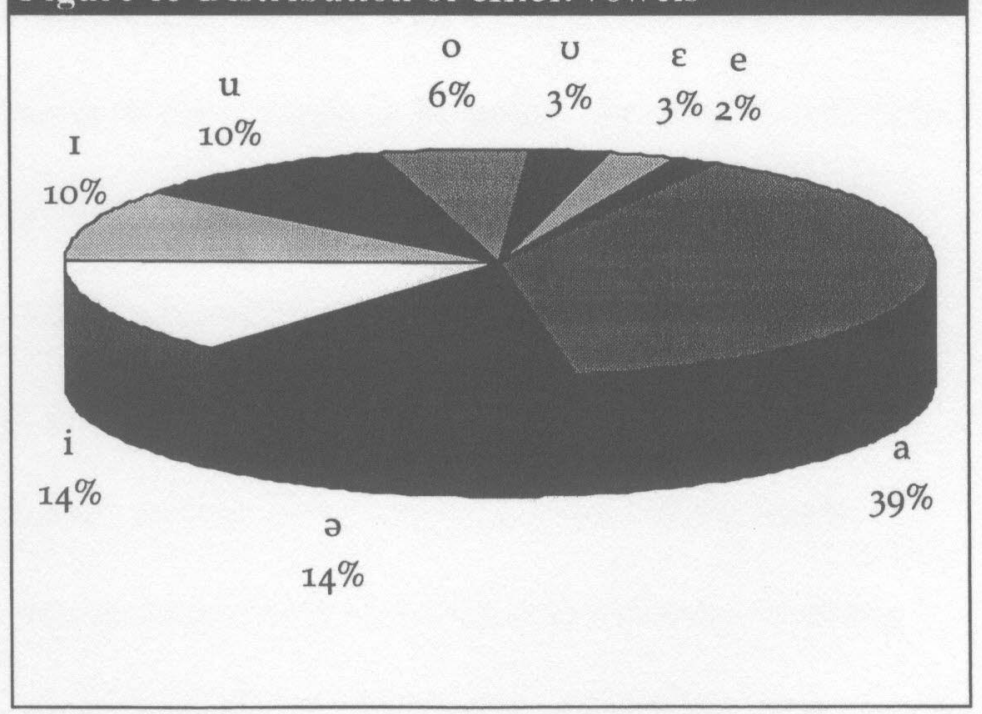


next year, there will be an ever-increasing need for greater depth in grammatical descriptions which will, in turn, provide a solid grammatical foundation upon which the expanding language program can rely in the years to come.

\subsubsection{Lexication}

The third process involved in codification of the corpus is lexication. In the previous two sections, decisions were made regarding the orthography, syntax, and phonology. All of these areas rely on the lexicon for their data. Thus, Tony and I naturally spent most of our time working on developing the lexicon (see Figure 13). In this section I will describe the process of developing the database, choosing primary entries, and adding new words.

The database Tony has used to organize his data is Buseman, Early, Pedrotti, \& Yoder's (1996) Shoebox 3.0. This software program was created for assembling and organizing linguistic data. When I began working with Tony, he was in the process of developing the database by listing as many words as he could. He culled words from a number of different sources on both the regional CJ and GR črnvk. His first preference was, naturally for words recorded from the GR area. As stated above, he also collected field recordings of conversations with a tribal elder. The new words were used in creating new database records if there were no other related words already in the lexicon. Alternate pronunciations were added as variants to existing records. Tony also used his own knowledge of $\check{c}_{I n v k}$ to supplement the other sources. 
Additionally, analyses and descriptions of regional CJ were studied and some words were added to the $\check{c}_{m}$ muk lexicon. A sample of the user interface for the database is illustrated in Figure 16.

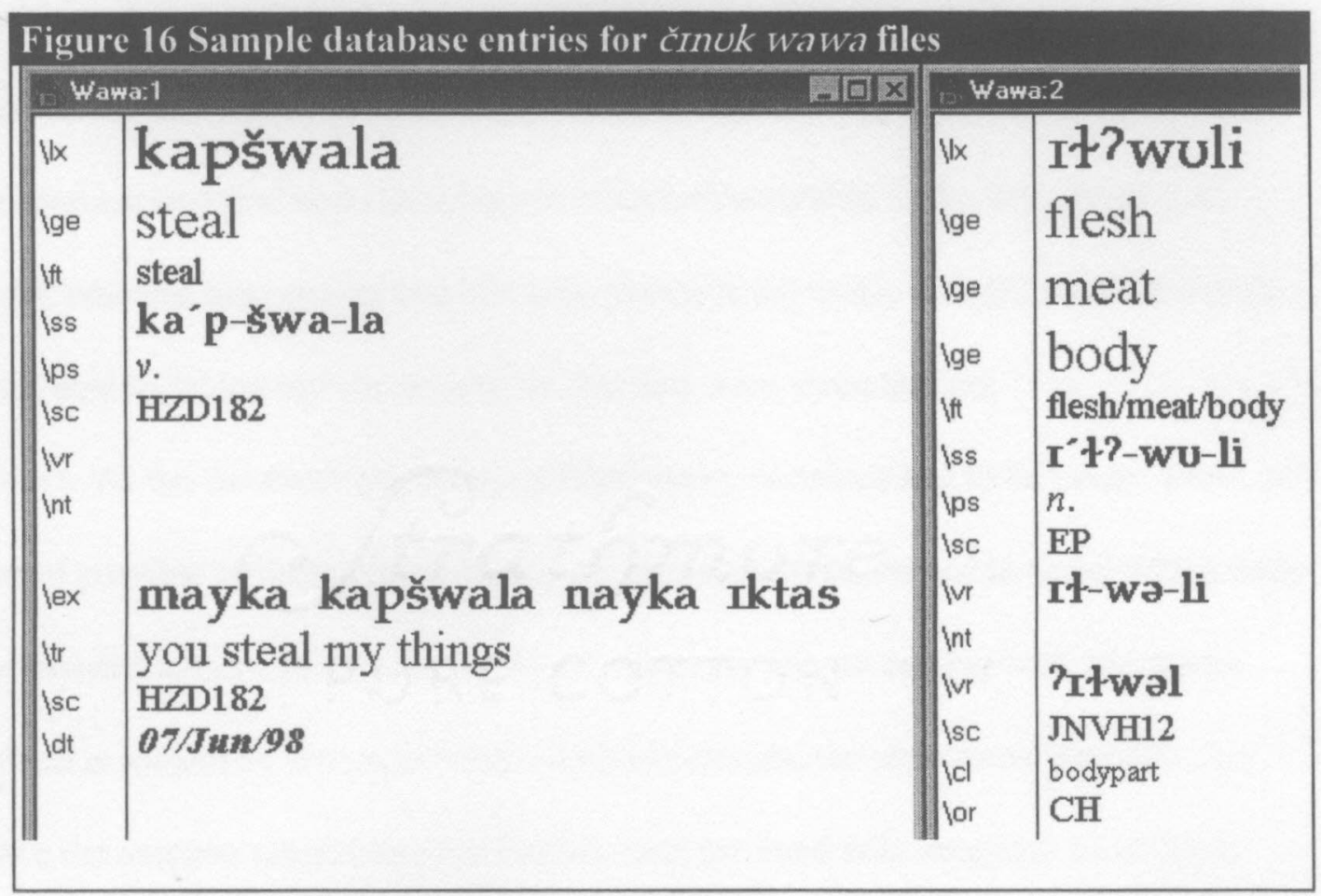

I was able to play a decided role in fleshing out the database that Tony started. Sometimes Tony and I would sit together at the computer and discuss particular words or sounds. Typically, he held the notebook containing papers on čmuk and dictated words or example sentences to me. I sat at the computer and entered the data as they were given to me. Working together, we were able to work more quickly and 
thoroughly because of the input we gave each other. At other times, Tony would sit at the computer and we would go through the records one at a time. He would show me what he had done since the time I was last there. As we perused the lexical entries, I would notice inconsistencies that he had missed in the midst of the changes he was making. These inconsistencies were due in large part to the addition of fields to the newest records which were not in the first records. For example, the part of the lexicon entered first had etymological information entered under the "notes" (Int) field, whereas later entries had this information listed under "origin" (lor). We were then able to "clean up" the records so that they were more unified.

As the database was being updated, many decisions had to be made. From our list of possible pronunciations for any given lexical item, we had to select which form we wanted to have as the primary entry. Since we are not dealing with a language which is spoken by any significant number of people, the choices we make do not have the extreme constraints and implications involved with language planning in other settings. I informed Tony that to select the primary lexical entry we could do one of two things: simply choose one of the variants that seems appropriate or try to choose the one variant that is most representative of a majority of the variants. Tony replied by saying that he thought we were doing both. One example is the word for 'land/place/earth', Ilr?i. As shown in Table 8 number one, there are six possible pronunciations available for this item. Using the principle of "majority rules," the first 


\begin{tabular}{|c|c|c|c|}
\hline & e $8 \mathrm{Ld}$ & elc & on exam \\
\hline 11 & $117 ?$ & 2 & kopa \\
\hline & Iləhi & & kapa \\
\hline & Ilə? $\mathrm{i}$ & & kapu \\
\hline & Ilrhi & & kaba \\
\hline & Ili?i & & kuba \\
\hline & Ili & & koba \\
\hline & & & kupa \\
\hline & & & $\operatorname{kop}^{h} a^{\prime}$ \\
\hline
\end{tabular}

and last two sounds are $I, 1, ?$, and $i$

respectively. For the middle segment, however, there is a plurality: two of each vowel. Tony chose the high front lax vowel because it was more like the first, stressed syllable. In number two of Table 8 the relational marker (REL) translated variously as 'to/on/in/with' is listed with all eight of its possible realizations. For this example, our choice of a primary entry was made based not on the most common features shared by the candidate items, but on which variant would best represent the range of attested pronunciations ${ }^{11}$. If we had used the normal criteria, our choice for orthographic representation would have been kaba instead of kopa because: (i) the first vowel [a] occurs more frequently than [o]; and (ii) the voiced bilabial stop was found in recordings gathered from GR elders. However, in this situation, with the attestation of $k o p^{h} a^{\prime}$ (occasionally aspirated voiceless bilabial stop when stressed as here), the orthographic representation kopa was chosen. This representation allows for both aspirated (marked) and unaspirated (unmarked) voiceless bilabial stops. These examples illustrate some of the factors we took into consideration when making decisions about which candidate item would appropriately be considered the primary entry for each database record.

Over time Tony and I became extremely aware of the need to introduce new 
words into the crmuk lexicon. We accomplished this primarily in two ways: (i) by combining existing words and particles and (ii) by borrowing words from other languages. When we talked, Tony and I would often insert English words into our otherwise čmuk utterances. For example,

$$
\begin{aligned}
& \text { (1) qata mayka wawa } \text { talk/say/speak DEM } \\
& \text { how } 2 \text { sg word? } \\
& \text { 'How do you say this word?' } \\
& \text { (2) na.... tu? } \text { ?wan a question } \\
& \text { 1sg have } \\
& \text { 'I have a question.' }
\end{aligned}
$$

At times, having to thus resort to English became frustrating. We needed words for such things as 'word', 'question', and 'mean'. Tony came up with the idea of taking wawa, the word for 'talk/speak', and using wa as the term for a 'word'. This back formation made a lot of sense to me, too. As with any proposed changes to the lexicon, we do not know if people will use the newly created word or not, but chances are good that they will because a group of community members is only now beginning to learn the language. They do not have preconceived notions of how to say certain

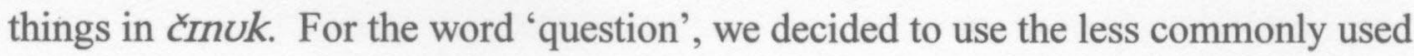
question particle na. We infixed the question particle into wawa, the word for 'speak/talk'. The result was wanawa. For the verb to 'mean', we used our newly created term for 'word' wa as an infix within tomtom 'feel/think/heart', resulting in təmwatom. Tony and I made good use of these coinages in subsequent discussions. 
Tony informs me that while wa seems to be fairly well accepted, the latter two have not been used.

Future lexication decisions will be addressed by Tony and the CTGR core language group čmuk $l u ? l u$, at least for the next year or so. Those who finish the class, may possibly teach the language in the community when they have completed the training. Thus, the process will be infused with the creativity of a group of committed community members, rather than having to rely on an outside linguist. 


\section{Chapter Four Notes}

1 Literally, čmok $l u$ ?lu means 'Chinook gather/come together' but refers, in this case, to the Chinook language-learning group.

2 The KTC\&HB hired their three employees (see §1, note 5) to do the work the Board proposes. The Board members meet periodically to discuss issues that have arisen and to get updates on the work being done in the KTC\&HB offices.

3 paston tIlxam taska wawa white people $3 \mathrm{pl}$ say, talk, speak

"White people (i.e., non-Indians) say"

4 The software developer, Marvin Plunkett, who designed software for teaching Cherokee, has become very interested in $\check{c}^{\prime} n u k$. At least partially, in an attempt to learn the language himself, he developed the talking word teacher based on an existing CJ dictionary (Pasco, 1993). He used the accompanying cassette as the source for the sound files. Then Tony digitally recorded the module, in order to insure consistency in pronunciation.

5 These are approximate times for corpus planning activities engaged in by Tony Johnson and Greg Davis while working together. The amount of time spent on each activity by Tony when working alone has neither been observed nor depicted in this chart.

6 Neither Tony nor I havedone a phonemic analysis of $c_{r n u k}$ based on the data compiled in the lexical database. Past phonemic analyses seem to be lacking certain distinctions, especially in regard to the vowels.

7 Apparently there is a means of converting TrueType fonts for use on Apple Macintoshes, but we have not addressed this issue yet.

8 I am using "V" here to represent all sorts of predication-verbs, attributives (advectives and advectival nouns), equational nouns, etc.

9 Zenk (1984) notes that Wilson Bobb, who grew up in the same extended family as Victoria Howard, also used clitic pronouns.

$10 d r \varepsilon t$ is so well-known that even people who grew up in the GR area not speaking $\check{c}^{\prime} r n u k$, recognize and sometimes use this word.

11 The most recent decision about this relational marker was to use kapa instead of kopa. After consultation with Henry, Tony has become convinced that this form is the best for GR because of the fact that most GR Indians pronounced it in this way. 


\section{Conclusion}

This final chapter provides a glance back at this current project. First of all, I will describe what the project encompassed. I will also provide an evaluation of the language planning undertaken by the CTGR and myself, focusing on accomplishments and limitations. I will also discuss prospects for success in attaining the goals of the language plan. Based on my observations, I will also make some recommendations most of which are directly applicable to the Grand Ronde case, but which, to a certain extent, could also apply to other groups in comparable sociolinguistic settings. From that point on, the focus will shift towards interpreting this case study as it relates to other, more generalized settings. Thus, this chapter affords a look back at the work already done as well as providing a glimpse of the prospects for the near future.

\subsection{Summary}

This case study of the language planning efforts of the Confederated Tribes of the Grand Ronde Community of Oregon spanned a little more than five months. Over 150 hours were spent in participant observation over the course of this research. In that time, I, as a linguistic intern, worked with Tony, the Tribe's language specialist, to develop a variety of language materials for the eventual teaching of crnok within the Grand Ronde community. The overarching goal of the language planning efforts at 
GR is to create anew a cohesive community in which crmok is spoken in at least some social domains. črnuk will be spoken in addition to English, creating a stable diglossic situation. This thesis is an attempt to document the early stages of that language planning process.

\subsection{Evaluation of the Language Planning Process, Myself, and Future Prospects}

Based solely on my observations and the information that was shared with me while working in Grand Ronde, it is somewhat difficult to evaluate the language planning undertaken by the CTGR in the offices of the KTC\&HB. Nevertheless, I will attempt to provide some feedback on the process with the purpose of increasing the likelihood for the plan's success.

As with any language planning situation, there are positive and negative aspects to the language planning process. I'll start with the negative, so as to end on a positive note. (N1) One of the things which struck me when I went to visit with language practitioners in Warms Springs and Siletz was the amount of teamwork they exhibited. Throughout all the stages of the language planning process, they work together with language teachers, cultural specialists, educators, curriculum designers, computer programmers, etc. to make decisions. Tony has been working in isolation in the KTC\&HB offices. The other Tribal staff who have knowledge of and experience with culture are in a different location (see Figure 8). Language planning efforts would be significantly enhanced by broadening the input into the process by as many 
stakeholders as possible, especially, informed ones. (N2) A second criticism is that the elders who speak črnuk need to be more involved in the language planning process. They naturally cannot be forced to participate, but it would be good for them to be given their rightful position of honor as holders of this important language for the CTGR. I must acknowledge that at least one of the elders has met with Tony many times and given him feedback on the database he is compiling, in addition to providing a knowledgeable conversation partner for him. (N3) Finally, it seems that there is too much emphasis on formal education in the ANA planning grant application. The woes of relying too heavily on the schools have been discussed above. In order to establish a viable language for the community and home, instruction must be geared towards providing increased opportunities for the acquisition of domain-specific language. Language learners must not simply learn the grammar and vocabulary of $\check{c}_{m} n u k$, they must learn how to use it in the community and home. Schools have, historically, done a poor job of producing such results.

Despite these criticisms, there are several positive aspects of the language planning process in GR. (P1) First of all, the Tribal Council supports language revitalization efforts with črnuk. Kathryn Harrison (personal communication to ANA, March 27, 1998), as Tribal Chair of the CTGR, pledges the support of the Tribe for čmuk.

The Tribes have consistently supported the concepts of timely and appropriate planning and community development.... Appropriate funding and adequate culture protection and language preservation have been and will remain high 
priorities for the Tribe. We are willing to make the commitment of resources to attain these goals for our members.

The Tribe's commitment is also evidenced by the creation of a language specialist position, a position which did not exist before 1997. Because of its importance to the culture of the Tribe, this position will hopefully be maintained irrespective of outside funding. (P2) In parallel with the Tribe's commitment to developing a language program, the KTC\&HB has put top priority on language. The support of the Board members, people extremely committed to maintaining their unique culture, enables substantive work to be done in this important area. (P3) Third, the KTC\&HB is fortunate to have such a talented, visionary like Tony as their language specialist. He is not simply doing a job to make a living; he has all of his life invested in this job. When he has children, he wants them to grow up speaking črnuk. His knowledge of, and connection with his own people's culture and history, has equipped him to be a role model in the GR community. He is proud to be šawaš 'Indian'. And he is the kind of person who GR Indians might be willing to listen to. (P4) Another positive aspect of the planning process is that provisions have been made to continue the language planning process regardless of whether they receive funding from the federal government or not. This is crucial. They will likely have to adjust their plans somewhat, but there seems to be enough support from the tribal government to accomplish the essential tasks which lie ahead. (P5) Finally, and possibly most importantly, there is the crmuk $l u ? l u$. This group of fifteen to twenty committed 
community members have agreed to meet regularly for a year to learn črnuk, help out in language planning, and, eventually, teach the language. This group has a great deal of potential for making a significant contribution to the welfare of the Tribe through the investment they are making in language, in culture, and in themselves.

The first part of this section has dealt with an evaluation of the language planning process. Now, I would like to provide a self-evaluation of my role in the language planning process in GR. Again I will start with the negative and end with the positive. (N4) First off, because I was not aware of my somewhat limited linguistic training ${ }^{1}$, I did not have the awareness to sense my need of consultation with other linguists. One example of this was my suggestion that we mark the two diphthongs in črnuk as $\left[\mathrm{a}^{\mathrm{i}}\right]$ and $\left[\mathrm{a}^{\mathrm{u}}\right]$. The diphthongs seemed to me to function as discrete units, so I wanted a symbol to represent this relationship. Tony thought of them in the same way, and thus I did not consult any one else on our decision. I realize that I should have talked with Henry Zenk right away to see what he thought. Later when we talked about it, he informed me that the diphthongs do not really function as one phonemic unit, and should thus be marked as [ay] and [aw] respectively. Now, I am painfully aware of my limitations as an applied linguist, and seek feedback from a variety of sources. (N5) In a similar vein, I did not take the time to do a formal phonemic analysis of crnuk. Everything Tony and I have developed to this point is still considered a draft. We need to have Henry look at all our data in 
order to compare it with the crnnuk he heard spoken in GR in the 1980's. Regardless of the unfinished nature of the corpus, I sense that I should have taken the time to subject the data we have to tests of phonemicity. Perhaps this can be carried out this next year with the help of Henry, who is actively involved in the teaching of the language in the crnok lu?lu. (N6) The crnnuk lu?lu provides the context for my third criticism of my self. I have not made time to attend any of the classes yet. I have spoken with both Tony and Henry, who have been leading the groups, but I have not observed the classes myself. Tony has told me that he would like me to help out as much as I can. Though I offer suggestions for the classes now in phone or e-mail conversations with Tony or Henry, I plan to take a more active role when I finish the work involved with this thesis.

Overall, I think the relationship between myself and the CTGR has been a good one. (P6) One of the first things I did was to try to learn as much as I could about the culture of GR and of Northwest Indians, in general. I asked many questions of Tony and he provided me with invaluable insights. At my bequest, Tony spent a significant amount of time talking about his people and their beliefs and customs. When I went to Siletz and Warm Springs to talk about their language programs, I was grateful for the advice Tony had shared with me. I was thus able to behave in a moreor-less culturally appropriate manner in my dealings with Indians both in Grand Ronde and on the other reservations. (P7) A second thing that was positive was that I 
endeavored to always bear in mind my role as an outside consultant. I was there to offer suggestions, provide alternative ways of approaching problems. I was not there to try to control the linguistic decision-making process because I was supposedly the expert. As a sovereign nation, the CTGR and their employees are responsible for making the decisions that affect them. I simply provided some perspective to allow Tony to make more informed decisions. (P8) Finally, I did not come with a long list of things I wanted to get from my interactions with Tony. Built into the participant observation design is the inherent hierarchical relationship between researcher and informant, with the researcher participating in the activities as directed by the informant. I joked with Tony about this reversal of relationships: "It's about time a pastən tIlXam 'White person' works for a šawaš. For too long, it's been the other way around." Tony jokingly replied, "Yeah, mayka na=ilaytix 'you are my slave'." When introduced to others, I was referred to as the linguistic intern. Besides dealing with the linguistic issues that arose, I also helped with computer problems and lent a supportive ear when a sympathetic listener was sought. This last role, that of a listener, was something I believe I was able to do as an outsider (because of the political nature of the discussions) who had established enough familiarity with the situation to be trusted with confidential information.

So far, I have evaluated the language planning process and myself. Finally, I would like to provide an evaluation of the prospects for success of the language plan in 
GR. These are my opinions and are not necessarily endorsed by the KTC\&HB or the CTGR as a whole. In the coming year, I believe that the crmuk $l u$ ? $u$ will successfully have learned to be at least minimally conversational in črnuk. They will then likely play a significant role in promoting the spread of $c$ mnuk throughout the community. At this point there may not be many people other than the crmuk $l u ? l u$ who show much interest in learning črnuk. In three years, however, I can foresee a far different picture. By that point, more local community members will be involved in language activities. A language curriculum will probably have been introduced in at least the first or second grades of the GR public school being taught by someone other than the home room teacher ${ }^{2}$. Several community classes will be going on at different times to accommodate people's work schedules. There will also likely be more cultural activities with some element of crnvk involved. In five years, if the language plan continues to receive support from Tribal Council and the community at large, there will be even more changes. More and more opportunities will arise for the use of čmvk in community and civic activities. It will not be a requirement for employment, but čmuk ability would likely give one an advantage in being hired to work for the

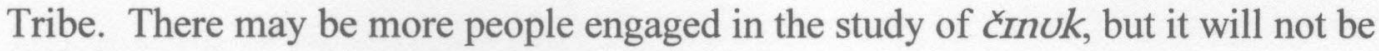
used by many people within their families because of the fact that, more than likely, not everyone will know the language sufficiently to express themselves in crmuk. In ten years, the people in the initial crmuk $l u ? l u$ will be fluent and will help to train a 
new set of teachers. If it becomes economically feasible, some CTGR tribal members may return to the GR area to re-establish their connections with their ancestors. One of the things that will draw them back is the increased focus on and attention to culture through čmuk. The original group of children who received supplemental črnuk instruction in school will be in high school and will hopefully be able to use their čmuk proficiency as a means of attaining state foreign language requirements. What will happen beyond that point? That question is too difficult to answer. Getting people to change their behaviors is no easy task, even if the change in behavior is something they really would like to adopt. How successful the KTC\&HB is at achieving the desired results will depend on a number of factors: the continued financial support of the Tribe, the continued interest of the community, and the continued efforts of language planners like Tony who can convince people how important the language is to them as Grand Ronde Indians.

\subsection{Recommendations}

As an observer of the language planning process in action in the offices of the KTC\&HB, I have formulated some recommendations which may help to improve the effectiveness of the language planning efforts.

R1.The KTC\&HB should plan for the domains in which crnnuk will be spoken. There will need to be an expansion of the vocabulary and possibly the syntax as well, in order to provide functionality in the expanded domains. If such planning is not 
undertaken, it is less likely that crmuk will be adopted for use in those domains because the language will not have the expressiveness to adequately serve the functions required of it.

R2. The KTC\&HB offices should be placed together with Cultural Resources Protection so that they can function more as a team. The two departments would not necessarily need to be rearranged in terms of their position within the organization, but ideally, they would at least share office space, so that even informal decisions could be conveniently discussed with others concerned about culture. Both groups would likely benefit from such an arrangement.

R3. A culture center could be created in which crmok activities could take place on a regular basis. This would be a place where people could access not only language materials but also other cultural information. Classes could meet there and interested learners could hone their language skills with self-access learning materials (possibly including a computer lab). This would entail a significant financial investment, but would also make an important statement about the importance of language and culture to the Tribe.

R4. The Tribal Council endorses the language planning efforts undertaken to this point. To really show their support, however, would involve a commitment to learning črnuk for themselves. They would thus add an increased measure of validity to the current language efforts. Now, at the community level, the čmvk $l u ? l u$ and 
other interested community members are involved; at the middle level of the Tribal government, Tony and the culture team have played a crucial role in the development of the language program. With support, in the form of a personal commitment to learning črnuk, from the highest levels of the Tribe, there would be a heightened sense of the legitimacy of črnuk within GR. Now may not be the best time for this to happen, but I believe it should happen, preferably sooner than later.

R5. As mentioned above in N3, it is important not to rely too heavily on formal

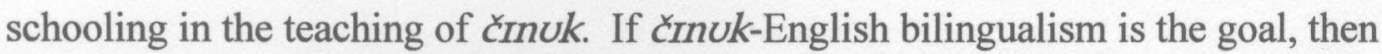
alternative means of language education must be explored. Schools have proven ineffective in efforts to reverse language shift (Fishman, 1991). No matter where the instruction takes place, it must be tailored to meet the objectives of the language plan.

R6. The survey process (see Figure 10) should be planned to end before the 3-year ANA implementation grant application is due. In other words, it should be started in October, so that it will be finished by the beginning of February. The implementation grant application is due towards the end of March.

R7. The Revitalization Plan phase (see Figure 10) should also begin soon enough to finish before the end of March, when the implementation grant application is due. The input from this group, including community participation, will enable grant 
writers to have a more realistic and potentially successful plan.

R8. As part of the pre-planning survey process, a means of measuring $\check{c}_{\text {mnuk }}$ proficiency should be developed. This will allow for comparison of the limited proficiency now with the improvements as a result of the implementation of an acquisition plan for črnuk.

\subsection{Significance of This Case}

Why is this case of language planning of interest to those not associated with the CTGR? I believe there are several reasons. Though only in the early stages of planning, this case provides an example of successful language planning. The success so far can be attributed, at least in part, to the clearly Native locus of control. All decisions are made by the language specialist in conjunction with the KTC\&HB, which serves an advisory role on such matters of culture. Outside experts have been brought in to work together in mutually beneficial relationships. This partnership, with the Tribe prescribing the limitations of the role outsiders can play, allows for selfdetermination, which is in line with the Tribe's sovereign status. Another factor which makes this case an example of effective language planning is the incorporation of community members in the planning process. The čmvk lu?lu group will play a key role in the development of $c_{\text {In }}$ k in GR. As needs arise in the group for new words or better ways of expressing things, the group will work together to address and solve these problems. Thus, this case is a good example of successful language planning in 
a minority language setting because of the support the efforts have, by at least some people, at all levels. Whether this strong start is followed up by continued commitment is something I am looking forward to observing, and hopefully helping to shape.

\subsection{Beyond Grand Ronde}

Stepping back from the particulars of the GR setting and looking at the broader context, there are some issues which could impact the effectiveness of language planning efforts in minority language settings. The issue of minority language rights is one which Hamel (1997) argues must be discussed when engaging in language planning. Historically, American Indian languages have been repressed through official government policy in an attempt to "civilize" them. In Bureau of Indian Affairs schools, "under strict English Only rules, students were punished and humiliated for speaking their native language as part of a general campaign to wipe out every vestige of their Indian-ness" (Crawford, 1995, p. 27). This legalized linguicide took place over more than a hundred years. Now, the United States government has adopted pro-Native language laws (Native American Languages Acts of 1990 and 1992).

To better understand the impact of such laws on American Indian languages, let me share a belief Tony related to me that he learned from his tribal elders:

However long it took to create a problem, it will take at least that long to fix it. Based 
on the one hundred plus years of oppressive policies of the government towards American Indian languages, it will take the current favorable policies many, many years before their effects will truly be seen and felt.

Thus, law makers need to be patient and not revoke the funding that is helping American Indians reclaim what is rightfully theirs - their languages and their cultures. Revitalizing dead or dying tribal languages is one area where Indians can regain the pride and respect for themselves and their unique culture that they deserve and desperately need. Laws, such as Proposition 227 which recently passed in California curtailing funding for bilingual education, have serious implications for the funding promised to Native Americans in the 1990 and 1992 Native American Language Acts. The funding sources, though separate, stem from the same ideological basissupporting languages other than English. This needs to be protected. If funding for Native American languages is axed, we would be taking a step in the wrong direction, namely towards decreased tolerance for other language ability or usage. In this free country, people need to be free to choose what language they speak and when, especially, for sovereign nations such as the CTGR. The funding should be continued because it is a step in the right direction - the direction of making reconciliation for the injustices inflicted upon the indigenous peoples of this continent.

So what does it matter if a language dies? Isn't it just survival of the fittest? Should we be concerned about it? Naturally, I think it is a shame when a language 
dies, for contained within that language is a unique means of expressing the culture of the people who used it and identified themselves with it. Even in the brief time I have

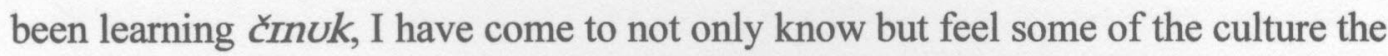
language represents. The čmvk word tomtom means 'heart, feel, think'. As Tony explained it to me, "when you think with your heart, it's impossible to do the wrong thing. You always do what is right because you do what your heart tells you is right. If you let your mind make decisions for you, you will find excuses or rationalizations for doing what you know is wrong."

kanawi Iktas Tony yaka tomtom tuš yaka munk ukuk all things Tony 3sg think/feel good 3sg do/make DEM 'He does what he believes is right'. 


\section{Chapter Five Notes}

1 In my MA program I have taken a number of both theoretical and applied linguistics classes, including Syntax, Semantics, Phonology, Computational Linguistics, Methods of Teaching English as a Second Language, Curriculum Design, etc. These classes did not, however, adequately prepare me for some of the challenges encountered in the field, as would be expected.

2 For the home room teacher to implement the $\check{c}$ mnvk language curriculum would require a good deal of language learning and training, which costs money. More likely than not, a language teacher endorsed (paid?) by the CTGR would teach the curriculum both in the public school and in before-, and after-school programs run by the Tribe.

3 This sentence was elicited from Tony without informing him that it was about him. My attempt at this notion follows. I did not trust my own črnvk intuition and wanted to use better language.

nayka tomtom Tony yaka tu?wan dret tuš tomtam 1sg think/feel Tony 3sg have AFFIRMATIVE good feel/heart 'I think Tony's got a good heart.' (i.e., 'He does what he believes is right.') 


\section{References}

Ayoungman, V. (1991). Siksika language renewal efforts: A description and assessment. Unpublished Ed.D. Dissertation, Arizona State University.

Boas, F. (1888). Chinook songs. Journal of American Folk-Lore, 1, 220-226.

Burnaby, B. (1996). Aboriginal language maintenance, development, and enhancement: A review of literature. In G. Cantoni (Ed.), Stabilizing indigenous languages (pp. 22-40). Flagstaff, AZ: Northern Arizona University.

Buseman, A., Early, R., Pedrotti, M., \& Yoder, B. (1996). Shoebox (Version 3.0): Summer Institute of Linguistics.

Cameron, D., Frazer, E., Harvey, P., Rampton, M. B. H., \& Richardson, K. (1992). Researching language: Issues of power and method. London: Routledge.

Cantoni, G. (Ed.). (1996). Stabilizing indigenous languages. Flagstaff, AZ: Northern Arizona University.

Cooper, R. L. (1989). Language planning and social change. Cambridge: Cambridge University Press.

Crawford, J. (1995). Endangered Native American languages: What is to be done, and why? The Bilingual Research Journal, 19(1), 17-38.

CTGRCO. (1996). Annual report 1996-97: A renewal of spirit . Grand Ronde, OR: The Confederated Tribes of the Grand Ronde Community of Oregon.

CTGRCO. (1997). Resource directory. Grand Ronde, OR: The Confederated Tribes of the Grand Ronde Community of Oregon.

CTGRCO. (1998). ANA language planning grant part IV: Program narrative. Unpublished Grant application.

Daniels, P. T., \& Bright, W. (Eds.). (1996). The world's writing systems. New York: Oxford University Press.

Dorian, N. C. (1994). Purism vs. compromise in language revitalization and language renewal. Language in Society, 23(4), 479-494.

Edwards, J. (1992). Sociopolitical aspects of language maintenance and loss: Towards a typology of minority language situations. In W. Fase, K. Jaspaert, \& S. Kroon (Eds.), Maintenance and loss of minority languages (pp. 37-54). Amsterdam: John Benjamins.

Fee, C. A. (1941). Oregon's historical Esperanto-the Chinook Jargon. Oregon Historical Quarterly, 42, 176-185.

Fernández Bell, M. R., \& Gilbert, G. (1996a). Journal of Pidgin and Creole Languages, Glossary A-C [WWW document] : Retrieved November 8, 1996 from the World Wide Web:

http://www.siu.edu/departments/cola/ling/glosya_c.htm.

Fernández Bell, M. R., \& Gilbert, G. (1996b). Journal of Pidgin and Creole Languages, Glossary G-L [WWW document] : Retrieved November 8, 1996 from the World Wide Web: http://www.siu.edu/departments/cola/ling/glosyg_l.htm. 
Fernández Bell, M. R., \& Gilbert, G. (1996c). Journal of Pidgin and Creole Languages, Glossary P-R [WWW document] : Retrieved November 8, 1996 from the World Wide Web: http://www.siu.edu/departments/cola/ling/glosyp_r.htm.

Fishman, J. A. (1991). Reversing language shift: Theoretical and empirical foundations of assistance to threatened languages. Clevedon, England: Multilingual Matters Ltd.

Fishman, J. A. (1994). Critiques of language planning: A minority languages perspective. Journal of Multilingual and Multicultural Development, 15, 9199.

Gibbs, G. (1863). A dictionary of the Chinook Jargon, or trade language of Oregon (Smithsonian Miscellaneous Collection 161). Washington, D.C.: Smithsonian Institution.

Grant, A. P. (1996). Chinook Jargon and its distribution in the Pacific Northwest and beyond. In S. A. Wurm, P. Mülhaüsler, \& D. T. Tryon (Eds.), Atlas of languages of intercultural communication in the Pacific, Asia, and the Americas (pp. 1185-1212). Berlin: Mouton de Gruyter.

Hajda, Y., \& Zenk, H. (1998). The early historiography of Chinook Jargon. Unpublished manuscript.

Hamel, R. E. (1997). Introduction: Linguistic human rights in a sociolinguistic perspective. International Journal of the Sociology of Language, 127, 1-24.

Hilbert, V., \& Hess, T. (1982). The Lushootseed language project. In W. Leap \& R. St. Clair (Eds.), Language renewal among American Indian tribes: Issues, problems, and prospects (pp. 71-89). Rosslyn, VA: National Clearinghouse for Bilingual Education.

Hinton, L. (1997). Small languages and small language communities: Survival of endangered languages: The California Master-Apprentice program. International Journal of the Sociology of Language, 123, 177-191.

Howay, F. W. (1943). Origin of the Chinook Jargon on the north west coast. Oregon Historical Quarterly, 44, 27-55.

Jacobs, M. (1932). Notes on the structure of Chinook Jargon. Language, 8(1), 27-50. Jacobs, M. (1936). Texts in Chinook Jargon. University of Washington Publications in Anthropology, 7(1), 1-27.

Kale, J. (1990). Language planning and the language of education in Papua New Guinea. In R. B. Baldauf, Jr. \& A. Luke (Eds.), Language planning and education in Australasia and the South Pacific (pp. 182-196). Clevedon: Multilingual Matters Ltd.

Kaplan, R. B., \& Baldauf, R. B., Jr. (1997). Language planning from practice to theory. Clevedon, England: Multilingual Matters Ltd.

Kaufman, T. S. (1971). A report on Chinook Jargon. In D. Hymes (Ed.), Pidginization and creolization of languages (pp. 275-278). Cambridge: Cambridge University Press.

Krauss, M. (1992). The world's languages in crisis. Language, 68(1), 4-10. 
Krauss, M. (1996). Status of Native American language endangerment. In G. Cantoni (Ed.), Stabilizing indigenous languages (pp. 16-21). Flagstaff, AZ: Northern Arizona University.

Lang, G. (1997, January). Gender \& Jargon: Voyageur wives \& the "founding" of Chinook Jargon. Paper presented at the Annual Meeting of the Society for Pidgin and Creole Linguistics, Chicago, IL.

Learn Chinook Jargon. (1998, May 1). Smoke Signals, p. 4.

Luke, A., McHoul, A. W., \& Mey, J. L. (1990). On the limits of language planning: Class, state, and power. In R. B. Baldauf, Jr. \& A. Luke (Eds.), Language planning and education in Australasia and the South Pacific . Clevedon, England: Multilingual Matters.

Marshall, D. F. (1994). Language maintenance and revival. Annual Review of Applied Linguistics, 14, 20-33.

Mitchell, K. (1998, May 1). Language Specialist develops Chinook dictionary. Smoke Signals $s_{2}$ pp. 4.

Otto, D. E. (1982). Language renewal, bilingualism, and the young child. In R. St. Clair \& W. Leap (Eds.), Language renewal among American Indian tribes: Issues, problems, and prospects (pp. 31-42). Rosslyn, VA: National Clearinghouse for Bilingual Education.

Pasco, D. (1993). Klahowya: A handbook for learning Chinook Jargon. (3rd ed.): (Available from Duane Pasco, 19330 Widme Rd. NE, Poulsbo, WA 98390.).

Pousada, A. (1996). Puerto Rico: On the horns of a language planning dilemma. TESOL Quarterly, 30(3), 499-510.

Roth, C. R. (1994). Towards an early social history of Chinook Jargon. Northwest Anthropological Research Notes, 28(1), 157-175.

Samarin, W. J. (1986). Chinook Jargon and pidgin historiography. Canadian Journal of Anthropology, 5(1), 23-34.

Samarin, W. J. (1988). Jargonization before Chinook Jargon. Northwest Anthropological Research Notes, 22, 219-238.

Schiffman, H. F. (1997). Six factors that enhance language maintenance, Summary of Kloss article in Fishman's volume Language Loyalty in the United States: 'German-American language maintenance efforts': Handout for LING 540, Language Policy . Retrieved April 10, 1998 from the World Wide Web: http://ccat.sas.upenn.edu/ harolds/540/.

Silverstein, M. (1972). Chinook Jargon: Language contact and the problem of multilevel generative systems. Language, 48(2, 3), 378-406, 596-625.

Silverstein, M. (1990). Dynamics of language contact. In I. Goddard (Ed.), Handbook of North American Indians: Languages (Vol. 17, pp. 100-150?). Washington: Smithsonian Institution.

Spack, R. (1998, March). English as the second language of America. Paper presented at the Teaching English to Speakers of Other Languages Convention, Seattle, WA. 
Spolsky, B. (1996). Conditions for language revitalization: A comparison of the cases of Hebrew and Maori. Current Issues in Language and Society, 2(3), 177-201. Spradley, J. P. (1979). The ethnographic interview. Fort Worth, TX: Harcourt Brace Jovanovich.

St. Clair, R. (1982). What is language renewal? In R. St. Clair \& W. Leap (Eds.), Language renewal among American Indian tribes: Issues, problems, and prospects (pp. 3-17). Rosslyn, VA: National Clearninghouse for Bilingual Education.

St. Clair, R., \& Leap, W. (Eds.). (1982). Language renewal among American Indian tribes: Issues, problems, and prospects. Rosslyn, VA: National Clearinghouse for Bilingual Education.

Thomas, E. H. (1970). Chinook: A history and dictionary of the Northwest Coast trade jargon. (Second ed.). Portland, OR: Binfords \& Mort.

Thomason, S. G. (1983). Chinook Jargon in areal and historical context. Language, 59(4), 820-870.

Thomason, S. G., \& Kaufman, T. S. (1988). Language contact, creolization, and genetic linguistics. Berkeley: University of California.

Tollefson, J. W. (1991). Planning language, planning inequality: Language policy in the community. London: Longman.

Zaharlick, A. (1982). Native Americans and literacy. In R. St. Clair \& W. Leap (Eds.), Language renewal among American Indian tribes: Issues, problems, and prospects (pp. 43-47). Rosslyn, VA: National Clearninghouse for Bilingual Education.

Zenk, H. B. (1984). Chinook Jargon and native cultural persistence in the Grand Ronde Indian Community, 1856-1907: A special case of creolization. Unpublished doctoral dissertation, University of Oregon, Eugene.

Zenk, H. B. (1988). Chinook Jargon in the speech community of Grand Ronde Reservation, Oregon: An ethnography-of-speaking approach to an historical case of creolization in process. International Journal of Sociology of Language, $71,107-124$.

Zenk, H. B. (1996). Phonological focusing and diffusion in Chinook Jargon. University of Oregon Anthropological Papers, 52, 173-199. 


\section{Appendixes}

\section{Appendix A-A Typology of Minority-Language-Situation Variables (Edwards, 1992).}

\begin{tabular}{|c|c|c|c|}
\hline & sponter & 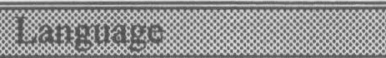 & 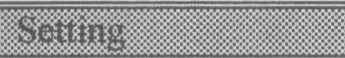 \\
\hline 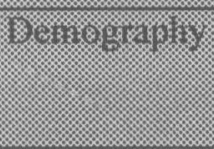 & $\begin{array}{l}\text { 1. Numbers and } \\
\text { concentrations of } \\
\text { speakers? }\end{array}$ & $\begin{array}{l}\text { 2. Extent of the } \\
\text { language? }\end{array}$ & $\begin{array}{l}\text { 3. Rural-urban } \\
\text { nature of setting? }\end{array}$ \\
\hline S10:6:61: & $\begin{array}{l}\text { 4. Socioeconomic } \\
\text { status of speakers? }\end{array}$ & $\begin{array}{l}\text { 5. Degree and type of } \\
\text { language transmission? }\end{array}$ & $\begin{array}{l}\text { 6. Nature of } \\
\text { previous/current } \\
\text { maintenance or } \\
\text { revival efforts? }\end{array}$ \\
\hline (3) & $\begin{array}{l}\text { 7. Linguistic } \\
\text { capabilities of } \\
\text { speakers? }\end{array}$ & $\begin{array}{l}\text { 8. Degree of language } \\
\text { standardization? }\end{array}$ & $\begin{array}{l}\text { 9. Nature of in- and } \\
\text { out-migration? }\end{array}$ \\
\hline 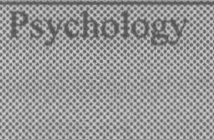 & $\begin{array}{l}\text { 10. Language } \\
\text { attitudes of speakers? }\end{array}$ & $\begin{array}{l}\text { 11. Aspects of the } \\
\text { language-identity } \\
\text { relationship? }\end{array}$ & $\begin{array}{l}\text { 12. Attitudes of } \\
\text { majority group } \\
\text { towards minority? }\end{array}$ \\
\hline W & $\begin{array}{l}\text { 13. History and } \\
\text { background of the } \\
\text { group? }\end{array}$ & $\begin{array}{l}\text { 14. History of the } \\
\text { language? }\end{array}$ & $\begin{array}{l}\text { 15. History of the } \\
\text { area in which group } \\
\text { now lives? }\end{array}$ \\
\hline 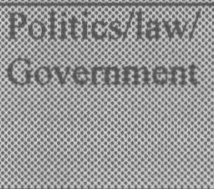 & $\begin{array}{l}\text { 16. Rights and } \\
\text { recognition of } \\
\text { speakers? }\end{array}$ & $\begin{array}{l}\text { 17. Degree and extent } \\
\text { of official recognition } \\
\text { of language? }\end{array}$ & $\begin{array}{l}\text { 18. Degree of } \\
\text { autonomy or } \\
\text { "special status" of } \\
\text { the area? }\end{array}$ \\
\hline (3) & $\begin{array}{l}\text { 19. Speakers' } \\
\text { attitudes and } \\
\text { involvement } \\
\text { regarding education? }\end{array}$ & $\begin{array}{l}20 . \text { Type of school } \\
\text { support for language? }\end{array}$ & $\begin{array}{l}\text { 21. State of } \\
\text { education in the } \\
\text { area? }\end{array}$ \\
\hline i. & $\begin{array}{l}\text { 22. Religion of } \\
\text { speakers? }\end{array}$ & $\begin{array}{l}\text { 23. Type and strength } \\
\text { of association between } \\
\text { language and religion? }\end{array}$ & $\begin{array}{l}\text { 24. Importance of } \\
\text { religion in the area? }\end{array}$ \\
\hline T:- & $\begin{array}{l}25 . \text { Economic health } \\
\text { of speaker group? }\end{array}$ & $\begin{array}{l}\text { 26. Association } \\
\text { between language(s) } \\
\text { and economic } \\
\text { success/mobility? }\end{array}$ & $\begin{array}{l}\text { 27. Economic health } \\
\text { of the region? }\end{array}$ \\
\hline 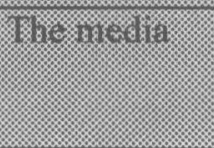 & $\begin{array}{l}\text { 28. Group } \\
\text { representation in } \\
\text { media? }\end{array}$ & $\begin{array}{l}\text { 29. Language } \\
\text { representation in } \\
\text { media? }\end{array}$ & $\begin{array}{l}\text { 30. General public } \\
\text { awareness of area? }\end{array}$ \\
\hline
\end{tabular}




\section{Appendix B-A Preliminary Typology of čmuk in Grand Ronde ${ }^{1}$}

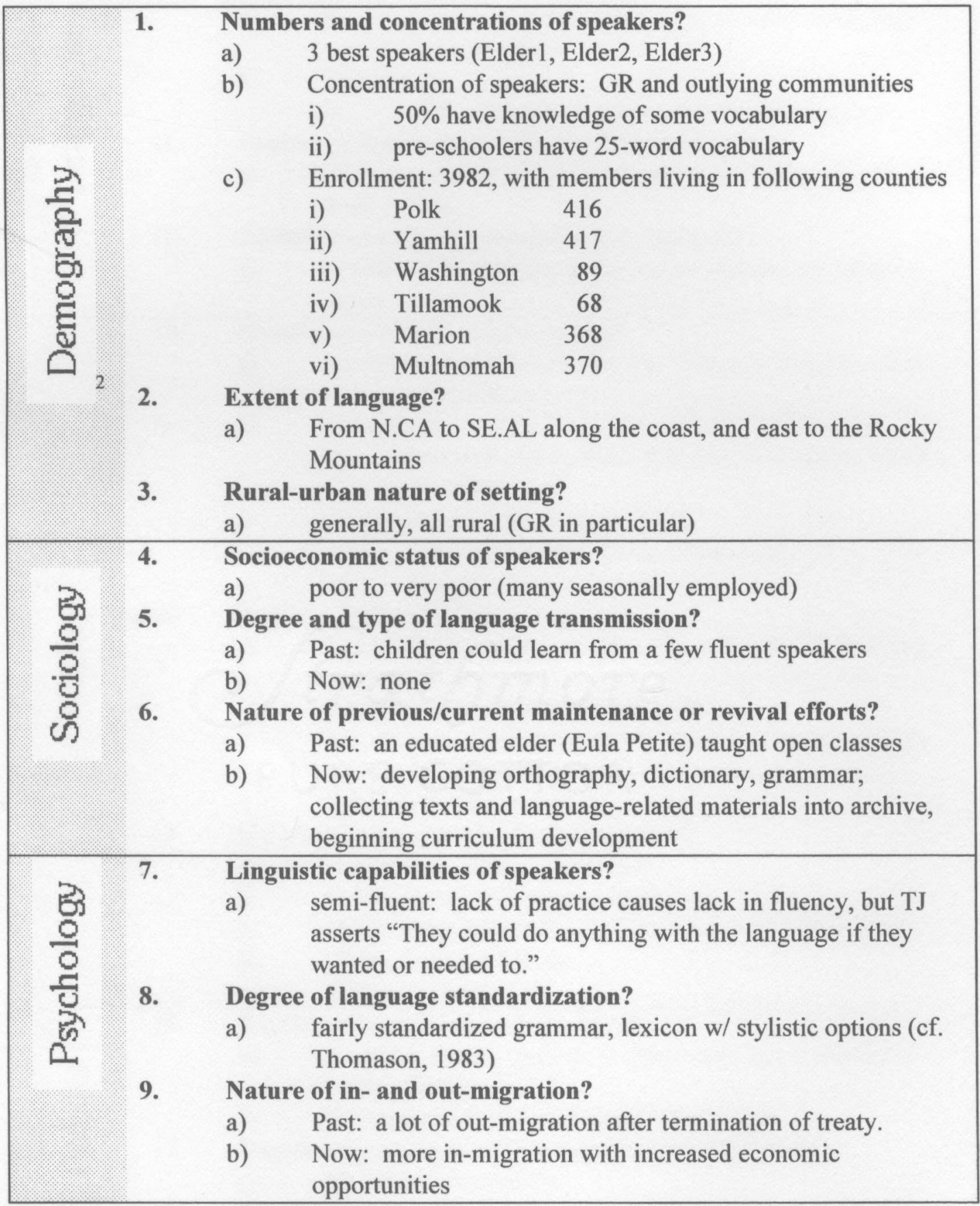

1 Information based on a conversation between Tony Johnson and Greg Davis (3/2/98), a letter of support from Dean Azule, Director Education Division, CTGR (3/26/98), and information provided by Margo Mercier, Enrollment, CTGR (5/26/98).

2 These oversimplified labels are misleading and constricting. They are used, here, in keeping with Edwards (1992) typology despite their lack of validity. 


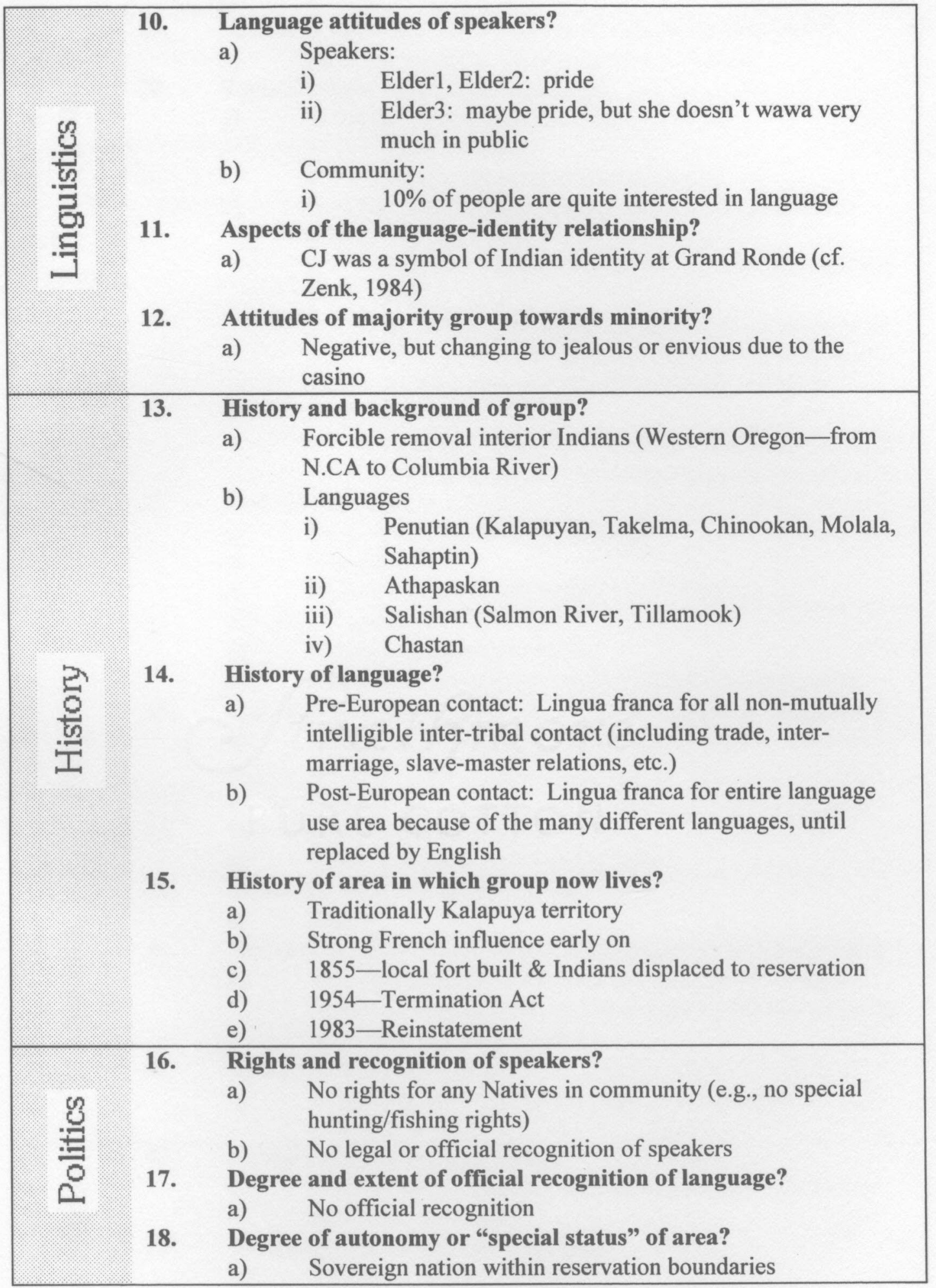




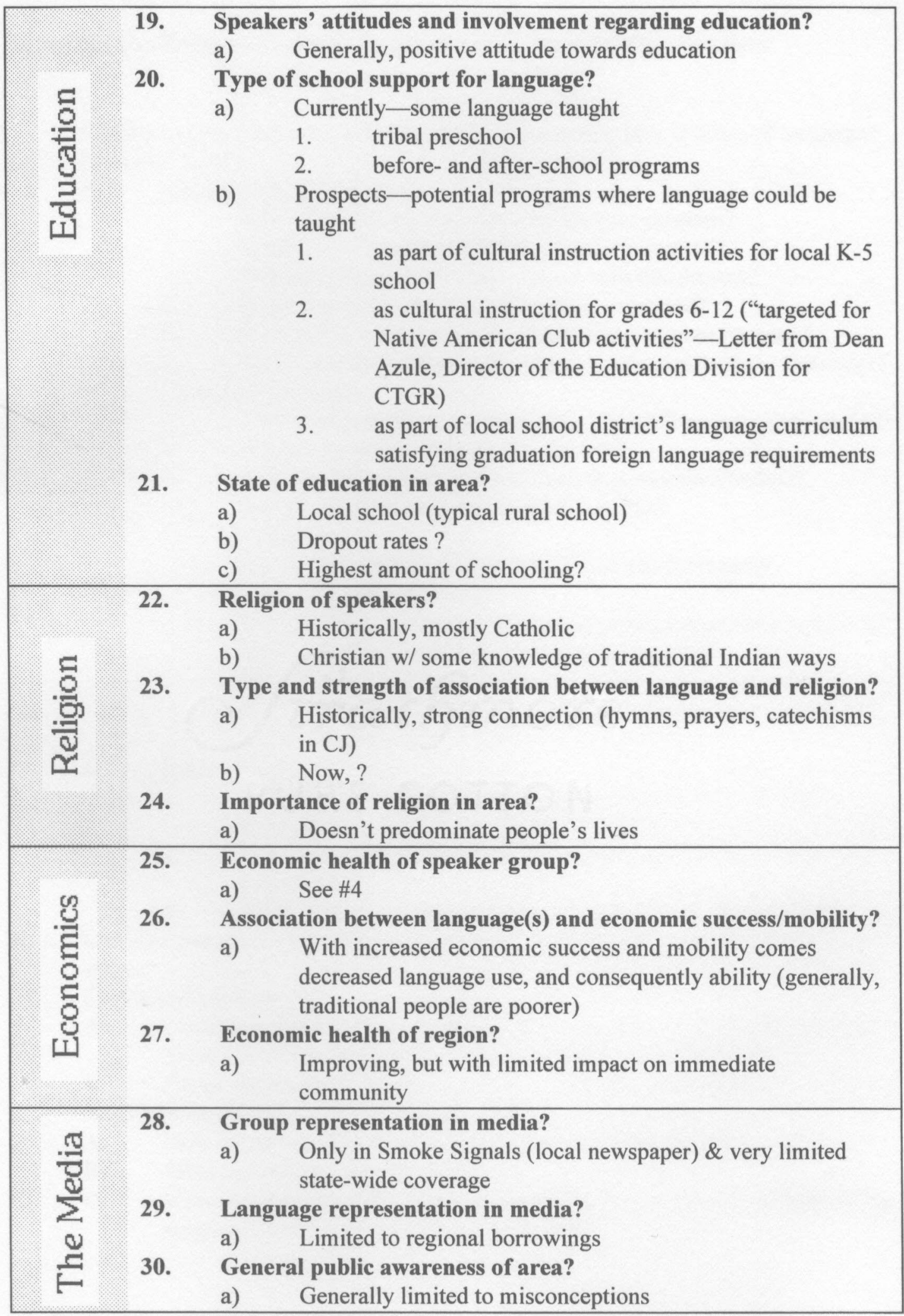




\section{Appendix C-Proposed Questions for Native Language Practitioners}

I. Could you give me the big picture of what is happening here in terms of language?

II. POSSIBLE TOPICS

A. Language Planning/Policy

1. Who does the language planning for your program?

2. What sort of language policies have been enacted?

3. What are the goals for language use with this project?

4. In what ways are the languages being promoted?

5. How will you determine the effectiveness of your program?

6. Who controls changes to the language (standardization, additions)?

B. Language Teaching

1. Which language(s) are you teaching? How/Why were they chosen?

2. Where else are those languages spoken?

3. Who are the teachers and how were they recruited/trained?

4. What would a typical class period look like?

5. Materials

a) What kinds of materials do you use in language teaching/learning?

b) Have you been able to adapt material from other programs?

c) Have you used any multimedia materials?

d) What role have computers played in your projects?

e) What restrictions do you have on your language materials (sensitivity)?

C. Support

1. What kind of community/tribal support do you have for your projects?

2. What percentage of the population study/speak the language, \& at what levels?

3. What kind of financial support do you have for your projects?

III. Can you give me an example of public sentiment/support/protest for or against your efforts?

IV. EXPERIENCE QUESTIONS

A. Could you tell me about some experiences you have had working with the Tribal Council to establish language policies?

B. Please tell me about some experiences teaching/mentoring/etc.?

V. NATIVE-LANGUAGE
A. How do you say the names of the language(s) being taught?
B. What is the language program called?
C. If money were no object, what would you do to improve the viability of the language(s) in this community and beyond? 


\begin{tabular}{|c|c|c|c|c|c|}
\hline $\begin{array}{r}\text { Ilr?i } \\
\text { earth }\end{array}$ & sister & $\begin{array}{l}a^{i} \text { saia } \\
\text { far }\end{array}$ & $\mathrm{a}^{\mathrm{u}}$ & $\begin{array}{l}\text { bastan } \\
\text { white } \\
\text { person }\end{array}$ & Сәq ${ }^{w}$ \\
\hline $\begin{array}{l}\text { Ćəm } \\
\text { mark/spot }\end{array}$ & $\begin{array}{l}\text { Črnuk } \\
\text { Chinook }\end{array}$ & $\stackrel{b}{c} u x$ & $\begin{array}{l}\text { dakta } \\
\text { doctor }\end{array}$ & $\begin{array}{r}\text { e pepa } \\
\text { paper }\end{array}$ & $\begin{array}{l}\mathcal{E} \\
\text { true dance }\end{array}$ \\
\hline $\begin{array}{r}\partial \text { masači } \\
\text { bad } \\
\end{array}$ & $\begin{array}{r}\text { tofo } \\
\text { turkey } \\
\text { buzzard } \\
\end{array}$ & $\begin{array}{l}\text { gIdəp } \\
\text { get up }\end{array}$ & $\begin{array}{l}g_{\text {əfi }}^{\mathrm{w}} \\
\quad \text { coffee }\end{array}$ & $\begin{array}{l}\text { hihi } \\
\text { laugh/play }\end{array}$ & $\begin{array}{l}\text { ixt Ikta } \\
\text { one what? }\end{array}$ \\
\hline $\begin{array}{r}\text { Kamtəks } \\
\text { know }\end{array}$ & $\begin{array}{l}\mathbf{K}_{\text {ata }}^{\mathrm{W}} \\
\text { quarter }\end{array}$ & $\mathrm{K}_{\mathrm{a}^{\mathrm{u}}}^{\prime}$ & $\begin{array}{l}\mathrm{K}^{\prime} \mathrm{w} \text { as } \\
\quad \text { afraid }\end{array}$ & $\begin{array}{l}\text { lulu } \\
\text { carry }\end{array}$ & good \\
\hline t' & $\begin{array}{r}\text { Makmək } \\
\text { eat/food }\end{array}$ & $\begin{array}{l}\text { Nanič } \\
\text { see/look }\end{array}$ & $\begin{array}{l}\text { O lagom } \\
\text { pitch }\end{array}$ & Paia & ṕrq \\
\hline qata & $\begin{array}{r}q^{w} \text { məm } \\
\text { five }\end{array}$ & hard & $\begin{array}{l}\text { q́ }^{\mathrm{w}} \text { әt } \\
\text { knock }\end{array}$ & $\begin{array}{r}\text { r lipret } \\
\text { priest } \\
\end{array}$ & $\begin{array}{r}\text { Skukəm } \\
\text { strong } \\
\end{array}$ \\
\hline $\begin{array}{l}\text { Suš } \\
\text { shoes }\end{array}$ & $\begin{array}{r}\text { təmtəm } \\
\text { heart }\end{array}$ & $\begin{array}{l}\text { talapus } \\
\text { coyote }\end{array}$ & $\begin{array}{r}\text { Ulali U } \\
\text { tuk } \\
\text { berry break }\end{array}$ & $\begin{array}{r}\text { Wawa } \\
\text { talk }\end{array}$ & $\begin{array}{l}\text { Xulxul } \\
\text { mouse } \\
\end{array}$ \\
\hline $\begin{array}{r}X^{W}+x^{w} a p \\
\text { hole }\end{array}$ & $\begin{array}{r}\text { Xalaqł } \\
\text { open } \\
\end{array}$ & $\begin{array}{l}X^{\mathrm{W}} \text { IC } \chi^{\mathrm{W}} \partial \mathrm{t} \\
\text { black bear }\end{array}$ & $\begin{array}{l}\mathrm{Ya}^{\mathrm{a} \text { ?im }} \\
\text { tell } \\
\end{array}$ & $\begin{array}{r}\check{Z} \text { lapiež } \\
\text { seat }\end{array}$ & \\
\hline
\end{tabular}

Produced by the Language Program of the KTC\&HB of the Confederated Tribes of Grand Ronde, OR 
Appendix E-CTGR Vision Statement, Preamble to Constitution, \& KTC\&HB Mission Statement

\section{Vision statement for CTGR (CTGRCO, 1997):}

The Tribe's vision is to be a tribal community known as a caring people, dedicated to the principles of honesty and integrity, building community, individual responsibility and self-sufficiency through personal empowerment, and responsible stewardship of human and natural resources; a community willing to act with courage in preserving tribal cultures and traditions for all future generations. (p. 3)

\section{Preamble to the Constitution of the Confederated Tribes of the Grand Ronde Community of Oregon (CTGRCO, 1997):}

We, the Indians of the Confederated Tribes of the Grand Ronde Community of Oregon, being a federally recognized Indian tribe pursuant to the Grand Ronde Restoration Act of November 22, 1983 (97 Stat. 1064) hereby adopt this Constitution in accordance with the Indians Reorganization Act of June 18, 1934 (48 Stat. 984), as amended, and establish our tribal government in order to form a better tribal organization, secure the rights and powers inherent in our sovereign status and guaranteed to us by Federal Law, preserve our culture and tribal identity, promote the social and economic welfare of our people, protect and develop our common resources, maintain peace and order, and safeguard individual rights. (p. 5)

\section{Kwelth Tahlkie Culture \& Heritage Board (KTC\&HB) Mission (CTGRCO, 1997):}

The mission of Kwelth Tahlkie Culture \& Heritage Society is to recognize, affirm, and celebrate the historical and contemporary cultural achievements of the Grand Ronde people; to preserve and perpetuate that culture and collaborate with other groups and individuals with similar aims, to collect, preserve and interpret articles of cultural patrimony as well as documents, language and oral history; to use such resources as educational opportunities for students and scholars alike. (p. 45) 


\section{Appendix F-Towards a prescriptive syntax of $\check{c ̌ n n}^{\prime} k^{1}$}

This is a working document. In particular, the pronominal system is still under investigation. It is included here as a possible feature of the language to be taught to Grand Ronde learners.

\section{NOTATIONAL CONVENTIONS:}

"=" is used when attaching clitics with neighboring words

"_" is used to mark compounds

V : Stress marks follow the stressed vowel

DEM: Demonstrative Pronoun

FUT: Future marker

word: Single underline signifies subject

word: Double underline signifies predicate

Pronouns occur in both short and long forms:

\begin{tabular}{|c|c|c|c|c|}
\hline \multirow[b]{3}{*}{ Person } & \multicolumn{2}{|r|}{ (4) } & \multirow{2}{*}{$x_{1}^{1}$} & \multirow[b]{3}{*}{ Meaning } \\
\hline & \multirow[b]{2}{*}{ Chitic } & 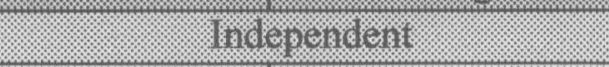 & & \\
\hline & & Semi-Clitic & Full & \\
\hline $1 \mathrm{sg}$ & na & nay & nayka & $\mathrm{I} / \mathrm{me} / \mathrm{my}$ \\
\hline $2 s g$ & $\mathrm{ma}$ & may & mayka & you/your \\
\hline $3 s g$ & ya & ya & yaka/yaxka & $\begin{array}{l}\text { he/him/his } \\
\text { she/her/it/its }\end{array}$ \\
\hline $1 \mathrm{pl}$ & nca & cay/say/nesay & nəsayka/ncayka & we/us/our \\
\hline $2 \mathrm{pl}$ & mca & məsay & məsayka/mcayka & you (all)/your \\
\hline $3 \mathrm{pl}$ & tas & tas & taska & they/them/their \\
\hline DEM & uk & uk & ukuk & this/that \\
\hline & & & $x$ & these/those \\
\hline
\end{tabular}

The clitics are the base forms and attach to the nearest word.

They are used in the following situations:

1. When used as a possessive pronoun:

a. ex. $n a=a^{\prime} w$

tr. 1 sg brother

ft. 'my brother'

b. ex. ya= kani'm

tr. 3sg canoe

ft. 'his canoe'

2. When used as a subject pronoun:

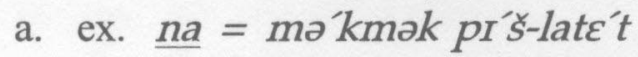

tr. 1 sg eat fish head

ft. 'I eat fish heads.' 
b. ex. $\underline{\text { na }}=t t^{\prime} k i \quad$ cá $q^{\prime}$

tr. 1sg want water

ft. 'I'm thirsty.'

c. ex. a'łqi na $=m u^{\prime}$ sam

tr. FUT 1sg sleep

$\mathrm{ft.}$ 'I'll sleep later.'

d. ex. a'lta na = łatuwa

tr. now 1 sg go

ft. 'I'm going now.'

\section{SUBJECT PRONOUNS}

Pleonastic subject pronouns accompany full noun subjects. In the unmarked case, subject pronouns occur in their clitic form and attach to the corresponding verbs. Subject pronouns appear modally as full forms with V-S order:

3. When they are the usual subject forms in attributive sentence constructions (V-S):
a. ex. tu'š ya'ka (but ya = tu'šs)
tr. good 3 sg
$\mathrm{ft}$. 'She is good.'
tr. angry $1 \mathrm{sg}$
ft. 'I'm angry.'
b. ex. sa'loks na'yka (but na = sa'loks)

4. When they are the usual subject forms in equational sentence constructions (V-S):
a. ex. tứs tu'čman ya'ka
(but ya =tu'š tu'čmən)
tr. good woman $3 \mathrm{sg}$
ft. 'She's a good woman.'

5. When they are the emphatically marked subject forms:
a. ex. máyka kapšwa la na = I'ktas
tr. 2sg steal 1sg things
$\mathrm{ft.}$ 'You stole my things!'
b. ex. na'yka tu'lu máyka
tr. 1sg win/beat 2 sg
ft. 'I beat you!'

Three degrees of emphatic marking are possible:
c. ex. na $=k a ' m t o k s$
ft. 'I understand.'
d. ex. na'yka kə'mtoks
ft. 'I understand.' 
e. ex. na'yka na=kə'mtəks

$\mathrm{ft}$. 'I'm the only one who understands.'

3pl yaka can be given an extra degree of emphatic marking by using the less common variant yaxka.

f. ex. na= papa' ya'xka čaku kakšət

tr. 1sg father 3sg become hurt

$\mathrm{ft}$. 'My father is the who's been hurt!'

Possessive Pronouns

6. Possessive pronouns combine with the possessed noun in the form, Pro-NP:

a. ex. na $=p^{\prime} a^{\prime}$

tr. 1 sg father

$\mathrm{ft.}$ 'my father'

b. ex. masay ha'ws

tr. $2 \mathrm{pl}$ house

$\mathrm{ft.}$ 'your house'

7. The possessive genitive occur $\mathbf{N P}_{\mathbf{1}}-\mathbf{P r o}_{\mathbf{1}}$-NP:

a. ex. $m u^{\prime} l a q$ ya $=$ siya $^{\prime} x^{w} \partial s$

tr. elk 3 sg eyes/face

ft. 'the elk's eyes'

b. ex. na= papa' ya $=$ ši $^{\prime} k s$

tr. $1 \mathrm{sg}$ father $3 \mathrm{sg}$ friend

ft. 'my father's friend'

\section{OBJECT PRONOUNS}

8. Object pronouns and subject pronouns in V-S attributive and equational constructions always occur in their independent forms:
a. ex. na =q́a't máyka
tr. 1 sg love 2 sg
ft. 'I love you.'
b. ex. dre't tu'š máyka
tr. right good $2 \mathrm{sg}$
ft. 'You're really great.'

\section{DECLARATIVE SENTENCES}

Declarative sentences follow the following patterns:

9. V-S word order occurs in sentences which contain adjectival and nominal predicates 

a. ex. ka k $k^{w} a$ ta'ska
tr. like $3 \mathrm{pl}$
ft. 'That's the way they are.'
b. ex. tonəs-mán u'kuk
tr. boy DEM
ft. 'That's a boy.'

10. S-V-O word order occurs in all sentences which contain transitive verbs
a. ex. na=trki lóqa
tr. 1sg want drink
ft. 'I want to drink.'

\section{ATTRIBUTIVE AND EQUATIONAL SENTENCES}

11. In attributive and equational sentences, where the predicate is a noun, noun phrase, or an adjective. (PRED-S order is preferred; S-PRED is also possible.)
tr.
man $3 \mathrm{sg}$
$\mathrm{ft}$.
'He is a man.'
a. Noun ex. PRED-S:main ya'ka
b. ex. S-PRED:ya=ma'n
c. Noun Phrase ex. PRED-S:pa'ł tománawas uk = kani'm - str k tr. full power/spirit DEM cedar tree
$\mathrm{ft}$ 'That cedar tree is full of power.'

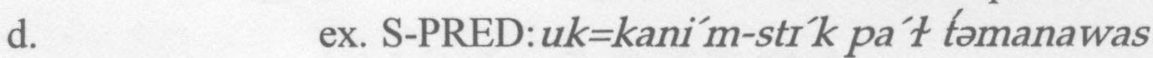
e. Adjective ex. PRED-S: haya'š uk = strk

tr. big DEM stick
ft. 'That stick is big.'
f. $\quad$ ex. S-PRED: $u k=s t$ 'khaya's

\section{NeGATIVE CONSTRUCTIONS}

12. Negative sentences are marked by the negatives (NEG) wik/wek and occur clause-initial:
a. ex. we'k ya =kə'mtəks čmu’k
tr. NEG $3 \mathrm{sg}$ know
Chinook
ft. 'She doesn't know Chinook.'

13. Negative sentences can alternatively be constructed the S-NEG-V form, but this is unusual and not preferred.
a. ex. ya=wi'k kə'mtəks črnuk
tr. 3sg NEG know
Chinook
ft. 'She doesn't know Chinook.' 


\section{IMPERATIVE SENTENCES}

Imperative sentences are constructed in two ways:

14. By deleting the second person pronoun:
a. ex. ča $k u$ yak ${ }^{w} a^{\prime}$
tr. come here
ft. 'Come here!'
b. ex. mi'łrt a'lta
tr. sit now
ft. 'Sit down now!'

15. With the emphatic marker tuš-spos, literally 'good if' (IMP) (not used in GR):
a. ex. tušspos ma ... łatuwa
tr. IMP 2sg go
ft. 'It would be good if you went.' or 'You should go.'

INTERROGATIVE SENTENCES

Interrogative sentences can be constructed in two ways:

16. Rising tone at the end of a statement or sentence (principal means):
a. ex. a'łqi ya = ła'tuwa yawa'-1
tr. FUT 3sg go there
$\mathrm{ft.}$ 'Will he go there later?'
b. ex. $m a=$ ta'tuwauk $=s a^{\prime} n^{\uparrow}$
tr. 2 sg go DEM day
ft. 'Are you going today?'

\section{ADVERBIALS}

The aspect (ASP) marker is the word hayu as opposed to hayu' (modally hayu' 'many, much'). hayu highlights actions that are continuous or repetitious. When hayu is used, it always precedes the verb it modifies.
17. ex. $m a=h a y u-k a^{\prime} k s ̌ a t ~ n a ́ y k a$
tr. 2sg ASP hurt 1sg
ft. 'You're hurting me.'

hayu is used in cases of continuous or repetitious action, unless:

18. Context makes it clear that it is an ongoing or repeated action:
a. ex.
tr.
tr.
a'lta I'kta ma = mu'nk ${ }^{\uparrow}$ now what $2 \mathrm{sg}$ do/make 'What are you doing now?' 
b. ex. Jane replies: na $=m u^{\prime} n k u^{\prime} p k^{w} I n a$

tr.

1 sg do/make basket

ft. 'I'm making a basket.'

19. A modal or time element is involved:

a. ex. $k^{w} a^{\prime} n t s o m n a=m u^{\prime} n k \quad u^{\prime} p k^{w} I n a$

tr. always $1 \mathrm{sg}$ do/make basket

ft. 'I always make baskets.'

\section{MODAL/TIME ELEMENTS}

20. Modal and time elements often appear clause-initial:

a. ex. alta na =ta'tuwa kapa $u k=h a^{\prime} w s$

- tr. now 1sg go REL DEM house

ft. 'Now I'm going to that house.'

\section{Appendix F Note}

1 This is not a description of GR čmuk, nor is it a description of regional CJ. Instead it is a working document which Tony and I developed, drawing from a number of sources in order to create a prescriptive syntax which could be taught to crnnvk learners in GR. 